Universidade de Brasília

\author{
Instituto de Química \\ Programa de Pós-Graduação em Tecnologias \\ Química e Biológica
}

\title{
Éteres difenílicos polibromados (PBDE) em sedimentos do Lago Paranoá, DF
}

\author{
Daniel Luiz Rodrigues da Annunciação
}

Orientador: Prof. Dr. Fernando Fabriz Sodré

Coorientadora: Profa. Dra. Fernanda Vasconcelos de Almeida

Brasília - DF

2017 
$\Psi$ Universidade de Brasília

Instituto de Química

Programa de Pós-Graduação em Tecnologias

Química e Biológica

\title{
Éteres difenílicos polibromados (PBDE) em sedimentos do Lago Paranoá, DF
}

\begin{abstract}
Tese apresentada ao Programa de Pós-Graduação em Tecnologias Química e Biológica da Universidade de Brasília, como parte dos requisitos para obtenção do título de Doutor.
\end{abstract}

Orientador: Prof. Dr. Fernando Fabriz Sodré

Coorientadora: Profa. Dra. Fernanda Vasconcelos de Almeida

Brasília - DF 


\section{Folha de Aprovação}

Comunicamos a aprovação da Defesa de Tese de Doutorado do (a) aluno (a) Daniel Luiz Rodrigues da Annunciação, matrícula no 12/0078597, intitulada "Éteres difenílicos polibromados (PBDE) em sedimentos do Lago Paranoá, DF", apresentada no (a) Auditório Azul do Instituto de Química (IQ) da Universidade de Brasília (UnB) em 31 de março de 2017.

Prof. Dr. Fernando Fabriz Sodré

Presidente de Banca (IO/UnB)

Prof. Dr. Ângelo Henrique de Lira Machado

Membro Titular (IQ/UnB)

Prof. Dr. Igor Cardoso Pescara

Membro Titular (IFGoiano/GO)

Prof. Dr. Jonatas Gomes da Silva

Membro Titular (UCB/DF)

Prof. Dr. Marco Tadeu Grassi

Membro Titular (UFPR/PR)

Profa. Dra. Ana Cristi Basile Dias

Membro Suplente (IQ/UnB)

Em 31 de março de 2017. 


\section{AGRADECIMENTOS}

A Deus, pois a Ele pertencem os louros da vitória.

A minha Mãe Maria Rita (In Memorian).

A meu Pai.

As minhas filhas Maria Rita e Ana Clara (Amo Vocês!).

Ao meu Padrinho Manoel Tranquilino.

A minha família (Pereira Rodrigues).

Ao Professor Fernando Fabriz Sodré. Tive o privilégio de ter como orientador um dos maiores profissionais em Química Ambiental. Obrigado pela orientação, exemplo, conhecimento e apoio nos momentos de dificuldade e incerteza.

A Professora Fernanda Vasconcelos de Almeida. Obrigado pela coorientação, exemplo e apoio ao longo desses anos.

Aos amigos Alan Campos e Alexandre Bittencourt. Nos momentos mais difíceis os amigos se tornam irmãos.

Aos Professores e Companheiros de Pós-Graduação do Grupo de Automação, Quimiometria e Química Ambiental (AQQUA).

Ao Instituto Federal de Educação, Ciência e Tecnologia de Goiás, por conceder-me licença para cursar o doutorado.

Ao Instituto Nacional de Ciências e Tecnologias Analíticas Avançadas, pelo apoio.

Ao Batalhão de Policiamento Ambiental da PMDF, por ceder a embarcação e apoio dos militares para realização das coletas no Lago Paranoá.

Aos amigos da turma II/95 do CFN (adsumus)

A todas as pessoas que direta ou indiretamente cooperaram com este... 
"Eu sou seu Criador. Você estava sob meus cuidados mesmo antes de nascer" (Isaias 44.2)

"The Only Easy Day Was Yesterday" (Navy Seals) 


\section{RESUMO}

Esse estudo buscou investigar a ocorrência de PBDE em sedimentos do Lago Paranoá - DF. Para tanto, um método analítico foi desenvolvido, validado e aplicado para determinação de nove congêneres (BDE-28, BDE-47, BDE-66, BDE-85, BDE-99, BDE-100, BDE-138, BDE-153 e BDE-154) em amostras de sedimento. O método consistiu na extração sólido-líquido assistida por ultrassom, seguido de etapas de clean-up e análise por cromatografia gasosa com detecção por captura de elétrons. O método se mostrou seletivo, linear ( $R$ $>0,9967)$, tendo valores de $\operatorname{LOD}\left(0,03\right.$ a $\left.0,32 \mathrm{ng} \mathrm{g}^{-1}\right)$ e $\operatorname{LOQ}\left(0,1\right.$ a $\left.1,1 \mathrm{ng} \mathrm{g}^{-1}\right)$ compatíveis com níveis de PBDE encontrados na literatura, recuperações entre

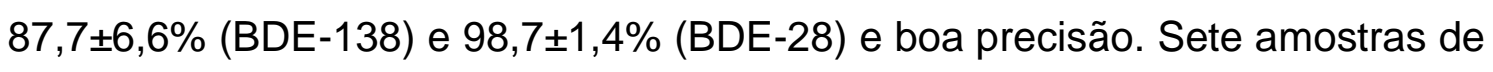
sedimento do Lago Paranoá foram investigadas onde foi possível verificar

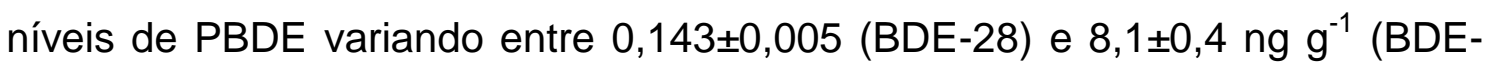
66). Níveis mais elevados para $\triangle P B D E$ foram observados nas imediações das estações de tratamento de esgoto Sul $\left(19 \pm 2 \mathrm{ng} \mathrm{g}^{-1}\right)$ e Norte $\left(8,79 \pm 0,03 \mathrm{ng} \mathrm{g}^{-1}\right)$, corroborando com o papel do lançamento de esgotos como uma das principais fontes de aporte de PBDE. Verificou-se semelhança entre os perfis de concentração dos congêneres nos sedimentos com a proporção de PBDE na formulação comercial pentaBDE (DE-71). A distribuição dos PBDE no ambiente, estimada pelo modelo de fugacidade do software EQC Model (level 1), sugeriu sua presença no ar $\left(0,009\right.$ a $\left.0,5 \mathrm{ng} \mathrm{m}^{-3}\right)$, no aerossol $(0,001 \mathrm{a}$ $\left.0,012 \mathrm{ng} \mathrm{m}^{-3}\right)$, na coluna de água $\left(0,004\right.$ a $\left.0,2 \mathrm{ng} \mathrm{L}^{-1}\right)$, nos sólidos suspensos aquáticos $\left(0,7\right.$ a $\left.40,5 \mathrm{ng} \mathrm{g}^{-1}\right)$, em solos $\left(0,07\right.$ a $\left.4,1 \mathrm{ng} \mathrm{g}^{-1}\right)$ e em peixes $(0,437 \mathrm{a}$ 24,7 $\left.\mathrm{ng} \mathrm{g}^{-1}\right)$. Tais resultados foram compatíveis com aqueles descritos na literatura para estes compartimentos. Estimou-se, por meio do software EQC Model, um aporte de cerca de 220 toneladas de PBDE para o Lago Paranoá. A concentração de PBDE na água intersticial dos sedimentos foi estimada e comparada com valores de PNEC (predicted no-effect concentration) indicando provável risco a biota referente aos congêneres (BDE-47, BDE-66 e BDE-99) e evidenciado a necessidade de maiores investigações. Para a coluna de água, esta abordagem não evidenciou risco provavelmente em função da elevada hidrofobicidade dos PBDE aliada à sua tendência à bioconcentração. Este trabalho é um dos primeiros registros da presença de PBDE em sedimentos coletados no Brasil, servindo com suporte à geração de indicadores de 
qualidade mais autênticos com o cenário atual, à medida que as informações sobre a presença de PBDE em vários compartimentos ambientais ainda são escassos em nosso país. 


\section{ABSTRACT}

This study investigated the occurrence of PBDE in sediments of Paranoá Lake, in the Brazilian Federal District. An analytical method was developed, validated and applied for the determination of nine congeners (BDE-28, BDE-47, BDE-66, BDE-85, BDE-99, BDE-100, BDE- BDE-154) in sediment samples. The method was based on ultrasonic solid-liquid extraction, followed by clean-up and analysis by gas chromatography coupled to electron capture detection. The method was selective, presented good linearity $(R>0.9967)$ and values of LOD (0.03 to $0.32 \mathrm{ng} \mathrm{g}^{-1}$ ) and LOQ (0.1 to $\left.1.1 \mathrm{ng} \mathrm{g}^{-1}\right)$ compatible with PBDE levels of found elsewhere. Recoveries were between $87.7 \pm 6.6 \%$ (BDE-138) and $98.7 \pm$ $1.4 \%$ (BDE-28) with good precision. Seven sediment samples from Paranoá Lake were investigated and PBDE levels ranged from $0.143 \pm 0.005$ (BDE-28) to $8.1 \pm 0.4 \mathrm{ng} \mathrm{g}^{-1}$ (BDE-66). Higher levels of $\Sigma$ PBDE were observed in points located nearby South $\left(19 \pm 2 \mathrm{ng} \mathrm{g}^{-1}\right)$ and North $\left(8.79 \pm 0.03 \mathrm{ng} \mathrm{g}^{-1}\right)$ sewage treatment plants, corroborating with the role of wastewater disposal as one of the main sources of PBDE. A similarity between the concentration profiles in sediments and the proportion of PBDE in the commercial pentaBDE formulation (DE-71) was observed. The distribution of PBDEs in the environment, estimated by the fugacity model of the EQC Level 1 software, suggested their presence in

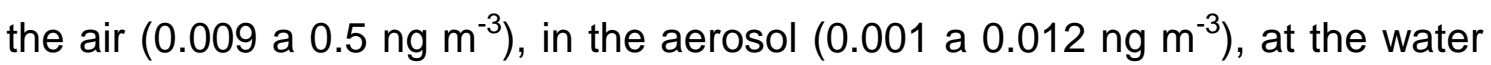
column ( 0.004 a $\left.0.2 \mathrm{ng} \mathrm{L}^{-1}\right)$, at the aquatic suspended solids $\left(0.7\right.$ a $\left.40.5 \mathrm{ng} \mathrm{g}^{-1}\right)$, in soils $\left(0.07\right.$ a $\left.4.1 \mathrm{ng} \mathrm{g}^{-1}\right)$ and in fishes $\left(0.437\right.$ a $\left.24.7 \mathrm{ng} \mathrm{g}^{-1}\right)$. These results were comparable with those described in the literature for these compartments. It was estimated, through the EQC Model software, a contribution of about 220 tons of PBDE to Lake Paranoá. The concentration of PBDE in the interstitial water was estimated and compared to predicted no-effect concentration (PNEC) values indicating a probable risk for the congeners (BDE-47, BDE-66 and BDE-99) as well as evidencing the need for further investigations. Risk was not evidenced for the water column probably due to the high hydrophobicity of the PBDEs and their tendency for bioconcentration. This work is one of the first reports of the presence of PBDE in sediments collected in Brazil, supporting the generation of more authentic quality indicators considering the current scenario, as the information about the presence of PBDE in several environmental compartments is still scarce in our country. 


\section{SUMÁRIO}

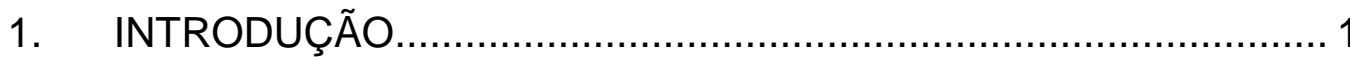

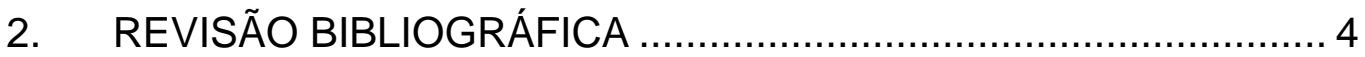

2.1. Éteres Difenílicos Polibromados .......................................... 4

2.2. Produtos comerciais contendo PBDE .................................... 6

2.3. Combustão e mecanismo de ação dos PBDE ......................... 9

2.4. Propriedades de relevância ambiental ................................... 11

2.5. Presença no ambiente ….................................................. 13

2.6. Determinação de PBDE em matrizes ambientais .................. 18

2.6.1. Amostragem e preservação ……………………............. 19

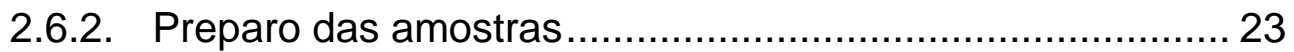

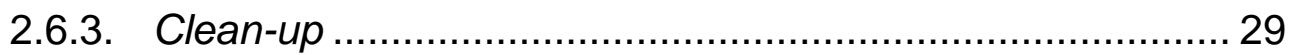

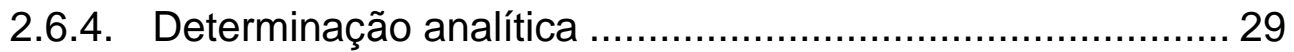

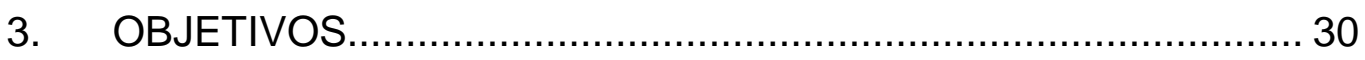

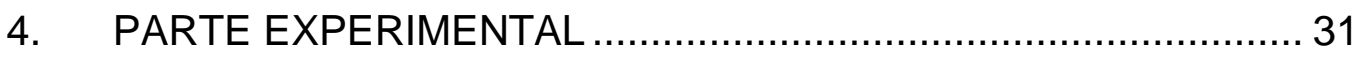

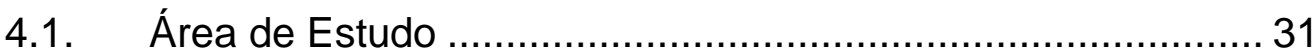

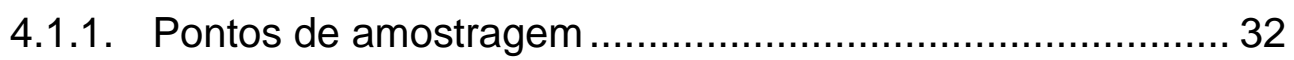

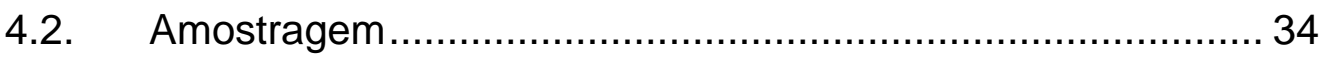

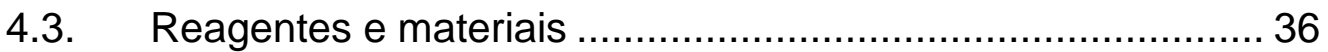

4.4. Limpeza de vidrarias ......................................................... 37

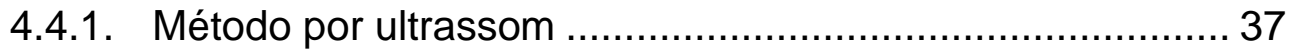

4.4.2. Método por calcinação ……….......................................... 38

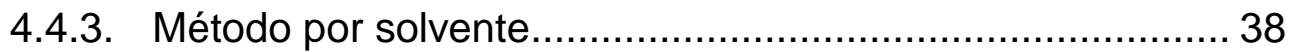

4.5. Obtenção e Preparo de amostras …………………….......... 38

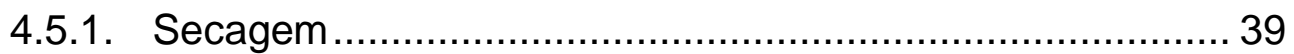

4.5.2. Extração dos analitos e clean-up dos extratos.................... 39

4.5.3. Escolha do solvente de extração ....................................... 40 
4.6. Método instrumental de análises........................................ 41

4.7. Validação do método analítico …………………................. 42

4.7.1. Curva analítica e linearidade............................................ 42

4.7.2. Limite de detecção (LOD) e limite de quantificação (LOQ) . 43

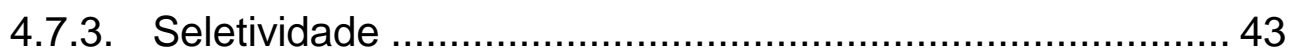

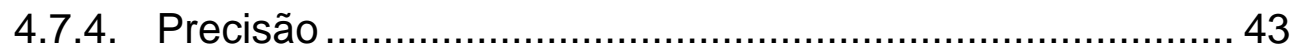

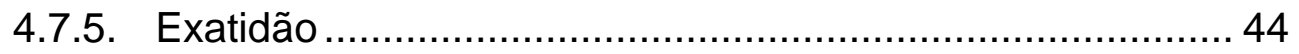

4.8. Estudo da fugacidade dos PBDE ......................................... 44

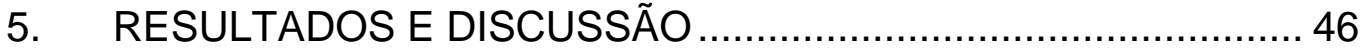

5.1. Validação do método Analítico ............................................... 46

5.1.1. Separação e detecção …………………….................. 46

5.1.2. Parâmetros de mérito analítico ....................................... 47

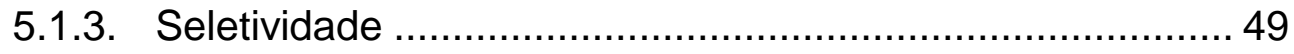

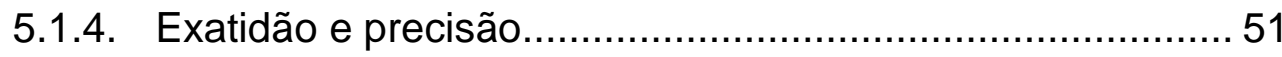

5.2. Determinação de PBDE em sedimentos do Lago Paranoá ... 55

5.3. Estudo da fugacidade dos PBDE ......................................... 64

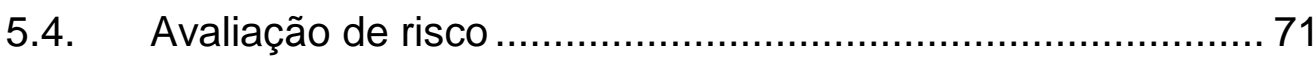

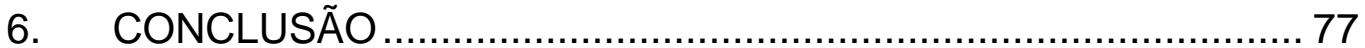

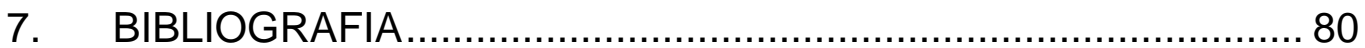

8. ANEXOS 


\section{ÍNDICE DE FIGURAS}

Figura 1. Estrutura básica do Éter Difenil Polibromado - PBDE (sendo $m+$

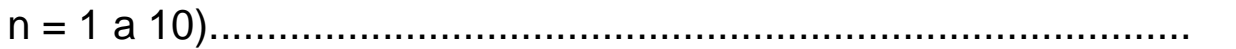

Figura 2. Estrutura básica da Bifenila Policlorada (sendo $m+n=1$ a 10) .. 5

Figura 3. Reação simplificada de síntese do BDE-209 a partir da

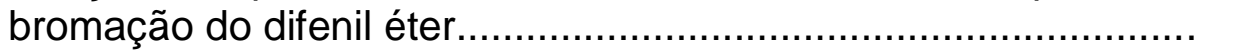

Figura 4. Importação do produto "éter decabromo difenílino" pelo Brasil no período de 1989 a 1996.

Figura 5. Gráfico esquemático das fases do processo de combustão..... 10

Figura 6. Esquema das principais rotas de aporte e distribuição dos PBDE no ambiente.

Figura 7. Esquema de instrumentação dos amostradores atmosféricos do tipo ativo.

Figura 8. Esquema de amostrador atmosférico do tipo passivo.

Figura 9. Materiais empregados pelo Grupo AQQUA para amostragens de líquidos sendo: (A) Garrafa de Van Dorn, (B) Frasco de vidro do tipo âmbar, e (C) Balde.

Figura 10. Materiais empregados pelo Grupo AQQUA para amostragens de solos e sedimentos, sendo: (A) Pá e enxada, (B) Pá de jardinagem, e (C) Draga de Van Veen

Figura 11. Métodos de secagem de amostras empregados no Laboratório do Grupo AQQUA, sendo: (A) Liofilizador (Liotop - L101), (B) Estufa de circulação de ar (Ethik Technology - 402/D), e (C) secagem ao ar em capela de exaustão.

Figura 12. Esquema de um sistema de extração Soxhlet, sendo: (a)Reservatório de solvente, (b) Fonte de aquecimento, (c) Sistema extrator, e (d) Condensador.

Figura 13. Banhos de ultrassom utilizados no laboratório do Grupo AQQUA, sendo: (a) Cole Pamer - 8893, e (b) UltraCleaner - 1400A

Figura 14. Sistema MAE marca Ethos D, Milestone Sorisole, sendo: (A) imagem do equipamento, e (B) Tubos de extração alocados no rotor do sistema fechado assistido por micro-ondas.

Figura 15. Mapa do Distrito Federal e localização da Bacia Hidrográfica do Paranoá.

Figura 16. Localização dos pontos de amostragem, sendo: ETS Estação de Tratamento de Esgoto Sul; CNB - Imediações do Clube Nipo Brasileiro; RBG - afluência dos ribeirões do Gama e Cabeça de Veado; PJK - Ponte JK; BIC - Baia do late Clube de Brasília; ETN - Estação de Tratamento de Esgoto Norte; PBG - Ponte do Bragueto.

Figura 17. Coleta de amostra de sedimento, sendo: (a) içamento da draga de Van Veen, (b) abertura da draga, (c) amostra coletada, e (d) amostras acondicionadas em caixa térmica. 
Figura 18. Estruturas químicas, nomenclaturas, coeficientes de partição octanol/água (Log Kow) e solubilidade em água (Sw) dos nove congêneres investigados nesse estudo.

Figura 19. Cromatograma mostrando a separação dos nove congêneres presentes na solução padrão de PBDE LMS - Accustandard.....

Figura 20. Cromatogramas de extratos de sedimento (A) sem tratamento para remoção do enxofre e (B) com tratamento para remoção do enxofre....

Figura 21. Cromatogramas indicando a presença do interferente halogenado heptacloro epóxido presente no solvente isoctano.

Figura 22. Correlação entre os percentuais de recuperação e Log Kow para: (A) MRC e (B) sedimento fortificado.

Figura 23. Correlação obtida entre os resultados de recuperação para material de referência certificado e sedimento fortificado

Figura 24. Comparativo dos níveis de concentração de PBDE em sedimentos aquáticos desse estudo, e de outros locais...

Figura 25. Composição percentual dos congêneres em ETS, CNB, ETN, BIC e produto pentaBDE

Figura 26. Rota de desbromação dos PBDE proposta por HUANG et al. (2014)

Figura 27. Diagrama de distribuição do BDE-47 nos compartimentos ambientais, segundo o software EQC Model - Level I.

Figura 28. Razão MEC/PNEC para avaliação de risco de PBDE em sedimento.

Figura 29. Razão MEC/PNEC para avaliação de risco de PBDE na coluna d'água. 


\section{ÍNDICE DE TABELAS}

Tabela 1. Quantidade de átomos de bromo substituintes e número teórico de congêneres de PBDE .

Tabela 2. Principais congêneres encontrados na mistura comercial penta-BDE, estruturas químicas, número de registro no Chemical Abstracts Service (CAS) e propriedades físico-químicas de interesse ambiental...........

Tabela 3. Principais congêneres encontrados na mistura comercial octa-BDE, estruturas químicas, número de registro no Chemical Abstracts Service (CAS) e propriedades físico-químicas de interesse ambiental...

Tabela 4. Principal congênere da mistura comercial deca-BDE, estrutura química, número de registro no Chemical Abstracts Service (CAS) e propriedades físico-químicas de interesse ambiental.

Tabela 5. Pontos de amostragem, descrições e coordenadas geográficas..

Tabela 6. Condições experimentais para análises de PBDE por GCECD.

Tabela 7. Condições experimentais utilizadas durante a separação cromatográfica dos analitos investigados.

Tabela 8. Limite de detecção (LOD), limite de quantificação (LOQ), faixa linear, linearidade e sensibilidade do método proposto para os nove congêneres de PBDE.

Tabela 9. Exatidão e precisão para o método proposto.

Tabela 10. Concentrações (ng g ${ }^{-1}$ ) dos congêneres investigados em amostras de sedimento do Lago Paranoá.

Tabela 11. Dados de entrada utilizados no estudo da fugacidade empregando o software EQC Model - Level I.

Tabela 12. Particionamento dos congêneres no ambiente segundo estimativa do EQC Model - Level I.

Tabela 13. Estimativas de concentração dos PBDE investigados no ponto amostral ETS

Tabela 14. Estimativas de concentração dos PBDE investigados no ponto amostral CNB

Tabela 15. Estimativas de concentração dos PBDE investigados no ponto amostral ETN

Tabela 16. Estimativas de concentração dos PBDE investigados no ponto amostral BIC

Tabela 17. Dados para as avaliações de risco de PBDE em sedimentos do Lago Paranoá.

Tabela 18. Dados para as avaliações de risco de PBDE na coluna d'água do Lago Paranoá. 


\section{LISTA DE SIGLAS E ABREVIATURAS}

ANVISA - Agência Nacional de Vigilância Sanitária

AQQUA - Grupo de Automação, Quimiometria e Química Ambinetal

ASE - Extração Acelerada por Solvente (do inglês, Accelerated Solvent Extraction)

BDE - Éter Difenílico Bromado (do inglês, Brominated Diphenyl Ether)

BIC - Baia do late Clube de Brasília

BPMA - Batalhão de Polícia Militar Ambiental

BZ - Ballschmiter-Zell

CAESB - Companhia de Saneamento Ambiental do Distrito Federal.

CAIQ/UnB - Central Analítica do Instituto de Química da Universidade de Brasília

CAS - do inglês, Chemical Abstracts Service

CNB - Clube Nipo Brasileiro

CV - Coeficiente de Variação

decaBDE - Formulação comercial retardante de chama

DF - Distrito Federal

ECD - Detector por Captura de Elétrons (do inglês, Electron Capture Detector)

ECOSAR - do inglês, Ecological Structure Activity Relationships

EPA - Agencia de Proteção Ambiental Americana (do inglês, Environmental Protection Agency) 
EQC - do inglês, Equilibrium Criterion

ETE - Estação de tratamento de esgoto

ETN - ETE - Norte

ETS - ETE Sul

FR - Retardantes de chama (do inglês, Flame Retardants)

GC - Cromatografia Gasosa (do inglês, Gas Chromatography)

HRGC - Cromatografia Gasosa de Alta Resolução (do inglês, High Resolution Gas Chromatography)

HRMS - Espectrometria de Massas de Alta Resolução (do inglês, High Resolution Mass Spectrometry)

INMETRO - Instituto Nacional de Metrologia, Qualidade e Tecnologia

IT - do inglês, lon Trap

IUPAC - União Internacional de Química Pura e Aplicada (do inglês, International Union of Pure and Applied Chemistry)

$K_{\text {ow }}$ - Coeficiente de partição octanol/água

$\mathrm{LD}_{50}$ - Dose letal mediana (do inglês, Lethal Dose)

LMS - Estudo do Lago Michigan (do inglês, Lake Michigan Study)

LOD - Limite de Detecção

LOQ - Limite de Quantificação

LP - Lago Paranoá

MAE - Extração Assistida por Micro-ondas (do inglês, Microwave-Assisted Extraction)

MAPA - Ministério da Agricultura, Pecuária e Abastecimento 
MDIC - Ministério do Desenvovimento, Indústria e Comércio

MEC - Concentração Medida no Ambiente (do inglês, Measured Environmental Concentration)

MRC - Material de Referência Certificado

MS - Espectrometria de Massas (do inglês Mass Spectrometry)

nd - Não Detectável

octaBDE - Formulação comercial retardante de chama

PBDE - Éteres Difenílicos Polibromados (do inglês, Polybrominated Diphenyl Ethers - PBDE)

PBG - Ponte do Bragueto

PCB - Bifenila Policlorada (do inglês, Polychlorinated biphenyls)

pentaBDE - Formulação comercial retardante de chama

PJK - Ponte JK

PLE - Extração por Líquido Pressurizado (do inglês, Pressurized Liquid Extraction)

PMDF - Polícia Militar do Distrito Federal

PNEC - Concentração em que não há efeito adverso (do inglês, Predicted No Effect Concentration)

POPs - Poluentes Orgânicos Persistentes (do inglês, Persistent Organic Pollutants)

RB - Ribeirão do Bananal

RC - Ribeirão Cabeça do Veado

RF - Ribeirão Riacho Fundo 
RG - Ribeirão do Gama

RGC - Ribeirões Gama e Cabeça do Veado

RT - Ribeirão do Torto

SAI - Setor de Indústrias e Abastecimento

SPE - Extração em Fase Sólida (do inglês, Solid Phase Extraction)

$S_{w}$ - Solubilidade em água (do inglês, water solubility) 


\section{INTRODUÇÃO}

Os avanços da ciência dos materiais poliméricos fizeram com que nas últimas décadas estivessem disponíveis às indústrias diversas classes de materiais plásticos com propriedades e aplicações distintas. Esses polímeros podem hoje ser encontrados em grande parte dos objetos do dia-a-dia, como nas peças de vestuário, nos equipamentos eletroeletrônicos, no mobiliário, nos veículos, na construção civil, entre outros. Tendo em sua grande maioria o petróleo como matéria prima, esses materiais conferem inflamabilidade aos objetos, necessitando a adoção de medidas que atendam aos mínimos requisitos de segurança (ALAEE et al., 2003; MARIANI et al., 2008).

Desta forma, os retardantes de chama (do inglês, Flame Retardants FR) são substâncias que, quando misturadas a esses materiais, agem inibindo o processo de combustão e, consequentemente, reduzindo riscos e danos provocados por incêndios. Dentre as mais de 175 substâncias utilizadas como FR, os éteres difenílicos polibromados (do inglês, polybrominated diphenyl ethers - PBDE) têm sido amplamente utilizados desde a década de 1960 em virtude de seu baixo custo e maior eficiência (ALAEE et al., 2003; YOGUI et al., 2009; PAPACHLIMITZOU et al., 2012).

Contudo, por serem aditivos misturados aos polímeros os PBDE não estão quimicamente ligados aos materiais podendo ser liberados com a ação do tempo. Assim, podem enriquecer partículas atmosféricas tanto em ambientes abertos quanto confinados e, em função de inúmeros processos antrópicos e naturais, surgir em ambientes aquáticos onde serão sedimentados ou acumulados na biota (ALAEE et al., 2003; LOKENSGARD, 2013).

Como apresentam elevada estabilidade química, característica essencial nos FR, os PBDE são considerados contaminantes ambientais persistentes. Em 2012, por exemplo, alguns congêneres foram banidos em conformidade com a revisão da lista de Poluentes Orgânicos Persistentes (POPs) da Convenção de Estocolmo (YOGUI et al., 2009; WANG et al., 2015; WANG et al., 2016). 
Vários estudos já investigaram a presença dos PBDE em material particulado atmosférico (HARRAD et al., 2006; BJÖRKLUND et al., 2012) e aquático (MÖLLER et al., 2011; MOON et al., 2012), no sedimento aquático (WANG et al., 2011; MOON et al., 2012; KLOSTERHAUS et al., 2012; YANG, et al., 2012) e em solos (WANG et al., 2011; PAROLINI et al., 2012). Além disso, esses compostos também foram identificados em matrizes biológicas como animais marinhos (LI, YAN, et al., 2010; RíOS et al., 2015), sangue humano (STASINSKA et al., 2014; FROMME et al., 2015; SAGIV et al., 2015), tecidos humanos (KALANTZl et al., 2009; CHEN et al., 2014) e leite materno humano (SIDDIQUE et al., 2012; XU et al., 2015). Estudos toxicológicos sugerem que a exposição de humanos aos PBDE está acompanhada de alterações imunológicas, hepatotóxicas e neurotóxicas, bem como da ação interferente endócrina (GASCON, et al., 2011; LIN et al., 2011; WANG et al., 2015; RíOS et al., 2015; XU et al., 2015).

No Brasil pouco se sabe sobre a utilização dos PBDE, bem como sobre seus níveis ambientais. Sabe-se, porém, que os principais processos de contaminação em ambientes urbanos estão intimamente associados ao aporte de esgoto bruto e ao descarte de efluentes de estações de tratamento de esgoto (ETE) (BILA et al., 2003; DHAGE et al., 2006; BORGHI et al., 2014; PI et al., 2016).

Assim, torna-se essencial o desenvolvimento de estudos visando à identificação e a quantificação de PBDE em ambientes aquáticos urbanos sujeitos ao aporte destas fontes de contaminação. Nesse contexto encontra-se no Lago Paranoá, localizado em Brasília, no Distrito Federal (DF). Esse reservatório recebe cargas pontuais e difusas de esgoto doméstico, além de efluentes de duas das dezessete ETE responsáveis por parte do tratamento de esgoto produzido no DF.

Diante deste quadro, este trabalho buscou desenvolver, validar e aplicar um método analítico para determinação de nove congêneres de PBDE (BDE$28,47,66,85,99,100,138,153$ e 154) em sedimentos aquáticos do Lago Paranoá, como forma de orientar o estabelecimento de indicadores de qualidade mais condizentes com o cenário atual, à medida que ainda são desconhecidos valores seguros desses contaminantes. 
Os resultados gerados, além de inéditos, também poderão subsidiar programas de gestão de resíduos e de poluentes orgânicos persistentes no Brasil, temas estes de interesse recente, tanto dentro do meio acadêmicocientífico, quanto nas diversas esferas regulatórias públicas. 


\section{REVISÃo BIBLIOGRÁFICA}

\section{1. Éteres Difenílicos Polibromados}

Os PBDE são compostos orgânicos halogenados cujas estruturas apresentam um átomo de oxigênio, de uma função éter, ligado a dois grupos fenil. Nesses grupos, existem 10 posições que podem ser substituídas por $1 \mathrm{a}$ 10 átomos de bromo (Figura 1).

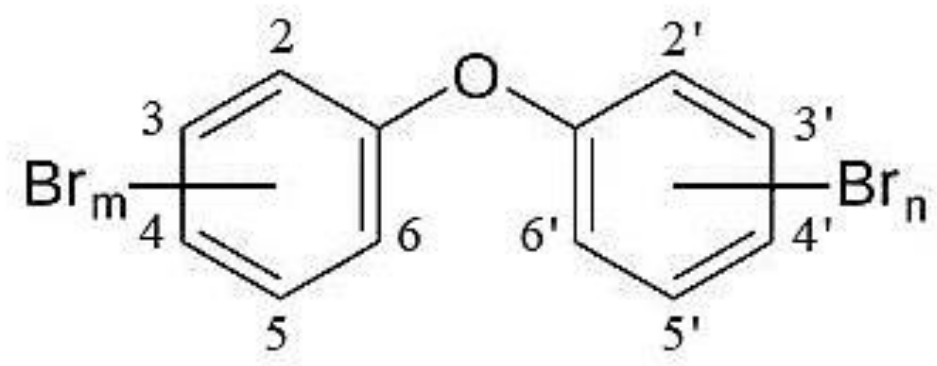

Figura 1. Estrutura básica do Éter Difenil Polibromado $-\mathrm{PBDE}$ (sendo $m+n=1$ a 10).

A variação do número de átomos de bromo, bem como suas posições nos anéis, faz com que seja possível a formação de 209 congêneres (Tabela 1), embora apenas alguns sejam estáveis e comercialmente relevantes (ALAEE et al., 2003; KRÓL et al., 2014) .

Tabela 1. Quantidade de átomos de bromo substituintes e número teórico de congêneres de PBDE (BALLSCHMITER et al., 1980).

\begin{tabular}{llll}
\hline $\begin{array}{l}\text { Quant. de átomos de } \\
\text { Bromo }\end{array}$ & $\begin{array}{l}\text { Fórmula } \\
\text { Molecular }\end{array}$ & $\begin{array}{c}\text { Massa molar } \\
\left(\mathrm{g} \mathrm{mol}^{-1}\right)\end{array}$ & No. de Congêneres \\
\hline 1 & $\mathrm{C}_{12} \mathrm{H}_{9} \mathrm{OBr}$ & 249,103 & 3 \\
2 & $\mathrm{C}_{12} \mathrm{H}_{8} \mathrm{OBr}_{2}$ & 327,999 & 12 \\
3 & $\mathrm{C}_{12} \mathrm{H}_{7} \mathrm{OBr}_{3}$ & 406,895 & 24 \\
4 & $\mathrm{C}_{12} \mathrm{H}_{6} \mathrm{OBr}_{4}$ & 485,791 & 42 \\
5 & $\mathrm{C}_{12} \mathrm{H}_{5} \mathrm{OBr}_{5}$ & 564,687 & 46 \\
6 & $\mathrm{C}_{12} \mathrm{H}_{4} \mathrm{OBr}_{6}$ & 643,584 & 42 \\
7 & $\mathrm{C}_{12} \mathrm{H}_{3} \mathrm{OBr}_{7}$ & 722,479 & 24 \\
8 & $\mathrm{C}_{12} \mathrm{H}_{2} \mathrm{OBr}_{8}$ & 801,376 & 12 \\
9 & $\mathrm{C}_{12} \mathrm{H}_{1} \mathrm{OBr}_{9}$ & 880,272 & 3 \\
10 & $\mathrm{C}_{12} \mathrm{OBr}_{10}$ & 959,167 & 1 \\
\hline
\end{tabular}


Para fácil identificação dos congêneres, a IUPAC (do inglês, International Union of Pure and Applied Chemistry) sugere o uso do sistema Ballschmiter-Zell (BZ), originalmente utilizado para dar nomenclatura aos PCB (Figura 2).

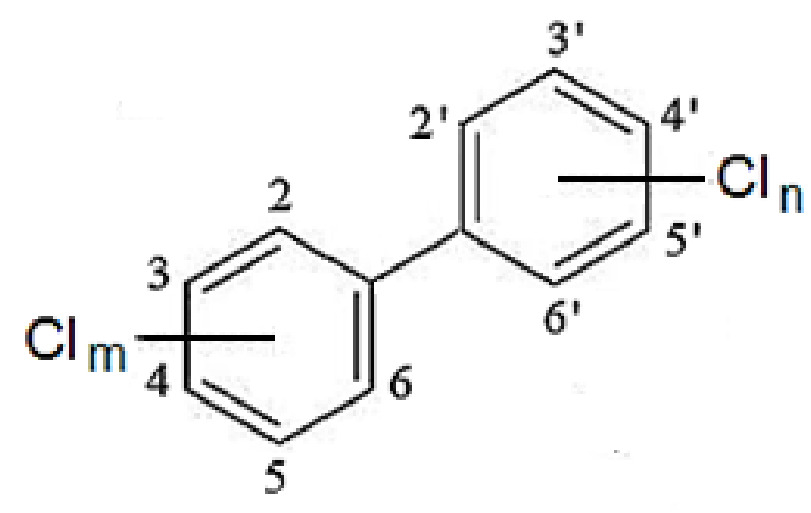

Figura 2. Estrutura básica da Bifenila Policlorada (sendo $m+n=1$ a 10).

Assim, cada congênere, precedido do acrônimo BDE, é numerado de 1 a 209 em função da quantidade de átomos de bromo presentes nos anéis (BALLSCHMITER et al., 1980; PENTEADO et al., 2001; ALAEE et al., 2003).

Já para a síntese industrial desses compostos, a principal rota baseia-se em uma reação de bromação do difenil éter na presença de excesso de bromo $\left(\mathrm{Br}_{2}\right)$, utilizando o catalisador de Friedel-Craft $\left(\mathrm{AlCl}_{3}\right)$, conforme reação apresentada na Figura 3 (RAHMAN et al, 2001; CHEN et al., 2012).

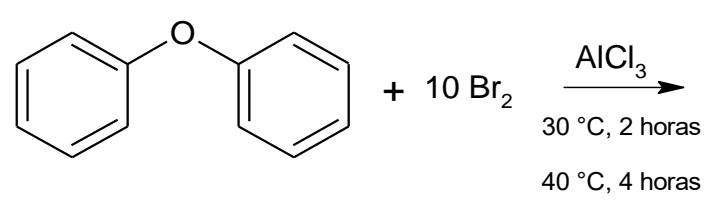<smiles>Brc1c(Br)c(Br)c(Oc2c(Br)c(Br)c(Br)c(Br)c2Br)c(Br)c1Br</smiles>

Figura 3. Reação simplificada de síntese do BDE-209 a partir da bromação do difenil éter (CHEN et al., 2012). 
A mistura dos reagentes é realizada num reator a vácuo sob agitação, com temperatura inicial mantida a $30{ }^{\circ} \mathrm{C}$ por um período de 1 a 2 horas, onde as taxas de bromação são verificadas através da liberação do $\mathrm{HBr}$ formado como subproduto. Após a bromação do éter difenílico, a temperatura é aumentada para $40{ }^{\circ} \mathrm{C}$ e mantida por mais 4 horas. São ainda necessárias, até a obtenção do produto final, etapas que envolvem lavagem, filtração, secagem, moagem e empacotamento. Apesar de ser um processo de produção relativamente simples e barato, ao longo de todas as etapas são perdidos 60 $\mathrm{kg} \mathrm{t}^{-1}$ (CHEN et al., 2012).

\subsection{Produtos comercials contendo PBDE}

Existem três formulações comerciais denominadas penta-BDE, octaBDE e deca-BDE que contém misturas de diferentes BDE. O penta-BDE possui maiores percentuais dos congêneres BDE-47, 99 e 100 (Tabela 2), sendo utilizados em espumas de poliuretano, mobiliários, materiais isolantes e têxteis, com demanda mundial estimada em aproximadamente 7500 toneladas no ano de 2006 (ALAEE et al., 2003; WARD et al, 2008; TALSNESS, 2008).

Tabela 2. Principais congêneres encontrados na mistura comercial penta-BDE, estruturas químicas, número de registro no Chemical Abstracts Service (CAS) e propriedades físico-químicas de interesse ambiental (TITTLEMIER et al., 2002; MACKAY et al., 2006).

\begin{tabular}{|c|c|c|c|}
\hline Congênere & BDE-47 & BDE-99 & BDE-100 \\
\hline Estrutura Química & & & \\
\hline Número CAS & $5436-43-1$ & $60348-60-9$ & $189084-64-8$ \\
\hline$M\left(\mathrm{~g} \mathrm{moL}^{-1}\right)$ & 485,8 & 564,7 & 564,7 \\
\hline Log $K_{\text {ow }}$ & 6,55 & 7,13 & 6,86 \\
\hline$S_{w}\left(\mu g \mathrm{~mL}^{-1}\right)$ & 0,015 & 0,0094 & 0,040 \\
\hline $\mathrm{P}\left(\mathrm{mmHg}\right.$ a $\left.25^{\circ} \mathrm{C}\right)$ & $1,4 \times 10^{-6}$ & $1,32 \times 10^{-7}$ & $2,15 \times 10^{-7}$ \\
\hline
\end{tabular}


O octa-BDE, aplicado em computadores, eletrodomésticos, telefones e peças automotivas, possuem maiores concentrações de BDE-183, 196, 197 e 207 (Tabela 3), com demanda mundial, estimada em 2006, de 3790 toneladas (ALAEE et al., 2003; WARD et al, 2008; TALSNESS, 2008).

Tabela 3. Principais congêneres encontrados na mistura comercial octa-BDE, estruturas químicas, número de registro no Chemical Abstracts Service (CAS) e propriedades físico-químicas de interesse ambiental (TITTLEMIER et al., 2002; MACKAY et al., 2006).

\begin{tabular}{|c|c|c|c|c|}
\hline Congênere & BDE-183 & BDE-196 & BDE-197 & BDE-207 \\
\hline $\begin{array}{l}\text { Estrutura } \\
\text { Química }\end{array}$ & & & & \\
\hline Número CAS & $207122-16-5$ & $446255-38-5$ & $117964-21-3$ & $437701-79-6$ \\
\hline $\mathrm{M}\left(\mathrm{g} \mathrm{moL}^{-1}\right)$ & 722,5 & 801,4 & 801,4 & 880,3 \\
\hline Log $K_{\text {ow }}$ & 7,14 & $8,5^{*}$ & $8,5^{*}$ & $9,0^{* *}$ \\
\hline $\mathrm{S}_{\mathrm{w}}\left(\mu \mathrm{gL}^{-1}\right)$ & 0,002 & $0,0003^{*}$ & $0,0003^{*}$ & $0,00016^{\star *}$ \\
\hline $\mathrm{P}\left(\mathrm{mmHg}\right.$ a $\left.25^{\circ} \mathrm{C}\right)$ & $3,51 \times 10^{-6}$ & $3,10 \times 10^{-8 *}$ & $3,10 \times 10^{-8 *}$ & $2,25 \times 10^{-8 * *}$ \\
\hline
\end{tabular}

M: massa molar, $K_{\text {ow }}$ : coeficiente de partição octanol/água, $\mathrm{S}_{\mathrm{w}}$ : solubilidade em água, $\mathrm{P}$ : pressão de vapor, ${ }^{*}$ estimado para os octaBDE, ${ }^{* *}$ estimado para os nonaBDE.

O deca-BDE (Tabela 4), com consumo mundial de 56100 toneladas em 2006, é formado pelo congênere BDE-209 (99\%) com traços de outros congêneres, sendo utilizado em materiais sintéticos, resinas de poliéster, poliolefinas, têxteis e carcaças de equipamentos eletroeletrônicos (ALAEE et al., 2003; WARD et al, 2008; TALSNESS, 2008). 
Tabela 4. Principal congênere da mistura comercial deca-BDE, estrutura química, número de registro no Chemical Abstracts Service (CAS) e propriedades físicoquímicas de interesse ambiental (TITTLEMIER et al., 2002; MACKAY et al., 2006).

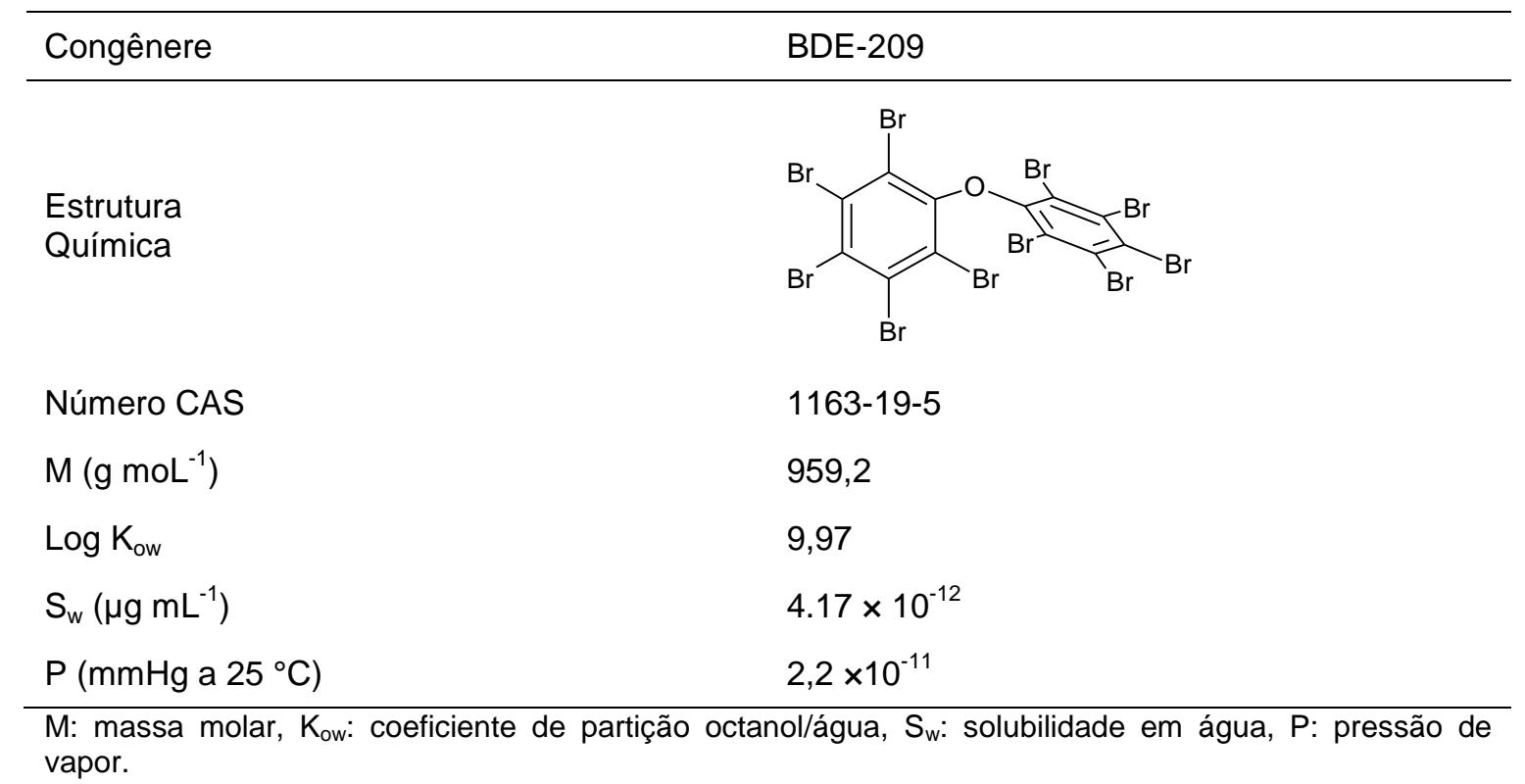

No Brasil, não existem registros de produção de FR contendo PBDE, que são obtidos pela indústria mediante importação. Segundo o Ministério do Desenvolvimento, Indústria e Comércio Exterior (MDIC, 2016), entre os anos de 1989 e 1996 foram importados 1010,7 toneladas do produto classificado como "éter decabromo difenílino" (Figura 4), provavelmente o deca-BDE por conter 99\% do congênere decabromado (BDE-209) em sua composição.

Entretanto, após esse período o produto foi reclassificado como "outros éteres aromáticos", não sendo possível definir os dados de importação de 1997 até os dias atuais, pois essa nomenclatura compreende um amplo grupo de substâncias. 


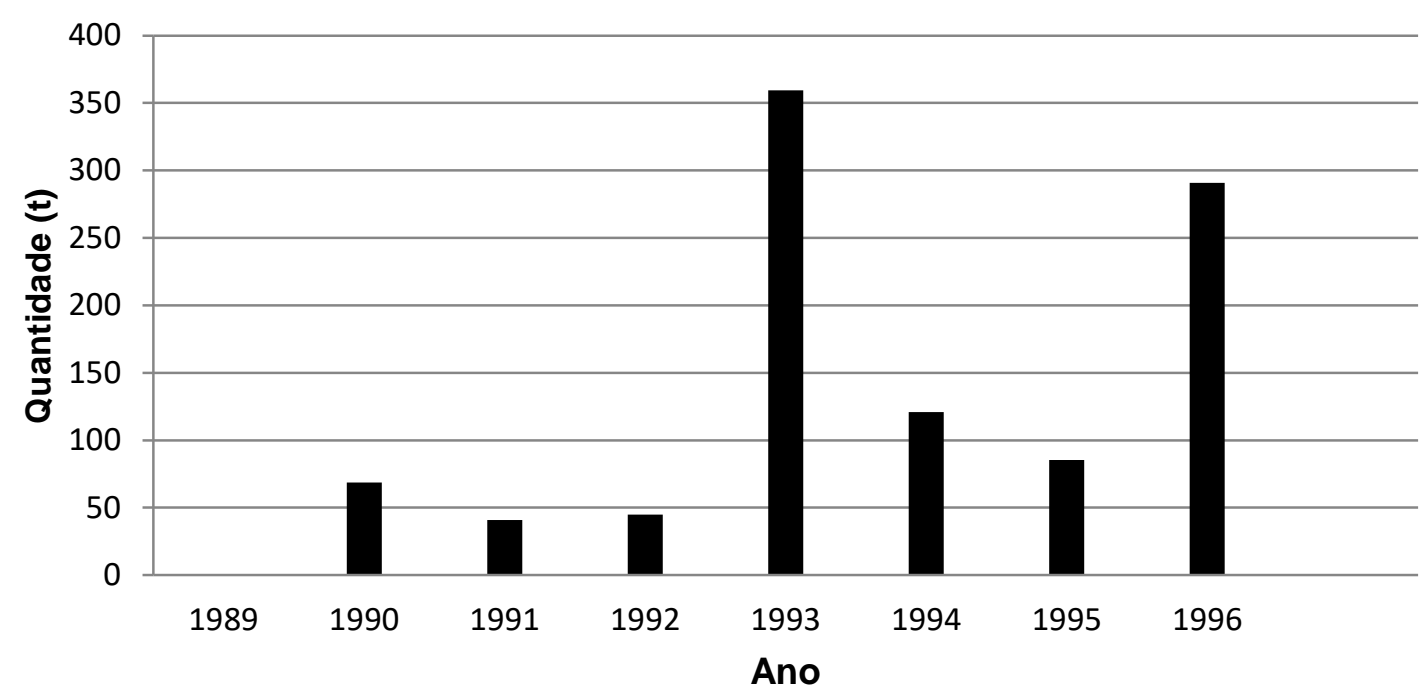

Figura 4. Importação do produto "éter decabromo difenílino" pelo Brasil no período de 1989 a 1996 (MDIC, 2014)

Embora os registros do MDIC não contenham dados dos produtos penta-BDE e octa-BDE, grandes quantidades de bens de consumo podem ter sido importados contendo esses produtos como FR, tornando cada vez mais complexa a tarefa de tentar quantificar o consumo desses no país.

Por outro lado, o Brasil promulgou a Convenção de Estocolmo mediante o Decreto Executivo $n^{\circ} 5472$, de 20 de junho de 2005, tornando-se parte da mesma (BRASIL, 2005). Ou seja, a proibição à utilização dos produtos FR contendo PBDE vale também no país, mas são inexistentes quaisquer tipos de ações voltadas ao controle de produção, importação, exportação e uso desses.

\subsection{Combustão e meCANISMO de AÇÃo dos PBDE}

De uma forma geral, a combustão pode ser definida como uma reação química, em fase gasosa, entre um material combustível e gás oxigênio. Esse processo pode ser dividido em cinco fases: (1) aquecimento; (2) pirólise; (3) ignição; (4) combustão e propagação, e (5) extinção (Figura 5) (GALLO et al., 1998; CHEN et al., 2012). 
Durante a fase de aquecimento, o calor proveniente de uma fonte externa é fornecido progressivamente ao material até que atinja sua temperatura de decomposição. A partir desse momento inicia-se a pirólise, ocorrendo liberação de substâncias como gases combustíveis (hidrocarbonetos e $\mathrm{CO}$ ), gases não combustíveis (vapor d'água e $\mathrm{CO}_{2}$ ), gases corrosivos $(\mathrm{HCl}$ e $\mathrm{HBr}$ ), líquidos (fragmentos de polímeros), partículas sólidas (fuligem) e radicais livres altamente reativos (H• e HO•) (GALLO et al., 1998).

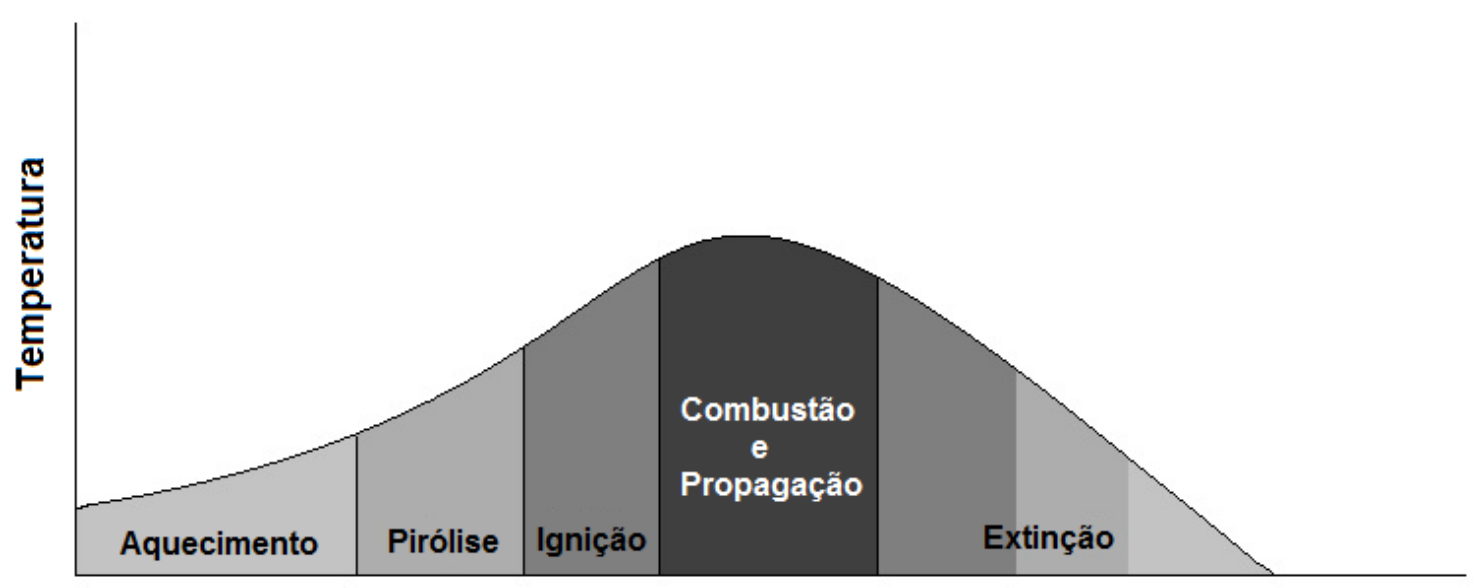

Curso da combustão

Figura 5. Gráfico esquemático das fases do processo de combustão (adaptado de GALLO et al., 1998).

Quando os radicais atingem a superfície do material se dá a ignição, onde em contato com o oxigênio desencadeiam reações de combustão altamente exotérmicas. Essas reações tendem a se propagar até que 0 material combustível e o oxigênio sejam consumidos, extinguindo processo de queima (GALLO et al., 1998; CHEN et al., 2012).

De forma geral, o mecanismo de ação dos PBDE se inicia durante a fase de pirólise, onde a decomposição térmica do FR causa homólise das ligações $\mathrm{R}-\mathrm{Br}$ e liberação de radicais bromo (Equação 1):

$$
R-B r \rightarrow R \bullet+B r \bullet
$$

Os radicais reagem com ligações $R-H$ dos compostos em combustão através da abstração de hidrogênio, formando o ácido bromídrico (Equação 2). 


$$
R-H+B r \bullet \rightarrow R \bullet+H B r
$$

$\mathrm{O}$ ácido reage com as espécies $\mathrm{H} \bullet$ e $\mathrm{HO} \bullet$ (Equações 3 e 4), dessa forma, impede as reações exotérmicas entre esses e o oxigênio. Como consequência, o sistema é resfriado, reduzindo a fase gasosa e inibindo a combustão.

$$
\begin{aligned}
& \mathrm{HBr}+\mathrm{H} \bullet \rightarrow \mathrm{H}_{2}+\mathrm{Br} \bullet \\
& \mathrm{HBr}+\mathrm{HO} \bullet \rightarrow \mathrm{H}_{2} \mathrm{O}+\mathrm{Br} \bullet
\end{aligned}
$$

Os radicais $\mathrm{Br} \cdot$ gerados como produto dessas reações podem novamente reagir com os compostos em combustão (Equação 2), regenerando o ácido bromídrico. Assim, pode ser dada sequência a novas reações com radicais $\mathrm{H} \bullet \mathrm{e} H \mathrm{H} \bullet$ até a extinção da combustão (GALLO et al., 1998; CHEN et al., 2012).

\subsection{Propriedades de Relevância ambiental}

O transporte, destino e comportamento de substâncias químicas no ambiente podem ser previstos através dos valores de algumas propriedades físico-químicas como pressão de vapor, solubilidade em água e coeficiente de partição octanol/ água ( $\mathrm{K}_{\mathrm{ow}}$ ) (FEITOSA et al., 2013).

Assim, com base na análise desses valores para os principais congêneres das misturas FR penta-BDE (Tabela 2), octa-BDE (Tabela 3) e BDE-209 (Tabela 4), é possível observar que os PBDE apresentam valores de pressão de vapor variando entre $2,21 \times 10^{-11}$ a $1,4 \times 10^{-6} \mathrm{mmHg}$ para os congêneres BDE-209 e BDE-47 respectivamente (RAHMAN et al., 2001; (TITTLEMIER et al., 2002). Portanto, em virtude da baixa volatilidade no ambiente esses contaminantes são transportados unicamente junto ao material particulado (atmosférico ou aquático), onde podem assim atingir longas distâncias (DE WIT, 2002; BRAEKEVELT et al., 2003; HARRAD et al., 2006; MACKAY et al., 2006; SAMARA et al., 2006; BARÓN et al., 2012; GORGY et al., 2013). 
Além disso, os valores de coeficiente de partição octanol/água ( $\log \mathrm{K}_{\mathrm{ow}}$ ) entre 6,55 (BDE-47) e 9,99 (BDE-209), demosntram elevada hidrofobicidade, ou seja, tendência em se acumular em meios hidrofóbicos. Consequentemente, esse comportamento tem reflexo nos baixos valores de solubilidade em água, cujas concentrações máximas são de $1,5 \times 10^{-2} \mu \mathrm{g} \mathrm{mL}^{-1}$ para o BDE-47, e $4,17 \times 10^{-12} \mathrm{mg} \mathrm{mL}^{-1}$ para o BDE-209 (RAHMAN et al., 2001; TITTLEMIER et al., 2002).

Com efeito, os PBDE adsorvidos tanto no material particulado atmosférico, quanto aquático, ao serem transportados, se distribuem no solo e, no caso de corpos de água, permanecem em suspensão, sedimentam ou são acumulados na biota (RAHMAN et al., 2001; TITTLEMIER et al., 2002; DE WIT, 2002; BRAEKEVELT et al., 2003; HARRAD et al., 2006; MACKAY et al., 2006; SAMARA et al., 2006; BARÓN et al., 2012; GORGY et al., 2013).

A estabilidade química é outro fator preponderante, pois após serem distribuidos nos diversos compartimentos ambientais, persistem em virtude da baixa suceptibilidade às reações de degradação. Essas reações só ocorrerão a menos que seja obtida energia necessária para homólise das ligações entre os átomos de bromo e carbono $\left(280 \mathrm{KJ} \mathrm{mol}^{-1}\right)$. Logo, isto será possível mediante uma fonte de aquecimento, como ocorre nas situações de combustão (Equação 1), ou irradiação de luz (SOLOMONS et al., 2001). Alguns estudos sugerem reações de desbromação redutiva mediadas por fotólise ou microorganismos anaeróbicos, onde PBDE superiores, sofrem desalogenação em espécies inferiores com menores níveis de bromação (TOKARZ et al., 2008; LEE et al., 2010; HUANG et al., 2014).

Em suma, com essas observações é possivel prever que os PBDE estão sujeitos a serem transportados por longas distâncias, sendo distribuidos em diversos compartimentos onde podem persistir e/ou bioacumular. Sem dúvida, essas informações demonstram a importância de estudos que ilustrem de qual forma ocorre a distribuição e comportamento de PBDE no ambiente, haja vista que tais aspectos ainda não estão completamente elucidados (PALMA et al., 2002). 


\subsection{Presença no ambiente}

Mesmo diante da ausência de um mapa global sobre a distribuição desses contaminantes no ambiente, sua presença vem sendo confirmada em várias matizes ao redor do planeta. Deste modo, esta revisão propôs por meio do esquema da Figura 6, as principais rotas de distribuição dos PBDE nos diferentes compartimentos ambientais, com base em alguns estudos.

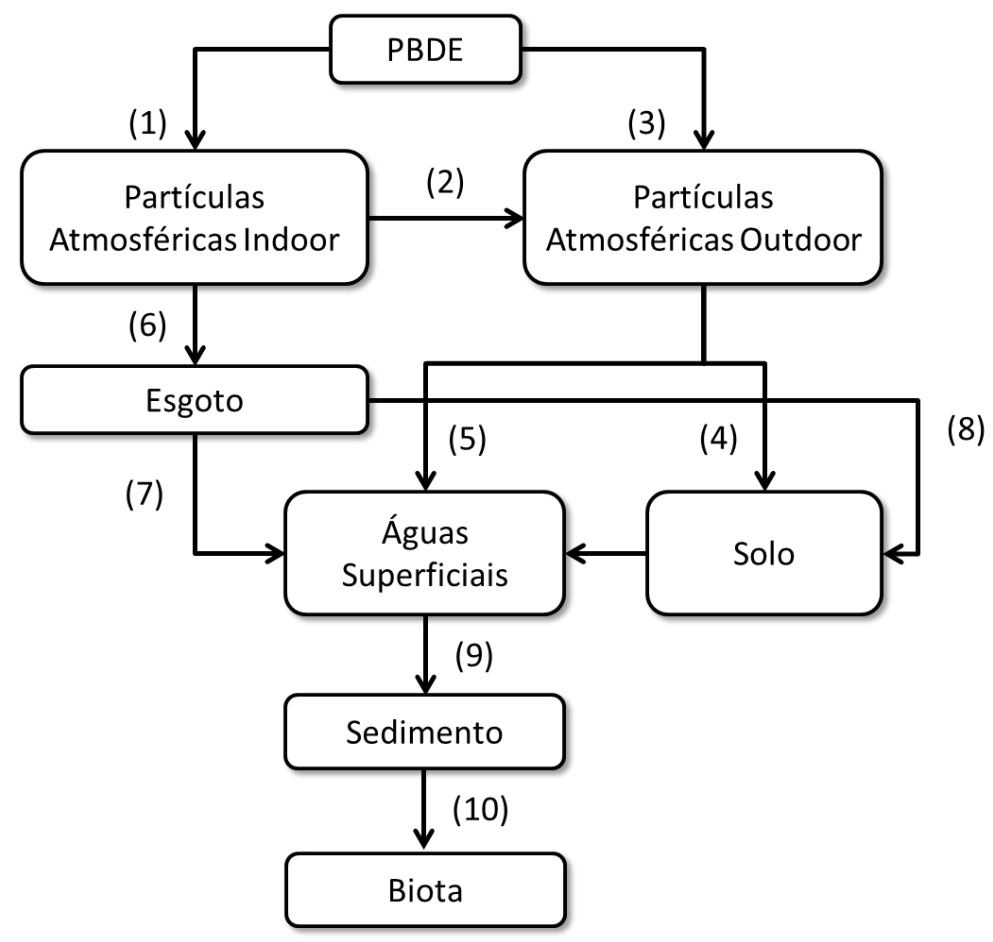

Figura 6. Esquema das principais rotas de aporte e distribuição dos PBDE no ambiente.

Considerando que os PBDE não são quimicamente ligados aos materiais, mas apenas misturados, a Figura 6 ilustra por meio das rotas 1 e 3 que há liberação destes contaminantes com a ação do tempo. Em função de suas carcaterísticas, notadamente sua elevada hidrofobicidade, PBDE possuem afinidade considerável com partículas orgânicas e inorgânicas que compõe os aerossóis atmosféricos. Ao serem liberados da mistura polimérica, os PBDE podem se acumular nas partículas atmosféricas que são continuamente depositadas sobre superfícies e ressuspendidas. A presença de PBDE no material particulado de atmosferas confinadas foi investigada por Harrad et al. (2006). 
Os autores investigaram, durante dois anos, a presença de PBDE em ambientes fechados de Birmingham, na Inglaterra, e verificaram maiores concentrações médias no interior de veículos $\left(709 \mathrm{pg} \mathrm{m}^{-3}\right.$ ), seguido de escritórios (166 $\left.\mathrm{pg} \mathrm{m}^{-3}\right)$, pequenos espaços públicos $\left(112 \mathrm{pg} \mathrm{m}^{-3}\right.$ ) e residências (52 $\mathrm{pg} \mathrm{m}^{-3}$ ). Os BDE-47 e 99 foram os congêneres mais prevalentes nas amostras investigadas. Em um trabalho semelhante realizado na Suécia, Björklund et al. (2012) quantificaram $92 \mathrm{pg} \mathrm{m}^{-3}$ de PBDE totais (10 congêneres) no material particulado de residências, enquanto que em escritórios e creches observaram níveis de até 4700 e $1200 \mathrm{pg} \mathrm{m}^{-3}$, respectivamente. Os autores também analisaram as saídas dos sistemas de ventilação de ar dos edifícios no intuito de identificar o transporte dos PBDE (rota 2) e observaram concentrações médias de 93, 3700 e $660 \mathrm{pg} \mathrm{m}^{-3}$, na saída dos sistemas de ventilação de residências, escritórios e creches, respectivamente.

Embora os trabalhos de Harrad et al. (2006) e Björklund et al. (2012) evidenciem a importância da contaminação ambiental advinda de bens de consumo contendo PBDE, a liberação destes contaminantes para atmosferas adjacentes também ocorre (rota 3), sob menores proporções, durante os processos industriais de produção e mistura dos PBDE aos materiais (SAKAl et al., 2001; JUGAN et al., 2010)

Uma vez adsorvidos no material particulado atmosférico os PBDE podem atingir longas distâncias. Möller et al. (2011), por exemplo, identificaram os congêneres BDE-28, 47, 66, 85, 99, 100, 153, 154, 183 e 209 em amostras de ar e de material particulado atmosférico em regiões distantes como as do mar da Groelândia Oriental. Os níveis de concentrações foram significativamente menores que os encontrados em atmosferas confinadas (HARRAD et al., 2006; BJÖRKLUND et al., 2012) variando entre 0,06 e $1,6 \mathrm{pg} \mathrm{m}^{-3}$ no ar e entre 0,03 e $0,46 \mathrm{pg} \mathrm{m}^{-3}$ no material particulado atmosférico. Dentre os congêneres estudados, os BDE-47, 99 e 100, representaram $89 \%$ do total quantificado.

O transporte desses contaminates pode ter como destino a deposição no solo, conforme representado na rota 4. Parolini et al. (2012) investigaram amostras de pastos localizados na região dos Alpes italianos e identificaram os congêneres BDE-47, 99, 100 e 183, sob níveis médios de $0,71 \mathrm{ng} \mathrm{g}^{-1}$. 
Nesta região, longe de centros urbanos e industriais, a presença dos PBDE foi atribuída à elevada estabilidade química e hidrofobicidade dos congêneres que mantiveram suas prioriedades durante $O$ transporte. Os autores evidenciaram também maior prevalência de PBDE em solos contendo maiores teores de carbono orgânico (PAROLINI et al., 2012). Em outro estudo, Wang et al. (2011), determinaram PBDE em amostras de solo da província de Zhejiang, na China, uma região caracterizada pela presença de indústrias de reciclagem de resíduos eletrônicos. As concentrações médias de BDE-209 foram elevadas, atingindo níveis de até $58 \mu \mathrm{g} \mathrm{g}^{-1}$. Segundo os autores, tais níveis de concentração se assemelham aos da poeira coletada no chão das oficinas de reciclagem de eletrônicos, cujos valores variaram de 5,5 a $80 \mu \mathrm{g} \mathrm{g}^{-1}$.

O material particulado atmosférico contendo PBDE também pode se depositar sobre ambientes aquáticos naturais, como exemplificado pela rota 5 , O trabalho realizado por Möller et al. (2011) no mar da Groelândia Oriental também evidenciou a presença de PBDE em amostras de águas. Os autores observaram concentrações de PBDE entre 0,03 e 0,64 $\mathrm{pg} \mathrm{L}^{-1}$, com prevalência dos congêneres BDE-47 e 99, corroborando a capacidade do material particulado atmosférico em transportar essas substâncias para regiões remotas do planeta.

Apesar dos resultados apontados por Möller et al. (2011), poucos estudos foram realizados para determinação de PBDE em águas, afinal a baixa solubilidade dos PBDE neste meio associada à sua elevada hidrofobicidade constituem fatores limitantes ao seu enriquecimento no meio aquático. Além disso, são esperados níveis de concentração bastante baixos, o que confere uma gama de fatores limitantes à obtenção de resultados confiáveis. Parte dos trabalhos com este intuito são realizados em regiões próximas a complexos industriais, tal qual o trabalho desenvolvido por Moon et al. (2012) no lago artificial Shihwa, na Coréia do Sul. A maior parte dos trabalhos, entretanto, são realizados em regiões que sofrem influencia direta da urbanização. Neste contexto, sabe-se que os PBDE também atingem ambientes aquáticos por meio do lançamento de esgoto, seja ele bruto ou mesmo tratado (XIANG et al., 2013; DENG et al., 2015). 
Neste caso, acredita-se que a presença de PBDE nas águas residuárias urbanas será influenciada à partir de uma sequência de processos comuns em ambientes domésticos, comerciais e até mesmo industriais. Nestes ambientes, PBDE sabidamente se acumulam sobre superfícies enriquecendo partículas atmosféricas, conforme mostrado anteriromente. Entretanto, a limpeza das superfícies nestes ambientes faz com que tais partículas sejam transferidas para as águas de lavagem, permanecendo agora na forma de partículas em suspensão. Após a limpeza destes ambientes, a água de lavagem poderá ser eliminada tanto via ralos, atingindo sistemas de esgotamento sanitários, quanto por meio de bueiros, atingindo redes de escoamento pluvial (rota 6). Ao serem eliminados junto às águas residuárias, os PBDE podem atingir ambientes aquáticos de forma direta ou ainda à partir de efluentes de estações de tratamento de esgotos (ETE), se os processos operantes em tais estações não forem suficientes para a remoção completa destes contaminantes. Essa situação é representada no esquema pela rota 7 (XIANG et al., 2013; DENG et al., 2015).

Nas ETE convencionais, os métodos de tratamento não são, de fato, completamente eficazes na remoção de compostos com elevada estabilidade química, como os PBDE. Deste modo, Xiang et al., (2013) observaram níveis de 1,68 a 4,64 $\mathrm{ng} \mathrm{L}^{-1}$ desses contaminates nos efluentes de uma ETE localizada em Xangai, na China. Da mesma forma, Deng et al. (2015), ao investigarem a presença de PBDE em quatro ETE da cidade de Hong Kong, evidenciaram que entre 52 a $80 \%$ dos PBDE permanecem no efluente final, sendo posteriormente lançados aos corpos aquáticos receptores. Os autores também sugerem que durante o tratamento, entre 21 e $45 \%$ dos PBDE são precipitados no lodo do esgoto. Assim, os riscos do empego dessas lamas para fins agrícolas foram descritos, revelando a contaminação de solos conforme ilustrado na rota 8 (CINCINELLI et al., 2012; KIM et al., 2017). Segundo Kim et al. (2017), as concentrações desses contaminantes em locais cuja utilização do lodo foi realizada por um período de 15 anos, tiveram seus valores elevados de 30 a 400 vezes em relação às concentrações iniciais. 
Uma vez lançados em corpos aquáticos receptores, os PBDE tendem a assumir comportamentos dependentes tanto de suas propriedades quanto das características do ambiente receptor. Em função de sua baixa solubilidade, os PBDE poderão se acumular na biota aquática, nos sólidos em suspensão e, invariavelmente, no sedimento de fundo ilustrado na rota 9 (RAHMAN et al., 2001; TITTLEMIER et al., 2002; DE WIT, 2002; BRAEKEVELT et al., 2003; HARRAD et al., 2006; MACKAY et al., 2006; SAMARA et al., 2006; BARÓN et al., 2012; GORGY et al., 2013).

Os sedimentos aquáticos consistem em partículas de matéria orgânica e inorgânica de diferentes tamanhos, que se acumulam de forma não consolidada nos leitos de lagos, rios, represas, áreas alagáveis e oceanos. No geral, esse material tem 0 ambiente terrestre como origem, onde se desprendem e são transportados como material particulado, depositando nos corpos hídricos e formando as camadas sedimentares em diferentes áreas de acordo com suas propriedades. Desta forma, se tornam o sumidouro de uma variedade de resíduos biológicos, químicos e poluentes, desempenhando um importante papel na caracterização de ambientes aquáticos (MOZETO et al., 2006; ROCHA et al., 2009; GARRISON, 2010; MANAHAN, 2013).

Esse compartimento ambiental tem sido extensivamente investigado na literatura com relação à presença de PBDE. Vários estudos evidenciam que as altas concentrações em sedimentos aquáticos tem sido encontradas em regiões sob influência de pontos de descarga de águas residuárias e de efluentes de ETE. Dentre essas pode ser citada a Baia de São Francisco, EUA (KLOSTERHAUS et al., 2012); do rio Niágara, EUA e Canadá (SAMARA et al., 2006); dos rios de Chaohu, China (LI et al., 2012); dos Grandes Lagos, Canadá (YANG et al., 2012); lago Taihu, China (ZHOU et al., 2012); e do lago Shihwa, Coréia do Sul (MOON et al., 2012).

Junto à biota aquática, o sedimento é uma matriz de grande interesse, por estar diretamente ligada às transferências das espécies químicas para as cadeias alimentares aquáticas. Na Figura 6 esses processos são representados pela rota 10 sendo mediadas por organismos menores que compõem essa cadeia como crustáceos, moluscos, vermes, insetos e outros (MOZETO et al., 2006; MANAHAN, 2013). 
A presença dos PBDE na biota foi confirmada por Yu et al. (2009), entre os anos de 2005 a 2007, no estuário do Rio das Pérolas, China, demosntrando o potencial de biomagnificação de PBDE em quatro espécies de invertebrados e dez de peixes. Também na China, Gao et al. (2009) detectaram a presença desses poluentes em 16 espécies, dentre peixes, caranguejos e camarões, do Delta do Rio Yangtze. Nesse estudo os autores demostraram haver um perfil entre as concentrações dos PBDE na biota e no sedimento, implicando que esse seja uma fonte importante para contaminação dos organismos aquáticos.

Por fim, embora os estudos apresentados nessa revisão demonstrem ubiquidade dos PBDE no ambiente, os dados sobre esses no Brasil são escassos, sendo encontrados estudos de bioacumulação na biota. Dentre esses, pesquisas que detectaram esses contaminates em cetáceos e peixes marinhos (DORNELES et al., 2010; LAVANDIER et al., 2013; LAVANDIER et al., 2015; LAVANDIER et al., 2016) e de água doce (QUINETE et al., 2011) da região sudeste do país, afetada pela urbanização e industrialização.

Hara (2014) otimizou e aplicou um protocolo analítico para a determinação de PBDE em sedimentos de ambientes aquáticos urbanos e mananciais de abastecimento, localizados na bacia Hidrográfica do Alto Iguaçu, Região Metropolitana de Curitiba. O estudo demonstrou a presença dos congêneres BDE-71, BDE-85 e BDE-99 em amostras de regiões sob forte influência urbana e industrial.

\subsection{DeterminaçÃo de PBDE em MATRIZes ambientais}

O estudo de PBDE no ambiente envolve o estabelecimento de etapas de amostragem, preparo das amostras e determinação analítica. Tendo-se em vista que um resultado analítico é o maior balizador em tomadas de decisão, em especial nas questões ambientais, todas estas etapas estão sujeitas a protocolos baseados em critérios de controle/garantia de qualidade. 


\subsubsection{Amostragem e preservação}

A etapa de amostragem é a que possui maiores especificidades em relação ao tipo de matriz que será objeto de estudo, enquanto que nas etapas subsequentes, os métodos guardam similaridade. Dessa forma, a seguir serão descritos os métodos mais comuns para estudos de PBDE em amostras de ar, material particulado atmosférico, água, solo e sedimentos aquáticos.

\subsubsection{Material particulado atmosférico}

Tendo em vista as baixas concentrações desses contaminantes no ar (ng $\mathrm{m}^{-3}$ a $\mathrm{pg} \mathrm{m}^{-3}$ ) de ambientes internos e externos, essa etapa é comumente realizada de forma acumulada em diferentes modelos de amostradores do tipo ativo ou passivo. Em ambos os casos são empregados filtros e adsorventes sólidos para coleta dos analitos nas fases gasosa e/ou do material particulado (DENG et al., 2007; XIE et al., 2008; DEAN, 2009; TAKIGAMl et al., 2009; BESIS et al., 2012; WANG et al., 2015). No geral, a instrumentação dos sistemas de amostragem ativa consiste numa bomba com controlador e medidor de fluxo do ar, filtro e compartimento contendo adsorvente sólido, conforme esquema da Figura 7 (XIE et al., 2008; DEAN, 2009).

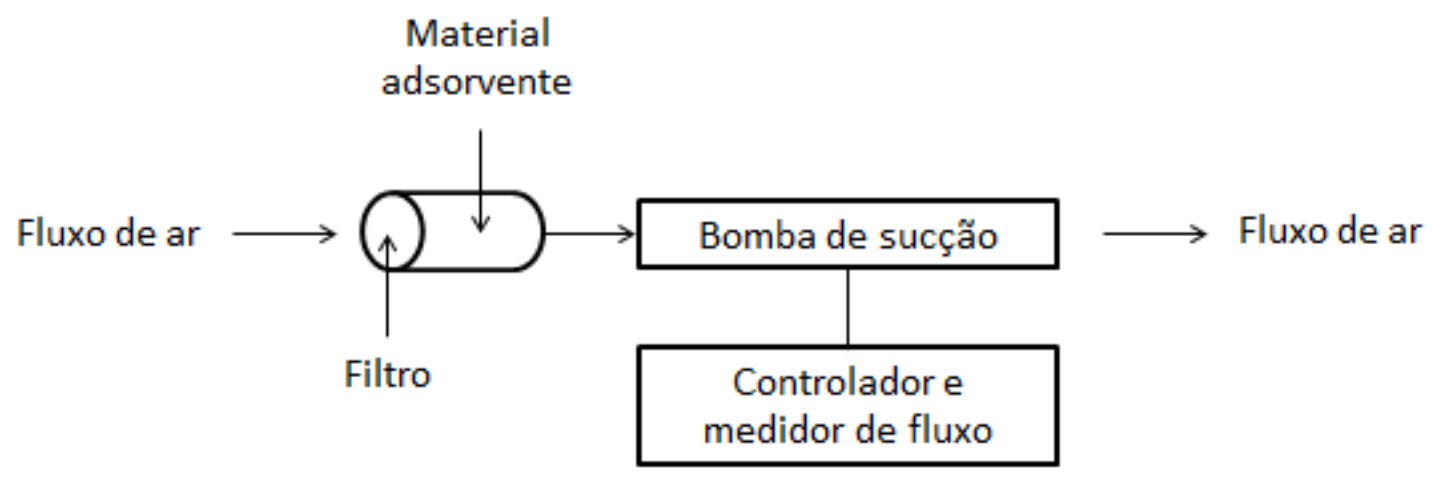

Figura 7. Esquema de instrumentação dos amostradores atmosféricos do tipo ativo.

Desta forma, o ar é bombeado para o interior do sistema de modo que o material particulado atmosférico seja separado inicialmente em filtro de fibra de vidro ou acetato de celulose. A seguir, a fase gasosa é levada ao compartimento contendo o material sólido afim de que os analitos ainda presentes sejam separados por adsorção. Na maioria dos casos esse material 
consiste em espuma de poliuretano (CHEN et al., 2006; CHEN et al., 2008; XIE et al., 2008; DEAN, 2009; MANDALAKIS et al., 2009; TAKIGAMI et al., 2009; BESIS et al., 2012; BJÖRKLUND et al., 2012; WATKIMS et al., 2013; WANG et al., 2015).

Embora esses sistemas possuam a vantagem de amostrar grandes volumes de ar em curtos períodos de tempo, seu emprego é limitado a determinados locais pela necessidade de fonte de energia elétrica, além de possuírem custo elevado de aquisição e manutenção (XIE et al., 2008). Assim, alguns trabalhos aproveitam a semelhança estrutural dos sistemas de ar condicionado para recolher nos seus filtros amostras de material particulado atmosférico, sendo então possível estimar a concentração de PBDE no interior de ambientes e analisar a exposição de humanos a esses contaminantes (TAN et al., 2007; KANG et al., 2011; Nl et al., 2011) (BESIS et al., 2014; WANG et al., 2014). Outra alternativa vem sendo a utilização de aparelhos aspiradores de pó para coleta de amostras de poeira depositadas sobre a superfície de objetos no interior de residências (SJÖDIN et al., 2008; TAKIGAMl et al., 2009; SHOEIB et al., 2012; STASINSKA et al., 2013), escritórios (BATTERMAN et al., 2010; KEFENI et al., 2012), creches (BJÖRKLUND et al., 2012) automóveis e pequenos espaços públicos (HARRAD et al., 2006).

Já os amostradores do tipo passivo atuam através de processos físicos como difusão e permeação, fixando os analitos em adsorvente acondicionado no interior de invólucros com aberturas que permitem exposição à atmosfera, de acordo com esquema da Figura 8.

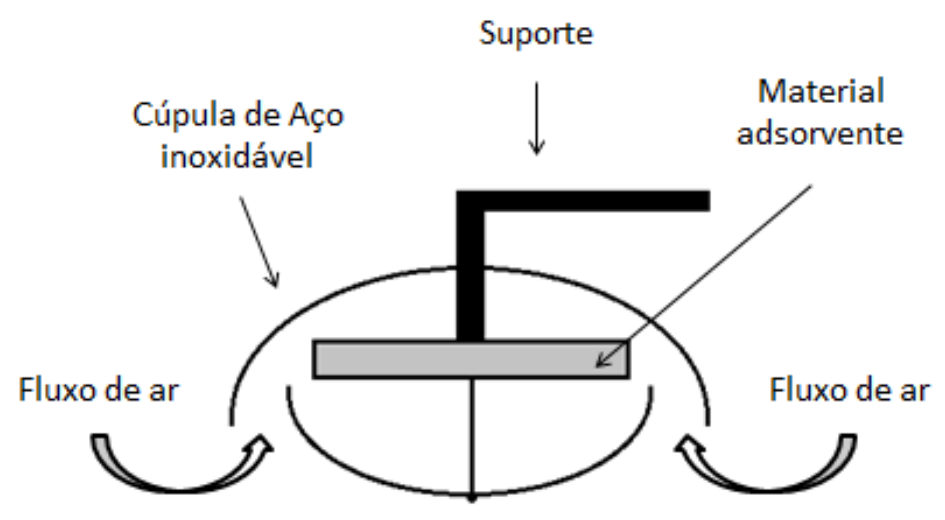

Figura 8. Esquema de amostrador atmosférico do tipo passivo. 
Desta forma, apresentam maior versatilidade nos estudos de PBDE em ambientes externos (HARRAD et al., 2006; Ll et al., 2012), à medida que não há necessidade de utilização de bomba de sucção que requer uma fonte de energia elétrica. Esses equipamentos são de instrumentação simples, fácil manuseio, baixo custo de aquisição e manutenção, além de poderem ser construídos atendendo certas especificidades. Contudo, demandam maiores tempos de amostragem em relação aos amostradores ativos (CRUZ et al., 2002; XIE et al., 2008; DEAN, 2009).

\subsubsection{2. Água}

Para a determinação de PBDE em águas superficiais, os métodos de amostragem reportados pela literatura são os mesmos comumente utilizados para compostos orgânicos em ambientes aquáticos. Na Figura 9 se encontram ilustrados alguns dos materiais usados pelo Grupo de Automação, Quimiometria e Química Ambiental (AQQUA) para as amostragem de líquidos.

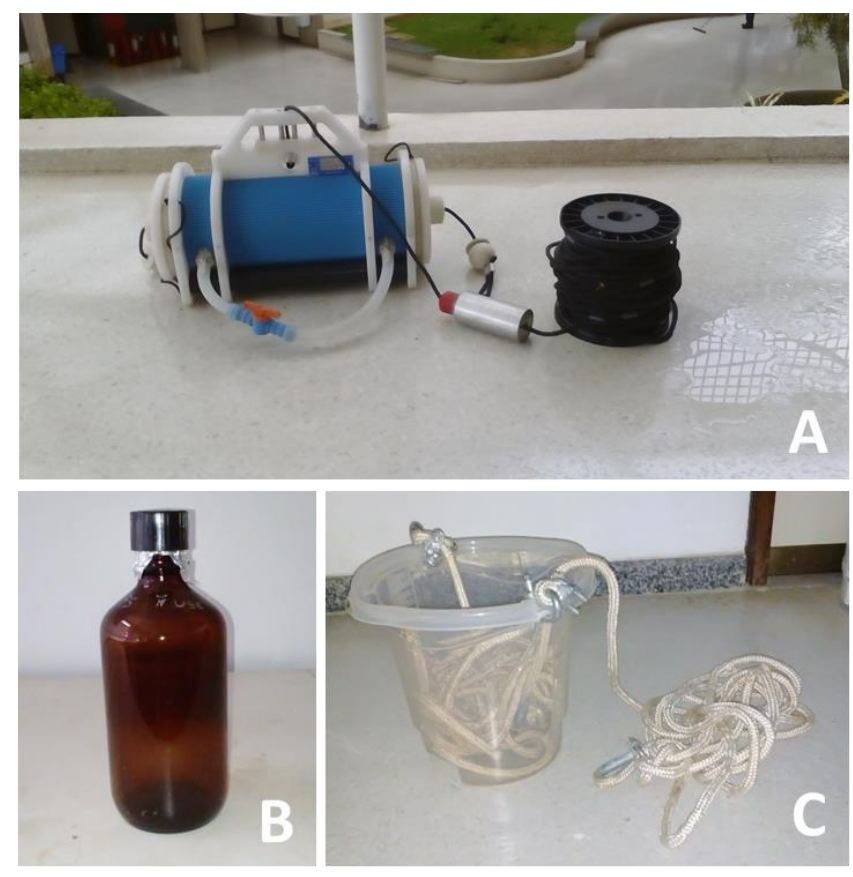

Figura 9. Materiais empregados pelo Grupo AQQUA para amostragens de líquidos sendo: (A) Garrafa de Van Dorn, (B) Frasco de vidro do tipo âmbar, e (C) Balde.

Conforme as ilustrações, essa etapa é realizada empregando garrafas de amostragem (WANG, et al., 2011), como as do tipo Hale e Van Dorn (Figura 9a), bem como em frascos de vidro do tipo âmbar (Figura 9b) (GUZZELLA, et 
al., 2011). Por outro lado, MOON et al (2012) fizeram o uso de baldes atados a cordas (Figura 9c) para amostragens de águas superficiais do lago Shihwa, na Coréia, onde os PBDE foram detectados. Essa prática permite que a etapa seja executada em locais de acesso limitado, onde o amostrador necessite coletar em distâncias onde não é possível o controle de abertura e fechamento dos frascos de amostragem. Outro aspecto importante é que esses recipientes permitem uma coleta de grandes volumes de amostra, haja vista a baixa concentração dos analitos nessa matriz.

\subsubsection{Solos e sedimentos aquáticos}

A amostragem de solos e sedimentos aquáticos é do tipo composta, sendo executada por amostradores e ferramentas usuais para estudos nessas matrizes. Na Figura 10 são ilustrados alguns equipamentos do Grupo AQQUA para amostragem dessas matrizes.
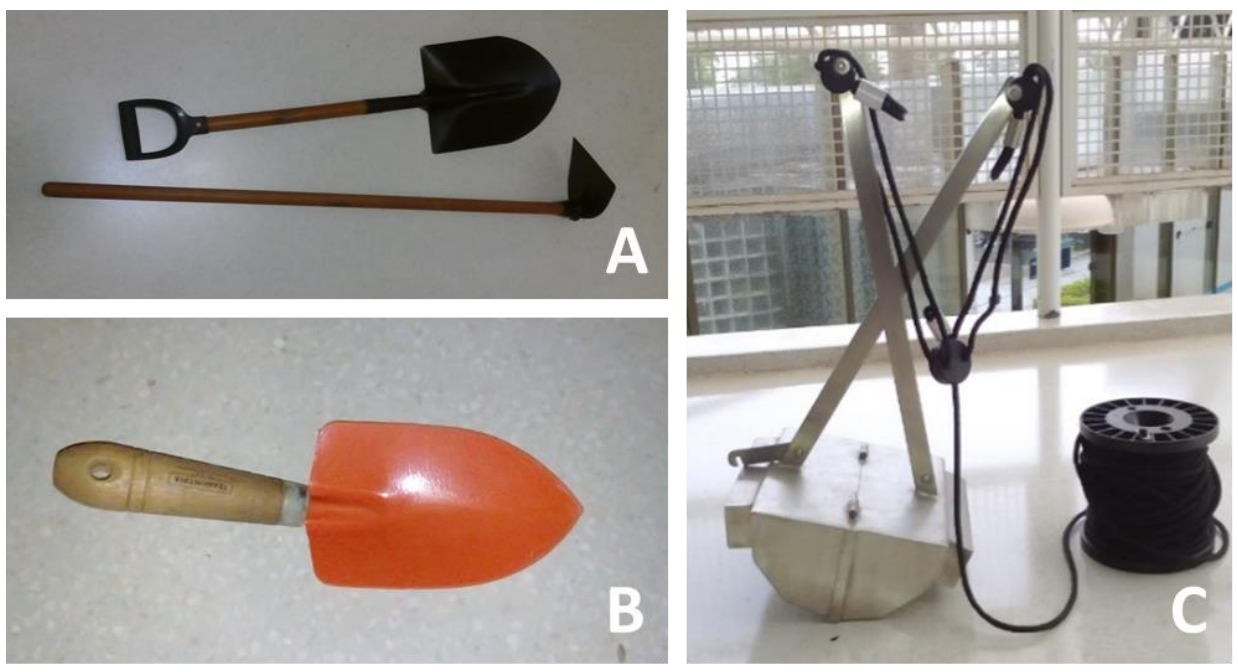

Figura 10. Materiais empregados pelo Grupo AQQUA para amostragens de solos e sedimentos, sendo: (A) Pá e enxada, (B) Pá de jardinagem, e (C) Draga de Van Veen

Conforme a Figura 10, nos estudos de PBDE são descritos a utilização de materiais simples como pás (Figura 10a) e espátulas de aço inoxidável (SÁNCHEZ-BRUNETE et al,. 2006; YUAN et al., 2012; ZHENG et al., 2012; GORGY et al., 2012; JIANG et al., 2012), uma vez que as coletas para estudos de PBDE são realizadas em camadas superficiais. 
Entretanto, ferramentas como trados (rosca, holandês e meia lua), enxadas (Figura 10A), pás de jardinagem (Figura 10B) e sondas são também perfeitamente utilizáveis nessa etapa (ROCHA et al., 2009; DEAN, 2009).

Para os sedimentos aquáticos, a amostragem é descrita através do emprego de sondas ou dragas (Figura 10C) em diversos modelos (ZHENG et al., 2004; MOON et al., 2007; MARIANI et al., 2008; VANE et al., 2010; WANG, et al., 2011; ZHAO et al., 2011; LI et al., 2012; LIU et al., 2012; PAROLINI et al., 2012). Esses equipamentos permitem uma amostragem representativa de diferentes tipos de sedimento, coletando grandes volumes de amostra em variadas profundidades (CETESB, 2011).

\subsubsection{Preparo das amostras}

O preparo das amostras envolve etapas de secagem, extração e remoção dos interferentes (clean-up), estando ao final os congêneres de PBDE disponíveis para determinação analítica. Os métodos empregados nessas etapas serão descritos a seguir para as principais matrizes investigadas, sendo essas compostas por material particulado atmosférico, solo, sedimento aquático e água.

\subsubsection{Secagem}

A secagem de amostras sólidas como os filtros contendo material particulado atmosférico, poeira, solo e sedimento aquático, objetiva a remoção de água. Assim, na Figura 11 se encontram ilustrados alguns métodos comumente empregados e que fazem parte da rotina analítica do Grupo AQQUA.

A Figura 11A ilustra a utilização de sistemas liofilizadores (MOON et al., 2007; WANG et al., 2011; MOON et al., 2012; CAl et al., 2012), ao ar através de estufas de circulação (Figura 11B) ou capela de exaustão (Figura 11C) (SAMARA et al., 2006; FULONG et al., 2013; STASINSKA et al., 2013), bem como com auxílio de agentes dessecantes como o sulfato de sódio anidro (GORGY et al., 2012; KLOSTERHAUS et al., 2012; YUAN et al., 2012). 

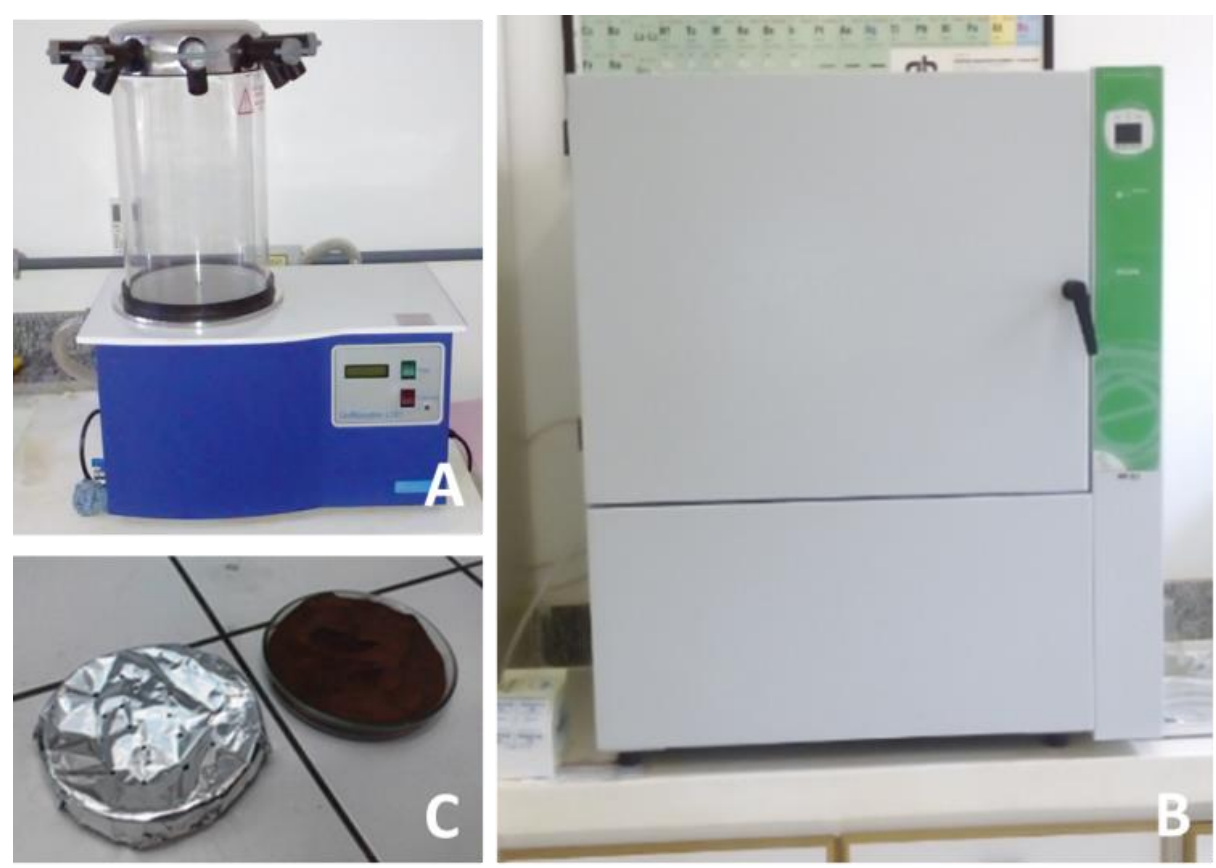

Figura 11. Métodos de secagem de amostras empregados no Laboratório do Grupo AQQUA, sendo: (A) Liofilizador (Liotop - L101), (B) Estufa de circulação de ar (Ethik Technology - 402/D), e (C) secagem ao ar em capela de exaustão.

Após a secagem das amostras de poeira, solo e sedimento, é necessária ainda a remoção das impurezas sólidas (pedras, folhas, galhos, raízes e etc), redução do tamanho das partículas (trituração ou peneiração) e homogeneização.

\subsubsection{Extração}

Para as extrações dos PBDE das matrizes abordadas nessa revisão as do tipo sólido-líquido são aplicáveis em material particulado atmosférico, poeira, solos e sedimentos. Os métodos utilizados envolvem Soxhlet, extração por ultrassom, extração assistida por micro-ondas e extração acelerada por solvente (Accelerated Solvent Extraction - ASE).

A extração Soxhlet (Figura 12) é a mais comum, principalmente por sua grande eficiência na extração de compostos orgânicos de matrizes complexas como os sedimentos, tendo a Agência de Proteção Ambiental dos Estados Unidos (Environmental Protection Agency - EPA) adotado em eu método oficial para determinação de PBDE em diferentes matrizes (EPA, 2007). 


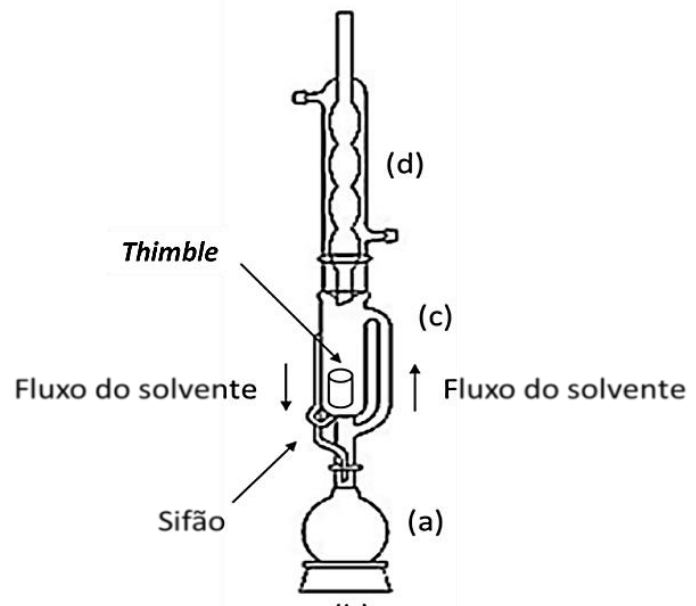

(b)

Figura 12. Esquema de um sistema de extração Soxhlet, sendo: (a) Reservatório de solvente, (b) Fonte de aquecimento, (c) Sistema extrator, e (d) Condensador.

Conforme ilustrado na Figura 13, o sistema utilizado para esse tipo de consiste num (a) reservatório da mistura de solventes sobre uma (b) fonte de aquecimento, (c) o sistema extrator e (d) um condensador. Dessa forma, a mistura de solventes do reservatório é evaporada pura até atingir 0 condensador, onde se liquefaz e goteja sobre a amostra acondicionada num "thimble" de celulose no interior do extrator. Nesse momento, a temperatura é suficientemente elevada para extrair e solubilizar o analito da matriz por gradiente de concentração. Esse contato ocorre até que o mesmo preencha quase completamente o volume do "thimble", escoando de volta ao reservatório através do sifão no extrator. Logo, a mistura de solventes pode ser redestilada repetidas vezes obtendo no reservatório um extrato com elevada concentração do analito (ZHANG, 2007; DEAN, 2009; CASTRO et al., 2010).

Diferentes misturas são utilizadas, sendo na maioria dos estudos de PBDE composta por solvente polar e apolar em proporções distintas. Os tempos de extração variam de 8 a 48 horas, dependendo da complexidade da matriz. Assim, Kefeni et al. (2012) analisando PBDE em amostras de poeira indoor realizaram extração em sistema Soxhlet com mistura solvente acetona/n-hexano (2:1) por um período de apenas oito horas. Já Takigami et al.(2009) e Batterman et al. (2010), analisando a mesma matriz optaram por tempos de extração de $16 \mathrm{~h}$ e $48 \mathrm{~h}$, respectivamente, mas usando apenas tolueno no primeiro caso, e mistura diclorometano/n-hexano (4:1) no segundo. 
Para matrizes mais complexas como solos e sedimentos aquáticos, os métodos optam por tempos maiores de extração, de modo a permitir a quebra das fortes interações analito/matriz aumentando a eficiência desta etapa. Dessa forma, na matriz solo Jiang et al. (2012) realizaram essa etapa utilizando mistura acetona/n-hexano por um período de 24 horas. De tal forma, trabalhos realizados por Yang et al. (2012), em amostras de sedimentos aquáticos, realizaram extrações em tempos de 24 em misturas diclorometano/n-hexano (1:1). Já Lee et al. (2012) utilixaram mistura e acetona/n-hexano (1:1) por um período de 48 horas. Sendo assim, trata-se de um método de extração de grande eficiência por permitir elevados percentuais de recuperação do analito, como a utilização de uma gama de mistura solventes. Em contrapartida esse método tem como desvantagens os longos tempos gastos para extração, o que torna-se tedioso, além da necessidade de grandes quantidades de amostra $(>200 \mathrm{~g})$ e misturas de solventes (>200 mL), haja vista que nas etapas subsequentes haverá necessidade de concentração dos extratos, principalmente por evaporação, sendo gerado quantidades excessivas de resíduos de solventes orgânicos tóxicos (COTTA et al., 2009; CASTRO et al., 2010).

Outro método descrito para extração sólido-líquido é a assistida por ultrassom, que de forma semelhante ao Soxhlet também é recomendada pela EPA, mas nesse caso para os compostos orgânicos de baixa volatilidade em amostras como solos e lodos (EPA, 1996; EPA, 1999; ZHANG, 2007).

O princípio baseia-se na sonicação de um solvente na qual a amostra estará imersa. Desta forma, através da ação de ondas de baixa frequência ocorrerá o fenômeno da cavitação, ou seja, formação de bolhas de alta pressão que difundem o solvente no interior da amostra e elevam a temperatura do solvente aumentando a solubilidade do analito (BENDICHO et al., 2012).

No Geral, são utilizadas pequenas quantidades de amostra $(<5,0 \mathrm{~g})$ e baixos volumes de solventes $(<100 \mathrm{~mL})$, suficiente para manter a amostra submersa. Assim são sonicados por aproximadamente 3 minutos, sendo 0 extrato em seguida separado da amostra por centrifugação e o procedimento repetido com nova adição de solvente. Essa troca permite a extração dos analitos por gradiente de concentração a cada nova substituição, obtendo-se assim um extrato acumulado (ZHANG, 2007). 
A instrumentação dos estudos de PBDE consiste no emprego de sondas (FULONG et al., 2013) ou equipamentos mais simples e baratos como banhos de ultrassom (SÁNCHEZ-BRUNETE et al., 2006; BJÖRKLUND et al., 2012). $\mathrm{Na}$ Figura 13 se tem representados dois modelos utilizados pelo Grupo AQQUA em sua rotina laboratorial.
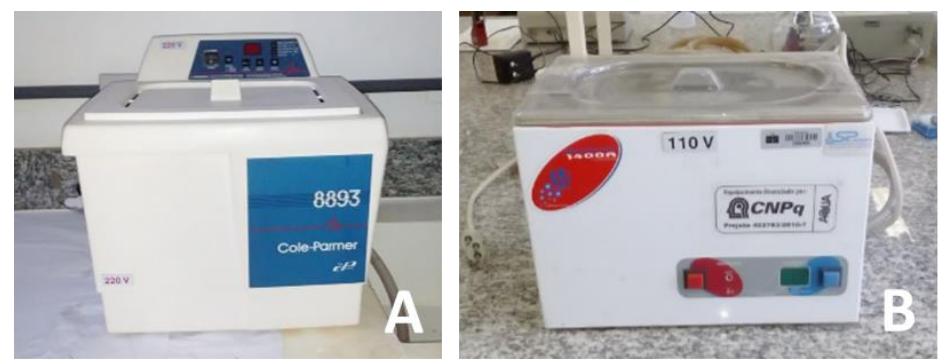

Figura 13. Banhos de ultrassom utilizados no laboratório do Grupo AQQUA, sendo: (a) Cole Parmer-8893, e (b) UltraCleaner-1400A .

A utilização desses equipamentos permite que o método de extração seja realizado de forma simples, em períodos relativamente curtos (<30 min), com baixos volumes de solventes. Além disso, tornam essa etapa mais segura em relação ao Soxhlet por ser realizada à pressão e temperatura ambiente, além de gerar menos resíduos.

Já a extração assistida por micro-ondas (Microwave-Assisted Extraction - MAE) utiliza a energia dessas ondas para gerar a rotação e movimento desorganizado de moléculas com dipolo permanente, levando ao aquecimento do solvente que se difunde na amostra e solubiliza os analitos (CAMEL, 2000; FIDALGO-USED et al., 2007; WANG et al., 2010). Eventualmente, não é possível a utilização de apenas um alcano puro como solvente de extração, sendo necessária a composição de uma mistura juntamente com solvente polar.

As misturas mais comuns envolvem hexano/acetona, confome estudo de Shin et al. (2007) em lodo de esgoto e Wang et al. (2011) em amostras de solos e sedimentos aquáticos. Na Figura 14 se tem ilustrado um sistema assistido por micro-ondas utilizado para extração de amostras sólidas. 

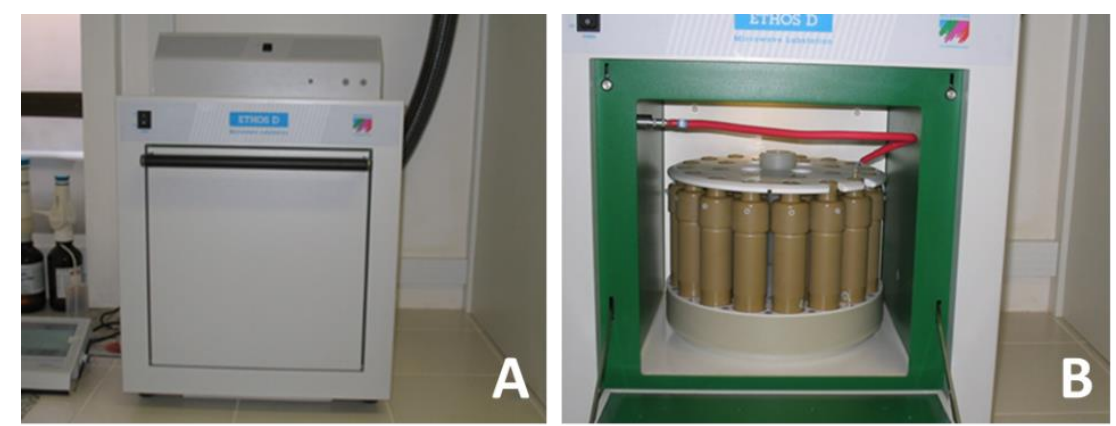

Figura 14. Sistema MAE marca Ethos $D$, Milestone Sorisole, sendo: $(A)$ imagem do equipamento, e (B) Tubos de extração alocados no rotor do sistema fechado assistido por micro-ondas

Conforme a Figura 14b se observa que esses sistemas usam tubos alocados no rotor do sistema, onde é acondicionado o material contendo o analito. Desta forma possibilitam a extração simultânea de grandes quantidades de amostra. Os equipamentos de MAE operam com controle de temperatura e mecanismos de alívio da pressão dos tubos, de modo a assegurar total segurança no processo (FIDALGO-USED et al., 2007; WANG et al., 2010).

$\mathrm{Na}$ extração acelerada por solvente (Accelerated Solvent Extraction ASE), também conhecida como extração por líquido pressurizado (Pressurized Liquid Extraction - PLE), o procedimento é realizado utilizando solventes em temperaturas $\left(50\right.$ a $\left.200{ }^{\circ} \mathrm{C}\right)$ e pressões (10 a $15 \mathrm{MPa}$ ) elevadas, permanecendo este ainda no estado líquido. Essas condições favorecem a quebra das interações entre a matriz e o analito, que assim pode ser solubilizado no solvente de extração. Como vantagens sobre os outros métodos podem ser citados a economia de tempo ( $\approx 20 \mathrm{~min}$ ), uso de solvente $(<15 \mathrm{~mL}$ ) e eficiência na recuperação dos analitos. No entanto, a utilização dessa técnica esbarra nos elevados custos de aquisição dos equipamentos (CAMEL, 2000; FIDALGO-USED et al., 2007; WANG et al., 2010).

Nos estudos de PBDE, a ASE têm sido empregada em amostras de material particulado atmosférico (KRÓL et al., 2014), poeira (HARRAD et al., 2006; SJODIN et al., 2008; STASINSKA et al., 2013), solos (GORGY et al., 2012; ZHENG et al., 2012) e sedimentos aquáticos (SAMARA et al., 2006; DODDER et al., 2012; KLOSTERHAUS et al., 2012). 
Para as extrações de PBDE em amostras de água, os métodos descritos na literatura utilizam extração em fase sólida (Solid Phase Extraction - SPE), cujo princípio se baseia na retenção do analito num sorvente sólido a partir de uma amostra líquida. Subsequentemente este é recuperado por eluição a partir de um solvente apropriado. No geral, utilizam a fase C18 (octadecil) como sorvente eluindo os PBDE com solventes polares e apolares (WANG, LIN, et al., 2011; GUZZELLA, POMA, et al., 2011; MOON et al., 2012).

\subsubsection{Clean-up}

Após a extração, uma série de compostos se encontram presentes no extrato, sendo necessária a remoção dos possíveis interferentes na determinação analítica. Essa etapa é realizada por cromatografia em coluna contendo fases estacionárias como sílica neutra, ácida e básica, alumina, nitrato de prata, florisil e/ou sulfato de sódio anidro. Assim, os extratos são eluídos e os interferentes são adsorvidos ou degradados. Posteriormente os analitos são recuperados de forma semelhante à SPE, eluído geralmente com solvente a ser utilizado posteriormente na etapa de determinação analítica (MOZETO et al., 2006; EPA, 2007; GUZZELLA et al., 2011; KLOSTERHAUS et al., 2012; SAHLSTRÖM et al., 2012; KRÓL et al., 2014).

\subsubsection{Determinação analítica}

A determinação analítica exige técnica instrumental capaz de separar e quantificar os congêneres de PBDE em níveis de concentração variando de $\mathrm{ng} \mathrm{g}^{-1}$ a $\mathrm{pg} \mathrm{g}^{-1}$. Basicamente é realizada empregando a cromatografia gasosa (Gas Chromatography - GC) acoplada a sistema de detecção por captura de elétrons (Electron Capture Detector - ECD), caracterizada pela seletividade a compostos halogenados. Sistemas de analisadores de massa (Mass Spectrometry - MS) em linha (tipo quadrupolo), ou captura de íons (ion-trap IT), vem ganhando destaque por serem capazes de detectar seletivamente íons e fragmentos de substâncias, tornando menos laboriosa a etapa de cleanup, além de melhorar os limites de detecção (Zheng et al., 2003; Collins et al., 2006; Paiva et al., 2010; Gorgy et al., 2013). 


\section{OBJETIVOS}

Este estudo teve como objetivo o desenvolvimento e validação de método analítico para determinação de nove congêneres de PBDE em amostras de sedimento do Lago Paranoá, um dos principais corpos aquáticos receptores de esgoto bruto e de efluentes de estações de tratamento de esgotos do Distrito Federal.

Ao mesmo tempo, como objetivo específico propôs:

a) Desenvolver e/ou adaptar métodos de extração concentração e cleanup para determinação composto de interesse em amostras de sedimento;

b) Elaborar e/ou aprimorar método rápido e robusto para a identificação e quantificação de PBDE por GC-ECD;

c) Estabelecer pontos amostrais ao longo do Lago Paranoá;

d) Investigar o comportamento dinâmico dos indicadores de PBDE no Lago Paranoá, identificando, se possível, sua pluma de contaminação e suas principais fontes;

e) Estudar a distribuição dos PBDE investigados, segundo o modelo de fugacidade, utilizando o software EQC Model - Level I, e

f) Realizar avaliação de risco de acordo com as concentrações dos PBDE nos sedimentos do Lago Paranoá, bem como na coluna d'água segundo as simulações relizadas pelo software EQC Model - Level I . 


\section{PARTE EXPERIMENTAL}

A seguir, serão descritas a área de estudo, bem como os procedimentos e materiais envolvidos no desenvolvimento e validação do método analítico empregado na determinação dos nove congêneres de PBDE em sedimentos do Lago Paranoá.

\section{1. ÁreA de Estudo}

A bacia do Paranoá, ilustrada na Figura 15, se localiza na região central do Distrito Federal (DF), entre as latitudes 15035' e 1559' Sul e longitudes $47^{\circ} 47^{\prime}$ e $48^{\circ} 05^{\prime}$ Oeste, tendo uma área de $1034 \mathrm{~km}^{2}$, onde se encontram as regiões administrativas de Brasília, Lago Norte, Lago Sul, Núcleo Bandeirante, Riacho Fundo, Candangolândia, Cruzeiro e Guará, bem como parte de Taguatinga (MACHADO et al., 2016; CBHP, 2017).

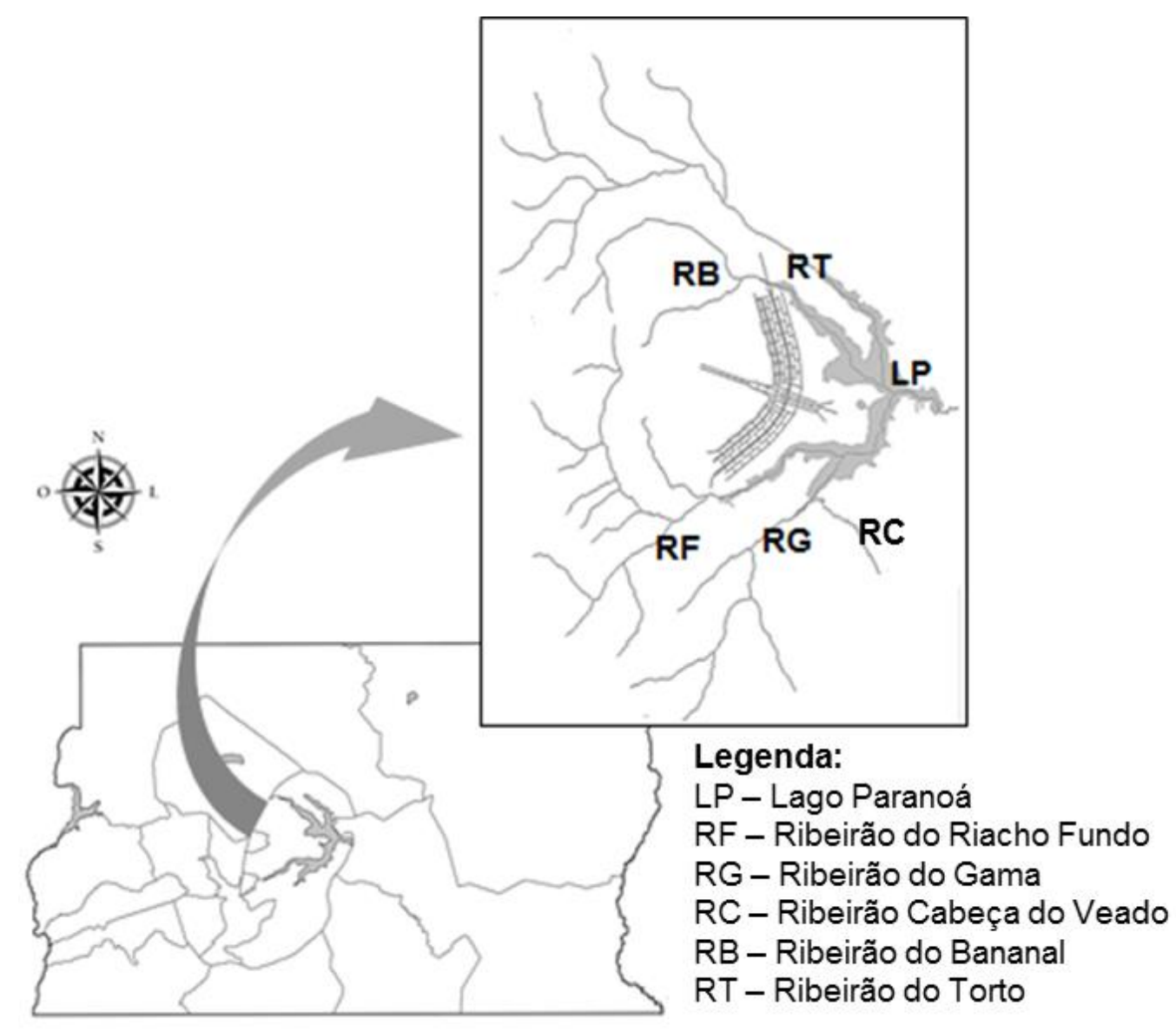

Figura 15. Mapa do Distrito Federal e localização da Bacia Hidrográfica do Paranoá 
De acordo com o mapa da Figura 15, a Bacia do Lago Paranoá ocupa $18 \%$ do território do DF, tendo como principais cursos de água os Ribeirões do Riacho Fundo (RF), Gama (RG), Cabeça do Veado (RC), Bananal (RB) e Torto (RT). O represamento das águas desses ribeirões, ocorrida em 1959, deu origem ao Lago Paranoá (LP), alagando terrenos abaixo de $1000 \mathrm{~m}$ de altitude em relação ao nível do mar. A criação do lago teve como objetivos contribuir com as condições climáticas do DF, além da gerar energia elétrica e criar opções de lazer para população (MACHADO et al., 2016; CBHP, 2017).

Seu volume é de aproximadamente 510 milhões de $\mathrm{m}^{3}$, cobrindo uma área de $38 \mathrm{~km}^{2}$. A profundidade média é de $13 \mathrm{~m}$, tendo o nível máximo atingido $40 \mathrm{~m}$. A ocupação de sua área se dá por 30\% de núcleos urbanos, $26 \%$ de formação savânica e $25 \%$ de formação campestre. As águas superficiais ocupam aproximadamente $5 \%$ da superfície da bacia (CBHP, 2017).

Esse reservatório é caracterizado por receber cargas pontuais e difusas de esgoto doméstico, através de redes de escoamento de águas superficiais, além de efluentes de duas das dezessete estações de tratamento de esgoto responsáveis pelo tratamento de todo o esgoto produzido no DF (CORREIO BRAZILIENSE, 2011; G1, 2013; G1, 2016; CAESB, 2017).

\subsubsection{Pontos de amostragem}

Os pontos para amostragem dos sedimentos são ilustrados na Figura 16 e foram definidos com base nas regiões onde ocorrem descargas de efluente bruto ou das ETE. Cada local recebeu um acrônimo para fácil identificação nas ilustrações, bem como na apresentação e discussão dos resultados.

De acordo com a Figura 16, o ponto ETS está localizado nas proximidades da Estação de Tratamento de Esgoto Sul, Essa ETE trata os efluentes de 700 mil habitantes $\left(1319 \mathrm{~L} \mathrm{~s}^{-1}\right.$ ano $\left.^{-1}\right)$ das regiões da Asa Sul, parte da área central de Brasília, Núcleo Bandeirante, Guará I e II, Cruzeiro, Octogonal, Sudoeste, parte do Lago Sul, parte do Riacho Fundo, SIA. e parte de Águas Claras (CAESB, 2017). 


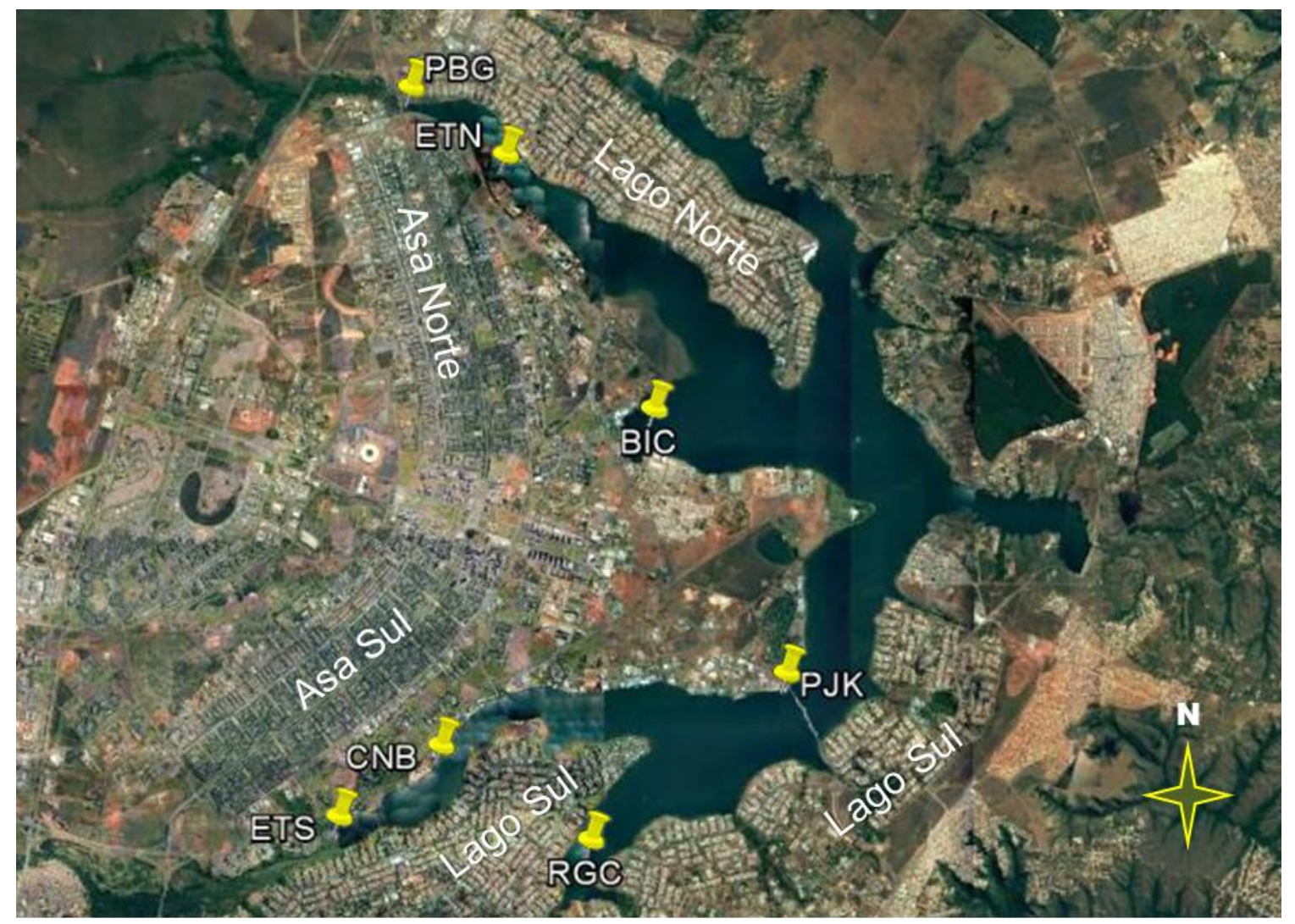

Figura 16. Localização dos pontos de amostragem, sendo: ETS - Estação de Tratamento de Esgoto Sul; CNB - Imediações do Clube Nipo Brasileiro; RBG afluência dos ribeirões do Gama e Cabeça de Veado; PJK - Ponte JK; BIC - Baia do late Clube de Brasília; ETN - Estação de Tratamento de Esgoto Norte; PBG - Ponte do Bragueto (Adaptado de Google Earth®).

Seguindo pelo mapa (Figura 16) se tem o ponto CNB, que está nas imediações do Clube Nipo Brasileiro. Essa área é influenciada pela descarga de redes de águas de escoamento superficial. Segundo informações do software Google Earth®, está a uma distância de $2,1 \mathrm{Km}$ do ponto ETS. Recentemente a Companhia de Saneamento Ambiental de Brasília (CAESB) restringiu o uso nesse local para banho e lazer, em virtude da proliferação de algas e cianobactérias. Segundo a companhia, esse fato está relacionado ao lançamento de esgoto bruto na região através dessas redes $(G 1,2016)$. Ainda no mapa é possível notar que o ponto RGC está localizado no extremo sul do Lago Paranoá, região onde ocorre afluência dos ribeirões do Gama e Cabeça de Veado. Esses tributários, também abordados na Figura 15, foram escolhidos como ponto a fim de verificar possíveis transportes de PBDE. 
Continuando na Figura 16 temos o ponto próximo da Ponte JK (PJK), sendo essa uma região turística muito frequentada para o lazer e prática de esportes aquáticos. Já na Baia do late Clube de Brasília está situado o ponto BIC. De forma semelhante ao ponto CNB, nessa região estão diversas redes para o lançamento de águas de escoamento superficial. Nos últimos anos, foram constatados alguns casos de aporte de efluentes sem qualquer tipo de tratamento (CORREIO BRAZILIENSE, 2011; G1, 2013; O GLOBO, 2014).

Ainda no mapa (Figura 16), o ponto ETN está localizado proximo à ETE Norte, responsável por tratar o esgoto de aproximadamente 180 mil habitantes $\left(450 \mathrm{~L} \mathrm{~s}^{-1} \mathrm{ano}^{-1}\right.$ ) das regiões da Asa Norte, Vila Planalto, parte da área central de Brasília, Lago Norte, Taquari, Vila Estrutural, Vila Varjão e Torto (CAESB, 2017). Por fim está o ponto PBG, localizado no extremo norte do lago e próximo à Ponte do Bragueto. Nesse local está o Calçadão da Asa Norte, um ponto de lazer que oferece aos frequentadores algumas atividades aquáticas. De acordo com software Google Earth ${ }^{\circledR}$ esse local está apenas 2,3 Km do ponto ETN, onde se encontra a ETE Norte. Na Tabela 5 são descritas as coordenadas de localização geográfica dos sete pontos escolhidos para o estudo ao longo do Lago Paranoá.

Tabela 5. Pontos de amostragem, descrições e coordenadas geográficas.

\begin{tabular}{llll}
\hline \multirow{2}{*}{ Ponto } & Descrição & \multicolumn{2}{l}{ Coordenada Geográfica } \\
\cline { 3 - 4 } & & Latitude & Longitude \\
\hline ETS & ETE Sul & $15^{\circ} 50^{\prime} 33.58^{\prime \prime}$ & $47^{\circ} 54^{\prime} 19.32^{\prime \prime}$ \\
CNB & Clube Nipo Brasileiro & $15^{\circ} 49^{\prime} 54.20^{\prime \prime}$ & $47^{\circ} 53^{\prime} 20.60^{\prime \prime}$ \\
RGC & Rib. do Gama e Cabeça de Veado & $15^{\circ} 50^{\prime} 46.50^{\prime \prime}$ & $47^{\circ} 51^{\prime} 54.45^{\prime \prime}$ \\
PJK & Ponte JK & $15^{\circ} 49^{\prime} 14.18^{\prime \prime}$ & $47^{\circ} 50^{\prime} 1.74 "$ \\
BIC & Baia do late Clube de Brasília & $15^{\circ} 46^{\prime} 47.87^{\prime \prime}$ & $47^{\circ} 51^{\prime} 18.02^{\prime \prime}$ \\
ETN & ETE Norte & $15^{\circ} 44^{\prime} 27.05^{\prime \prime}$ & $47^{\circ} 52^{\prime} 43.38^{\prime \prime}$ \\
PBG & Ponte do Bragueto & $15^{\circ} 43^{\prime} 49.80^{\prime \prime}$ & $47^{\circ} 53^{\prime} 37.70^{\prime \prime}$ \\
\hline
\end{tabular}

\subsection{Amostragem}

Escolhido os pontos, a amostragem foi realizada em 5 de dezembro de 2015 de acordo com metodologia descrita por Mozeto et al. (2006). Para o transporte se contou com auxílio de embarcação do Batalhão de Polícia Militar Ambiental (BPMA/PMDF). As coletas foram efetuadas por uma draga de Van Veen, conforme ilustrado na Figura 17. 

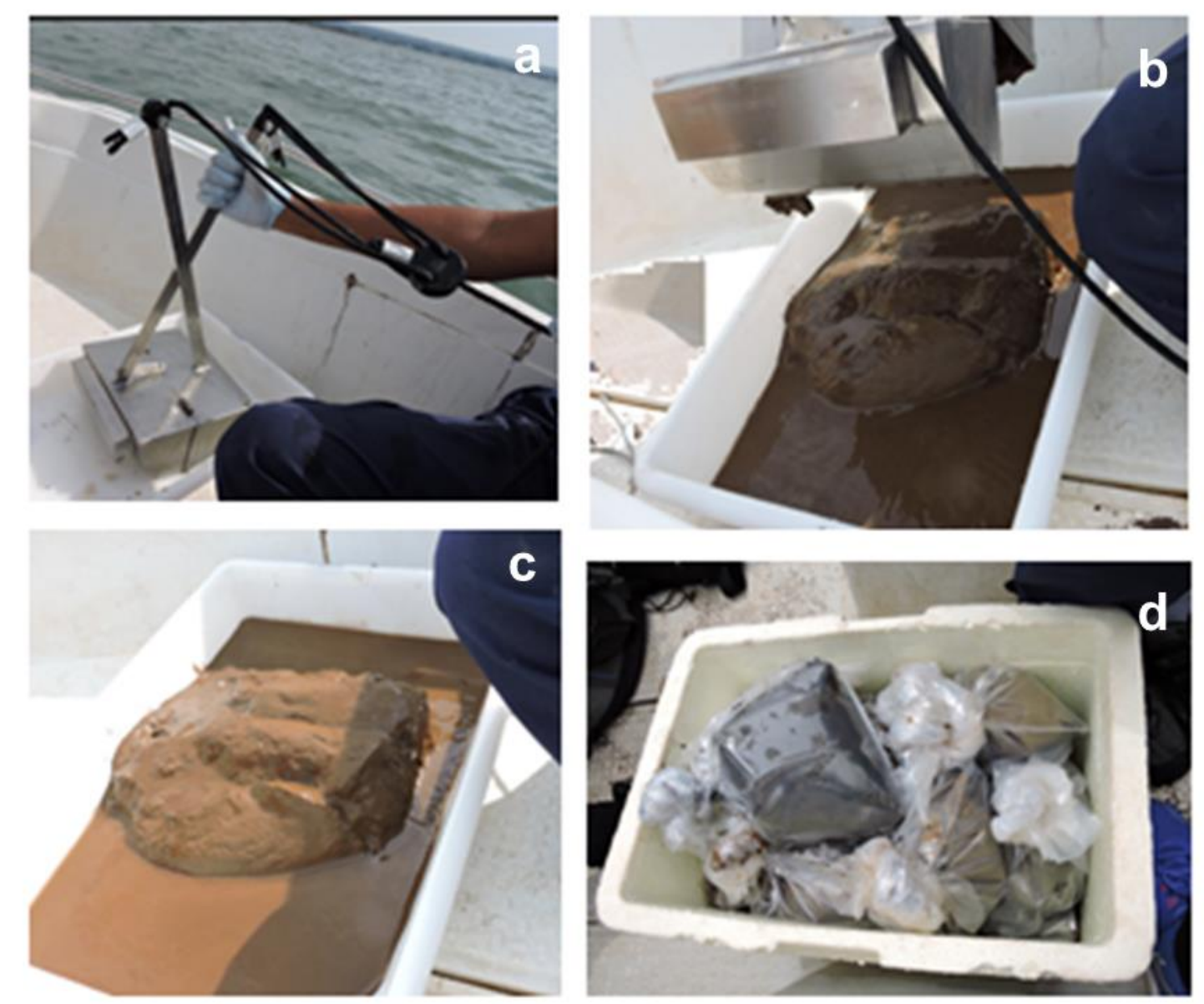

Figura 17. Coleta de amostra de sedimento, sendo: (a) içamento da draga de Van Veen, (b) abertura da draga, (c) amostra coletada, e (d) amostras acondicionadas em caixa térmica

Conforme mostrado na ilustração, após o içamento (Figura 17a) a draga foi aberta em bandeja (Figura 17b), para que se pudessem ser removidos da amostra galhos, vidros, plásticos e outras impurezas encontradas (Figura 17c). Além disso, com auxílio de uma espátula, o sedimento pôde ser transferido para sacos de coleta reduzindo a quantidade de água. As amostras foram devidamente rotuladas e acondicionadas em caixa térmica (Figura 17d) durante todo período de amostragem. Em laboratório, todas as amostras foram preservadas em freezer em temperaturas inferiores a $4{ }^{\circ} \mathrm{C}$, até o procedimento de secagem que será descrito posteriormente. 


\subsection{ReAGentes e materiaIS}

Todos os solventes e reagentes utilizados neste trabalho foram de pureza analítica ou superior. Acetona, diclorometano, hexano, isoctano e pentano, grau pesticida, foram adquiridos da Tedia (Fairfield, USA). Foram investigados nove congêneres da classe dos PBDE: BDE-28, BDE-47, BDE-66, BDE-85, BDE-99, BDE-100, BDE-138, BDE-153 e BDE-154, conforme Figura18. Para tanto foi utilizado o padrão Lake Michigan Study - LMS (10 $\mu \mathrm{g}$ $\mathrm{mL}^{-1}$ em isoctano), comercializado pela AccuStandard (New Haven, USA).<smiles>Brc1ccc(Oc2ccc(Br)cc2Br)cc1</smiles>

BDE-28 2,4,4'-Tribromodifenil éter $\log \mathrm{K}_{\mathrm{ow}}=5.98 ; \mathrm{S}_{\mathrm{w}}=70$<smiles>Brc1ccc(Oc2ccc(Br)cc2Br)c(Br)c1</smiles>

BDE-47 2,2',4,4'-Tetrabromodifenil éter $\log \mathrm{K}_{\mathrm{ow}}=6.55 ; \mathrm{S}_{\mathrm{w}}=15$<smiles>Brc1ccc(Oc2ccc(Br)c(Br)c2)c(Br)c1</smiles>

BDE-66 2,3',4,4'-Tetrabromodifenil éter $\log \mathrm{K}_{\mathrm{ow}}=6.73 ; \mathrm{S}_{\mathrm{w}}=18$<smiles>Brc1ccc(Oc2ccc(Br)c(Br)c2Br)c(Br)c1</smiles>

BDE-85

2,2',3,4,4'-Pentabromodifenil éter $\log \mathrm{K}_{\text {ow }}=7.03 ; \mathrm{S}_{\mathrm{w}}=6.0$<smiles>Brc1ccc(Oc2cc(Br)c(Br)cc2Br)c(Br)c1</smiles>

BDE-99 2,2',4,4',5-Pentabromodifenil éter $\log \mathrm{K}_{\mathrm{ow}}=7.13 ; \mathrm{S}_{\mathrm{w}}=9.4$<smiles>Brc1ccc(Oc2c(Br)cc(Br)cc2Br)c(Br)c1</smiles>

BDE-100

2,2',4,4',6-Pentabromodifenil éter $\log \mathrm{K}_{\mathrm{ow}}=6.86 ; \mathrm{S}_{\mathrm{w}}=40$<smiles>Brc1cc(Oc2ccc(Br)c(Br)c2Br)cc(Br)c1Br</smiles>

BDE-138

2,3,3',4,4',5'-Hexabromodifenil éter $\log \mathrm{K}_{\mathrm{ow}}=7.91 ; \mathrm{S}_{\mathrm{w}}=4.8 \times 10^{-3}$<smiles>Brc1cc(Br)c(Oc2cc(Br)c(Br)cc2Br)cc1Br</smiles>

BDE-153 2,2',4,4',5,5'-Hexabromodifenil éter $\log \mathrm{K}_{\text {ow }}=7.62 ; \mathrm{S}_{\mathrm{w}}=8.7 \times 10^{-4}$<smiles>Brc1cc(Br)c(Oc2cc(Br)c(Br)cc2Br)c(Br)c1</smiles>

BDE-154

2,2',4,4',5,6'-Hexabromodifenil éter $\log \mathrm{K}_{\mathrm{ow}}=7.39 ; \mathrm{S}_{\mathrm{w}}=8.7 \times 10^{-4}$

Figura 18. Estruturas químicas, nomenclaturas, Coeficientes de partição octanol/água (Log $\left.K_{o w}\right)$ e solubilidade em água $\left(S_{w} \cdot n g ~ \mathrm{~mL}^{-1}\right)$ dos nove congêneres investigados nesse estudo 
Para avaliação dos fatores de recuperação do método foram utilizadas duas amostras-modelo, um material de referência certificado (MRC) e outro material preparado a partir de amostras de sedimento do Lago Paranoá, cujo procedimento de preparo será mostrado detalhadamente no texto que segue. $\mathrm{O}$ MRC utilizado foi um sedimento certificado para PBDE/PCB (SQC072 - $50 \mathrm{~g}$ ) obtido da RTC - SQC072 (Laramie, WY, USA). Ácido clorídrico PA ACS (36,5 38\%), ácido sulfúrico PA (95 - 99\%), sulfato de sódio anidro PA, hidróxido de potássio PA e sílica gel $60(0,05-0,2 \mathrm{~mm}$ ), foram adquiridos da Vetec (Rio de Janeiro, BRA).

\subsection{LIMPEZA DE VIDRARIAS}

Considerando-se a expectativa em se determinar baixos níveis de concentração dos compostos investigados, bem como a necessidade de evitar interferências causadas por contaminação de vidrarias, foram estabelecidos diferentes procedimentos para limpeza dos materiais empregados durante a rotina analítica.

A limpeza inicial de todas as vidrarias e demais materiais baseou-se na lavagem com água, esponja e detergente neutro para revomer possíveis sujeiras presentes no vidro. A seguir o procedimento foi finalizado utilizando métodos que dependem do tipo de vidraria e são apresentados a seguir.

\subsubsection{Método por ultrassom}

Esse método foi utilizado para limpeza de vidrarias volumétricas. Inicialmente a vidraria foi lavada com etanol comercial e água destilada. Logo após, foi levada a banho de ultrassom (Cole-Parmer, 8893) por 15 minutos com cada um dos seguintes solventes em sequência: (1) acetona; (2) hexano e (3) isoctano. Em seguida, os materiais foram secos a temperatura ambiente e cobertos com papel alumínio. 


\subsubsection{Método por calcinação}

Utilizado para limpeza de vidrarias não volumétricas, essas foram lavadas com etanol comercial e água destilada. Logo após, foi secas à temperatura ambiente e tampadas com papel alumínio. Por fim, calcinadas em forno mufla por 3 horas a uma temperatura de $350^{\circ} \mathrm{C}$.

\subsubsection{Método por solvente}

Utilizado para limpeza de vidrarias volumétricas, foram lavadas com bastante etanol comercial e água destilada. Logo após, lavadas com pequenas alíquotas dos seguintes solventes: (1) acetona; (2) hexano e (3) isoctano (solventes em grau pesticida). Após secagem ao ar, foram cobertas com papel alumínio.

\subsection{Obtenção e Preparo de amostras}

Dois tipos de amostras-modelo foram utilizados nos estudos iniciais para avaliação dos fatores de recuperação do método, sendo uma certificada (MRC) e outra fortificada a partir de uma amostra de sedimento do Lago Paranoá. O MRC contém os congêneres BDE-47, BDE-99, BDE-100, BDE-153, BDE-154 e 209, enquanto que a amostra de sedimento isenta de PBDE foi obtida no banco de amostras do do Grupo AQQUA e fortificada com 3,33 $\mathrm{ng} \mathrm{g}^{-1}$ de cada um dos congêneres presentes no padrão LMS.

Para fortificação, seguindo adaptação de Bizkarguenaga et al. (2014), num béquer de $250 \mathrm{~mL}$ foram misturados $15,000 \mathrm{~g}$ de sedimento seco em 50,0 $\mathrm{mL}$ de acetona. A seguir, foi adicionado $1,0 \mathrm{~mL}$ da solução $50,0 \mathrm{ng} \mathrm{mL}^{-1}$ do padrão LMS, sendo o frasco coberto com papel alumínio e a mistura levada à agitação magnética por 12 horas. Após esse período, foram feitos pequenos furos na cobertura de papel alumínio, com a ponta de uma Pipeta de Pasteur, de modo a permitir a evaporação do solvente. Dessa forma o recipiente foi levado à capela, ao abrigo de luz, permanecendo em repouso por 48 horas. Após esse período, a amostra foi acondicionada em frasco de vidro do tipo âmbar e preservada em freezer sendo utilizada somente após 2 semanas. 
Para determinação dos analitos em ambas as amostras-modelo, o procedimento de preparo das amostras envolveu etapas de secagem, extração dos analitos e clean-up dos extratos, de modo a tornar o analito disponível para determinação analítica.

\subsubsection{Secagem}

O processo de secagem das amostras de sedimento foi realizado por liofilização ou por secagem em capela, sob fluxo de ar e com a porta semifechada, dispostas em placas de Petri tampadas com papel alumínio para evitar contaminação. Nesse papel, foram feitos pequenos furos com a ponta de uma Pipeta de Pasteur, permitindo a evaporação da água.

\subsubsection{Extração dos analitos e clean-up dos extratos}

Porções de $3,000 \mathrm{~g}$ de sedimento foram transferidos para tubos de ensaio com tampa contendo $10 \mathrm{~mL}$ da mistura acetona:hexano (1:1) ou acetona:pentano (1:1). O uso de hexano ou pentano durante a etapa de extração foi investigada neste trabalho visando a obtenção de resultados mais exatos. Neste caso, detalhes sobre o experimento envolvendo o uso de ambos os solventes encontram-se detalhados no sub-item 3.5.3.

Em seguida, os tubos contendo o sedimento foram submetidos à sonicação (40 Khz) (Kuson, 8893) durante cinco minutos. A suspensão resultante foi centrifugada (Kindly, KC5) a $2500 \mathrm{rpm}$ por 5 min e o sobrenadante foi retirado cuidadosamente com pipeta Pasteur de vidro e transferido para balões de vidro de fundo chato. Este procedimento foi repetido por mais quatro vezes e os sobrenadantes foram misturados de forma a gerar uma amostra acumulada. A esta amostra foi adicionado $1,0 \mathrm{~mL}$ de isoctano de forma de permitir a troca de solventes após evaporação parcial. A mistura foi então submetida à redução de volume em evaporador rotatório (Fisatom, 801).

O clean-up foi realizado no extrato resultante por cromatografia em coluna com fase estacionária formada por camadas de sílica ácida, sílica básica, sílica neutra e sulfato de sódio anidro como agente dessecante. 
A sílica ácida foi preparada misturando $400 \mathrm{~g}$ de sílica com $150 \mathrm{~mL}$ de ácido sulfúrico concentrado durante $2 \mathrm{~h}$. Após este período, a sílica ácida foi lavada com diclorometano e seca fluxo de $\mathrm{N}_{2}$. Para sílica básica, se misturou uma solução metanólica de hidróxido de potássio $(500 \mathrm{ml}$ de solvente e $112 \mathrm{~g}$ de $\mathrm{KOH}$ ) com $200 \mathrm{~g}$ de sílica. Esta mistura foi agitada durante $1 \mathrm{~h}$ a $55^{\circ} \mathrm{C}$, sendo a fase sólida transferida para uma coluna de vidro, lavada com $70 \mathrm{~mL}$ de diclorometano e seca primeiro com $\mathrm{N}_{2}$, e depois a $130{ }^{\circ} \mathrm{C}$ durante a noite. $\mathrm{A}$ sílica neutra foi obtida seguindo os passos de lavagem e secagem de preparação da sílica básica (MOZETO et al., 2006).

Os extratos finais foram eluídos com $50 \mathrm{~mL}$ de hexano (ou pentano) e concentrados em evaporador rotatório até volume final de 2,0 mL, sendo então adicionado $1,0 \mathrm{~mL}$ de isoctano como keeper'. O extrato foi novamente concentrado em evaporador rotatório até o volume final de 1,0 $\mathrm{mL}$ do keeper. Para remoção de enxofre, um interferente comum em análises cromatográficas com detecção por captura de elétrons, o extrato final foi tratado com tiras de cobre metálico por $24 \mathrm{~h}$ no escuro e sob refrigeração.

\subsubsection{Escolha do solvente de extração}

Antes da realização das extrações foram desenvolvidos ensaios de recuperação analítica voltados a verificar possíveis perdas dos analitos durante a etapa de redução de volume dos extratos empregando evaporador rotatório. Neste caso, foram avaliados os dois solventes apolares empregados como extratores, ou seja, hexano (pe $69^{\circ} \mathrm{C}$ ) e pentano (pe $36^{\circ} \mathrm{C}$ ). Assim, soluções contendo $5 \mathrm{ng} \mathrm{mL}^{-1}$ de cada PBDE, preparadas em $50 \mathrm{~mL}$ dos dois solventes, em triplicata, foram concentradas até o volume de $2,0 \mathrm{~mL}$, sendo então adicionado $1,0 \mathrm{~mL}$ de isoctano para a troca de solventes. A solução foi então evaporada até o volume final de $1,0 \mathrm{~mL}$ do keeper. As amostras concentradas foram analisadas, a fim de obter os valores de recuperação dos congêneres em cada um dos solventes.

\footnotetext{
${ }^{1}$ Solvente, geralmente com maior ponto de ebulição, empregado em etapa de concentração para reduzir as perdas do analito por evaporação.
} 


\subsection{MÉtodo INSTRUMENTAL DE ANÁLISES}

Neste trabalho foi utilizada a cromatografia gasosa (Gas Chromatography - GC) acoplada à detecção de captura de elétrons (Electron Capture Detector - ECD) como método instrumental para separação e quantificação dos PBDE. O equipamento, Shimadzu, modelo GC 2010 Plus, encontra-se disponível na Central Analítica do Instituto de Química da Universidade de Brasília (CAIQ - UnB). As condições experimentais ideais de injeção, fluxo de gás de arraste e ajuste do detector, utilizadas no GC-ECD, são apresentadas na Tabela 6.

Tabela 6. Condições experimentais para análises de PBDE por GC-ECD

\begin{tabular}{ll}
\hline Parâmetros do GC & \\
\hline Gás Carregador & Hélio \\
Pressão Inicial do Gás & $33,7 \mathrm{kPa}$ \\
Vazão Inicial do Gás na Coluna & $0,93 \mathrm{~mL} / \mathrm{min}$ \\
Vazão Inicial Total & $22,5 \mathrm{~mL} / \mathrm{min}$ \\
Volume de Injeção & $2,0 \mu \mathrm{L}$ \\
Modo de Injeção & Splitless \\
Razão de Split & $1: 20$ \\
Tempo de amostragem & $1,00 \mathrm{~min}$ \\
Modo de controle da vazão & Velocidade Linear \\
Velocidade Linear & $27,3 \mathrm{~cm} / \mathrm{seg}$ \\
Temperatura do Injetor & $250{ }^{\circ} \mathrm{C}$ \\
Vazão da purga & $3,0 \mathrm{~mL} / \mathrm{min}$ \\
\hline Parâmetros do Detector & \\
\hline Temperatura & $310^{\circ} \mathrm{C}$ \\
Razão de amostragem & $40 \mathrm{~ms}$ \\
Tempo de parada & $58,00 \mathrm{~min}$ \\
Tempo de Delay & $0 \mathrm{~min}$ \\
Corrente & $0,50 \mathrm{Na}$ \\
\hline
\end{tabular}

A separação cromatográfica dos analitos foi realizada em uma coluna Supelco $5 \mathrm{MS}$ (30 $\mathrm{m} \times 0,25 \mathrm{~mm} \times 0,25 \mu \mathrm{m})$ confeccionada com $5 \%$ de difenil e $95 \%$ de dimetilpolisiloxano. A separação foi realizada a partir da construção de uma rampa de aquecimento conforme dados mostrados na Tabela 7. 
Tabela 7. Condições experimentais utilizadas durante a separação cromatográfica dos analitos investigados

\begin{tabular}{ll}
\hline Rampa de aquecimento & \\
\hline Temperatura Inicial & $100^{\circ} \mathrm{C}$ \\
Tempo Inicial & $2 \mathrm{~min}$ \\
Programação de Temperatura & $15^{\circ} \mathrm{C} / \mathrm{min}$ até $160^{\circ} \mathrm{C}$ \\
& $4{ }^{\circ} \mathrm{C} / \mathrm{min}$ até $280^{\circ} \mathrm{C}$ \\
& Patamar em $280^{\circ} \mathrm{C}$ por $10,0 \mathrm{~min}$ \\
& $10^{\circ} \mathrm{C} / \mathrm{min}$ até $300^{\circ} \mathrm{C}$ \\
& Patamar em $300^{\circ} \mathrm{C}$ por $10,0 \mathrm{~min}$ \\
Temperatura Final & $300^{\circ} \mathrm{C}$ \\
Tempo Total de Análise & $58 \mathrm{~min}$ \\
Tempo de Equilíbrio do Forno & $3 \mathrm{~min}$ \\
\hline
\end{tabular}

\subsection{VALIDAÇÃo do MÉTOdO ANALíTICO}

Com a finalidade de constituir no Grupo AQQUA uma rotina analítica voltada à identificação e quantificação de PBDE em sedimentos aquáticos, tornou-se necessário validar adequadamente o método desenvolvido de modo que o mesmo apresentasse confiança. A seguir são descritos os parâmetros de mérito analítico escolhidos para validação do método analítico.

\subsubsection{Curva analítica e linearidade}

A linearidade consiste na capacidade do método instrumental em fornecer resultados diretamente proporcionais à concentração do analito, numa dada faixa de concentração. Pode ser mensurada pela construção de curvas de calibração, onde um gráfico é obtido através da relação da resposta do equipamento em função de várias concentrações do analito, bem como a equação da reta, a análise de regressão e os dados de regressão e determinação (LANÇAS, 2004). A equação 5 mostra a representação de uma equação de reta:

$$
y=a+b x
$$

onde, $y$ é a variável dependente, $x$ a variável independente, $a$ representa 0 coeficiente linear e $b$ o coeficiente angular da reta. 
As curvas analíticas foram preparadas por diluição da solução estoque $\left(2,26 \mu \mathrm{g} \mathrm{mL}^{-1}\right)$ do padrão LMS, nas concentrações de 0,$05 ; 0,1 ; 1,0 ; 5,0 ; 10,0 \mathrm{e}$ $20,0 \mathrm{ng} \mathrm{mL}^{-1}$, em isoctano. As soluções-padrão foram acondicionadas em vial de vidro do tipo âmbar $(1,5 \mathrm{~mL})$ com tampa e mantidas em freezer a temperatura inferior a $-10^{\circ} \mathrm{C}$.

\subsubsection{Limite de detecção (LOD) e limite de quantificação (LOQ)}

Limite de detecção (LOD) é definido como a menor concentração de um analito que pode ser detectada, porém, não necessariamente quantificada como um valor aceitável. Para o estudo, O LOD foi obtido através da concentração do analito que produziu um sinal três vezes a razão sinal/ruído do equipamento (INMETRO, 2011). Já o limite de quantificação (LOQ), que corresponde a menor concentração de um analito quantificada com exatidão, foi obtido através da concentração do analito que produziu um sinal dez vezes a razão sinal/ruído.

\subsubsection{Seletividade}

A seletividade do método pode ser definida como a capacidade do mesmo em determinar o analito de maneira inequívoca na presença de outras substâncias capazes de interferirem na determinação. Sua determinação foi realizada através da comparação entre cromatogramas do extrato de sedimento isento de PBDE e extrato de sedimento fortificado com 5,0 $\mathrm{ng} \mathrm{g}^{-1}$ dos nove congêneres (LANÇAS, 2004; INMETRO, 2011).

\subsubsection{Precisão}

De acordo com Inmetro (2011), a concordância entre diversos resultados analíticos de uma mesma amostra, ou padrão, é definida como precisão, sendo determinada em ensaios intraday e inter day. $\mathrm{O}$ coeficiente de variação $(\mathrm{CV})$ foi utilizado para determinar a precisão do método, conforme equação 6 (LANÇAS, 2004; INMETRO, 2011). 


$$
C V=\frac{s}{\bar{x}} \times 100
$$

onde, $s$ é o desvio padrão obtido para sete medidas independentes e $\bar{x}$ representa a concentração média determinada para as replicatas.

Para tal, foram avaliados dois níveis distintos de concentração de PBDE. No nível mais baixo (3,33 ng g-1) foi investigado a precisão intraday em sete alíquotas distintas da amostra-modelo fortificada, extraídas individualmente. Para a precisão inter day, utilizando o nível mais elevado de concentração (entre 84,8 e $286 \mathrm{ng} \mathrm{g}^{-1}$ ), foram analisadas sete alíquotas distintas do material de referência certificado. Convém mencionar que esta faixa de concentração é dependente da concentração certificada para cada analito presente no MRC.

Para determinação da precisão intermediária, foram realizados ensaios individuais de recuperação em três dias seguidos, ou seja, considerando-se a variação temporal sobre a precisão do método. Neste caso, os valores de CV foram estimados através dos ensaios realizados em triplicata.

\subsubsection{Exatidão}

A exatidão é definida como a concordância entre o valor encontrado e o valor aceito como referência. Foi determinada através de ensaio de recuperação do analito quando aplicado o método em estudo em amostra certificada $\left(8,48\right.$ a 28,6 $\left.\mathrm{ng} \mathrm{g}^{-1}\right)$ e amostra fortificada (3,33 $\left.\mathrm{ng} \mathrm{g}^{-1}\right)$ com diferentes níveis de concentração.

\subsection{EsTUDO DA FUGACIDADE DOS PBDE}

De uma forma geral, a fugacidade é a tendência de escape de uma determinada substância química, sendo análoga à pressão parcial e representada pela Equação 7.

$$
C=Z \times f
$$

em que $C$ é a concentração da substância em mol $\mathrm{m}^{-3}, Z$ é a capacidade de fugacidade em mol m${ }^{-3} \mathrm{~Pa}^{-1}$ e $f$ a fugacidade em Pa (Mackay, 1991). 
Desta forma, a Equação 7 demonstra que a fugacidade $(f)$ e concentração (C), são relacionadas a um fator denominado capacidade de fugacidade (Z), que mede a tendência de um compartimento ambiental em absorver uma substância química. Assim, um meio com maior capacidade de fugacidade apresentará elevada tendência em absorver uma substância, que como consequência terá nesse compartimento maior concentração. É importante destacar que a capacidade de fugacidade de um meio relaciona suas características, como as propriedades físico-químicas da substância de interesse (Mackay, 1991).

Diversos softwares foram desenvolvidos para avaliar o destino, distribuição e transporte de substâncias químicas no ambiente, segundo o modelo de fugacidade. Dentre esses estão o RAIDAR Model (Risk Assessment Identification and Ranking), ChemCAN (Chemical Fate in Canada) e o EQC Model (Equilibrium Criterion), ambos desenvolvidos pelo Centro de Modelação Ambiental e Química (Centre for Environmental Modelling and Chemistry) da Universidade de Trent, no Canadá (CEMC, 2004).

Neste trabalho foi empregado o software EQC Model em seu Nível I, que avalia o particionamento de uma quantidade de substância química entre os compartimentos (ar, aerossol, água, sólidos em suspensão, solo, sedimento) e biota (peixe) de um ambiente padrão, em que não ocorre fluxo de entrada, saída, transporte intermédio ou reações de degradação.

Para realização de uma simulação foi necessário fornecer como dados de entrada uma quantidade em massa de emissão dos PBDE, bem como suas propriedades (massa molar, coeficiente de partição octanol-água, ponto de ebulição, pressão de vapor e solubilidade em água) e características do ambiente (volume, densidade, carbono orgânico e fração lipídica para o caso da biota). Os dados de saída do modelo fornecem diagramas e tabelas contendo valores de fugacidade do sistema, coeficientes de partição, valores $Z$, concentrações, quantidades e percentuais em massa em cada compartimento. 


\section{RESULTADOS E DISCUSSÃO}

\subsection{Validação do mÉtodo Analítico}

\subsubsection{Separação e detecção}

A técnica de separação por cromatografia gasosa acoplada a detecção por captura de elétrons tem se mostrado uma importante ferramenta nos estudos ambientais. Os principais atrativos são as elevadas seletividade e detectabilidade a compostos orgânicos halogenados como os PBDE (VALENTE et al., 1996; COLLINS et al., 2006). A Figura 19 mostra um cromatograma obtido para a análise de uma solução padrão de PBDE contendo nove congêneres.

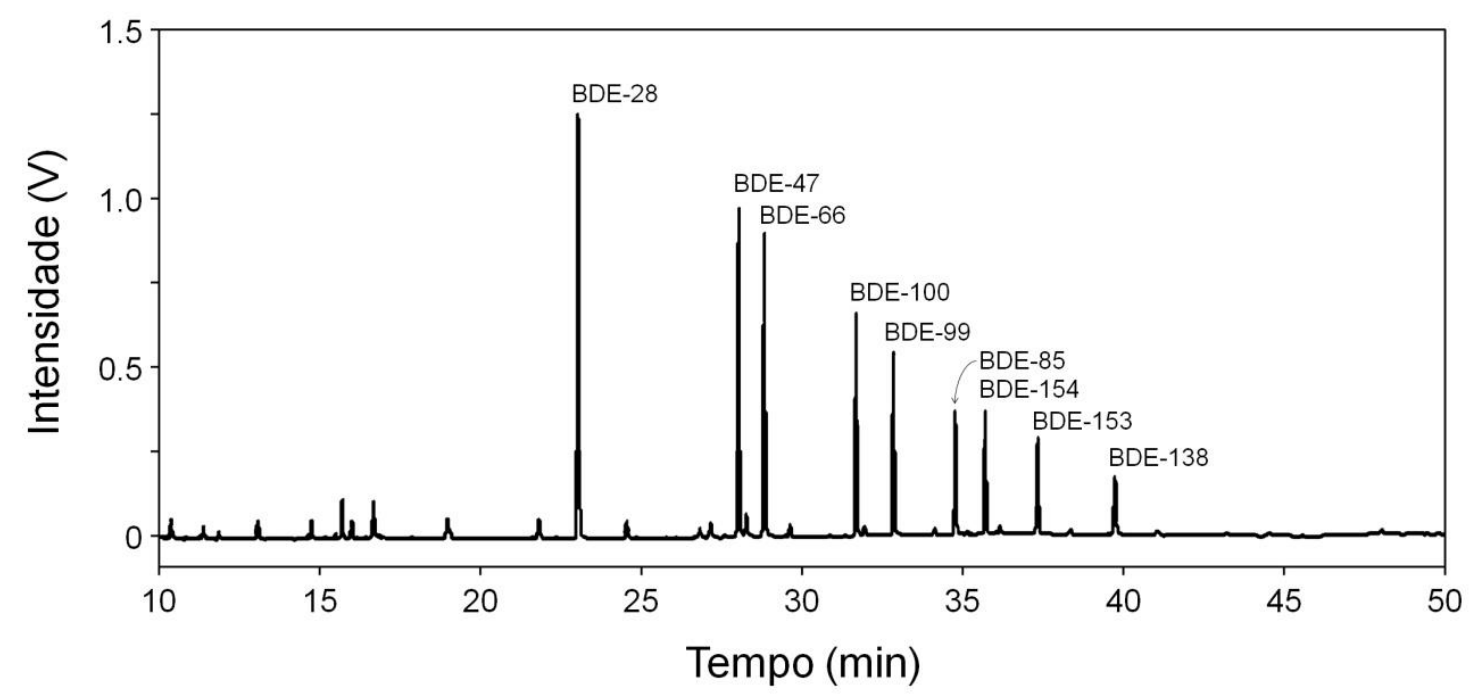

Figura 19. Cromatograma mostrando a separação dos nove congêneres presentes na solução 50,0 $\mathrm{ng} \mathrm{mL}^{-1}$ do padrão de PBDE LMS - Accustandard.

É possível observar que, utilizando GC-ECD, foi obtido um cromatograma com picos simétricos, não sobrepostos e seletivos para os nove congêneres do padrão LMS, o que atesta elevada eficiência da separação em aproximadamente 48 minutos. 
A coluna cromatográfica se apresentou eficiente e o solvente utilizado como keeper, ou seja, o isoctano, não acarretou em interações indesejáveis com os analitos. Outro aspecto que mereceu destaque foi o uso do sistema injetor no modo Splitless que não provocou sobrecarga de volume de amostra na coluna.

Com relação à detectabilidade, observa-se na Figura 19 um decréscimo na altura dos picos dos congêneres à medida que o número de átomos de bromo da substância aumenta. A princípio, o comportamento esperado seria exatamente o contrário, pois a detecção por captura de elétrons é mais sensível à medida que o número de halogênios também aumenta.

Contudo, Tollbäck et al., (2003) descrevem que, durante a separação cromatográfica, a temperatura do forno aumenta gradativamente, de modo que, em aproximadamente $300{ }^{\circ} \mathrm{C}$, os congêneres que ainda não chegaram ao detector podem sofrer degradação. Desta maneira, pode ser observado na Figura 19 a redução do sinal analítico dos congêneres BDE-85, BDE-153, BDE154 e BDE-138, que apresentam tempos de retenção superiores a 35 minutos.

Segundo Vonderheide (2009), essa instabilidade faz com que, para os congêneres de nove e dez átomos de bromo, seja necessário realizar uma separação cromatográfica à parte, utilizando colunas capilares curtas de $10 \mathrm{a}$ 15 metros, cujos os menores tempos de corrida cromatográfica não requerem elevadas temperaturas, garantindo assim uma maior detectabilidade para PBDE com números elevados de bromo.

\subsubsection{Parâmetros de mérito analítico}

Através das curvas analíticas, construídas para cada um dos nove congêneres, foi possível avaliar a linearidade da resposta do GC-ECD em função de diferentes concentrações (coeficiente de correlação, R), bem como estimar os limites de detecção (LOD) e quantificação (LOQ). Os parâmetros de mérito associados às curvas analíticas são mostrados na Tabela 8. 
Tabela 8. Limite de deteç̧ão (LOD) e limite de quantificação (LOQ) para o método proposto. Faixa linear, linearidade e sensibilidade do método instrumental para os nove congêneres de PBDE.

\begin{tabular}{|c|c|c|c|c|c|}
\hline Congêneres & $\operatorname{LOD}^{\mathrm{a}}$ & $\mathrm{LOQ}^{\mathrm{a}}$ & Faixa linear ${ }^{b}$ & $\begin{array}{l}\text { Coeficiente de } \\
\text { correlação }(R)\end{array}$ & Sensibilidade $^{c}$ \\
\hline BDE-28 & 0,03 & 0,1 & 0,05 to 20,0 & 0,9979 & $3,1 \times 10^{5}$ \\
\hline BDE-47 & 0,21 & 0,7 & 0,05 to 20,0 & 0,9985 & $2,6 \times 10^{5}$ \\
\hline BDE-66 & 0,23 & 0,8 & 0,05 to 20,0 & 0,9982 & $2,4 \times 10^{5}$ \\
\hline BDE-85 & 0,23 & 0,8 & 0,10 to 20,0 & 0,9983 & $1,1 \times 10^{5}$ \\
\hline BDE-99 & 0,26 & 0,9 & 0,05 to 20,0 & 0,9975 & $1,5 \times 10^{5}$ \\
\hline BDE-100 & 0,23 & 0,8 & 0,05 to 20,0 & 0,9981 & $1,8 \times 10^{5}$ \\
\hline BDE-138 & 0,32 & 1,1 & 0,10 to 20,0 & 0,9967 & $0,6 \times 10^{5}$ \\
\hline BDE-153 & 0,29 & 1 & 0,10 to 20,0 & 0,9974 & $0,9 \times 10^{5}$ \\
\hline BDE-154 & 0,23 & 0,8 & 0,10 to 20,0 & 0,9983 & $1,1 \times 10^{5}$ \\
\hline
\end{tabular}

Observa-se na Tabela 8 que os coeficientes de correlação apresentaram valores significativos em $P<0,001$, variando entre 0,9967 e 0,9985, demonstrando linearidade da resposta do método instrumental na faixa de concentração estabelecida. Convém mencionar que esses valores estão de acordo com o estabelecido pelas normas da Agência Nacional de Vigilância Sanitária $(0,99)$ e do Instituto Nacional de Metrologia, Qualidade e Tecnologia $(0,90)$ (ANVISA, 2003; INMETRO, 2011).

Os valores LOD e LOQ estimados para o método proposto, considerando a massa de 3,000 gramas de sedimento utilizada durante os procedimentos de preparo de amostra, variaram de 0,03 a 0,32 $\mathrm{ng} \mathrm{g}^{-1} \mathrm{e}$ 0,1 a $1,1 \mathrm{ng} \mathrm{g}^{-1}$, respectivamente. Esses valores proporcionam limites compatíveis com as concentrações de PBDE em sedimentos aquáticos de diversos estudos (SAMARA et al., 2006; GUZZELLA et al., 2008; VANE et al., 2010; MOON et al., 2012; YANG et al., 2012; ZHOU et al., 2012; LI et al., 2012; KLOSTERHAUS et al., 2012).

A sensibilidade, isto é, a inclinação da curva analítica de cada congênere, diminui à medida que aumenta a bromação. Este comportamento é o mesmo discutido para detectabilidade, sendo resultado da degradação dos congéneres mais bromados durante a análise cromatográfica. 


\subsubsection{Seletividade}

A complexidade da composição dos sedimentos aquáticos exige que o método analítico seja capaz de eliminar interferentes que alterem a resposta do método instrumental frente ao analito. Uma das principais fontes de interferência em métodos voltados à análise de substâncias halogenadas em sedimentos aquáticos é a presença de enxofre, principalmente os amostrados em regiões impactadas por descargas de efluentes. Esta interferência é especialmente importante nas análises por GC-ECD, impossibilitando muitas vezes a detecção e quantificação dos analitos (MECHLINSKA et al., 2012). Esta interferência não é eliminada através das etapas convencionais de cleanup, sendo necessários procedimentos adicionais de limpeza dos extratos por meio da redução do enxofre na superfície de tiras de cobre metálico, possibilitando assim sua eliminação como sulfeto de cobre $\left(K_{p s}=8 \times 10^{-37}\right)$. A Figura 20 mostra cromatogramas de dois extratos de sedimento, sendo um tratado com cobre metálico e o outro não.

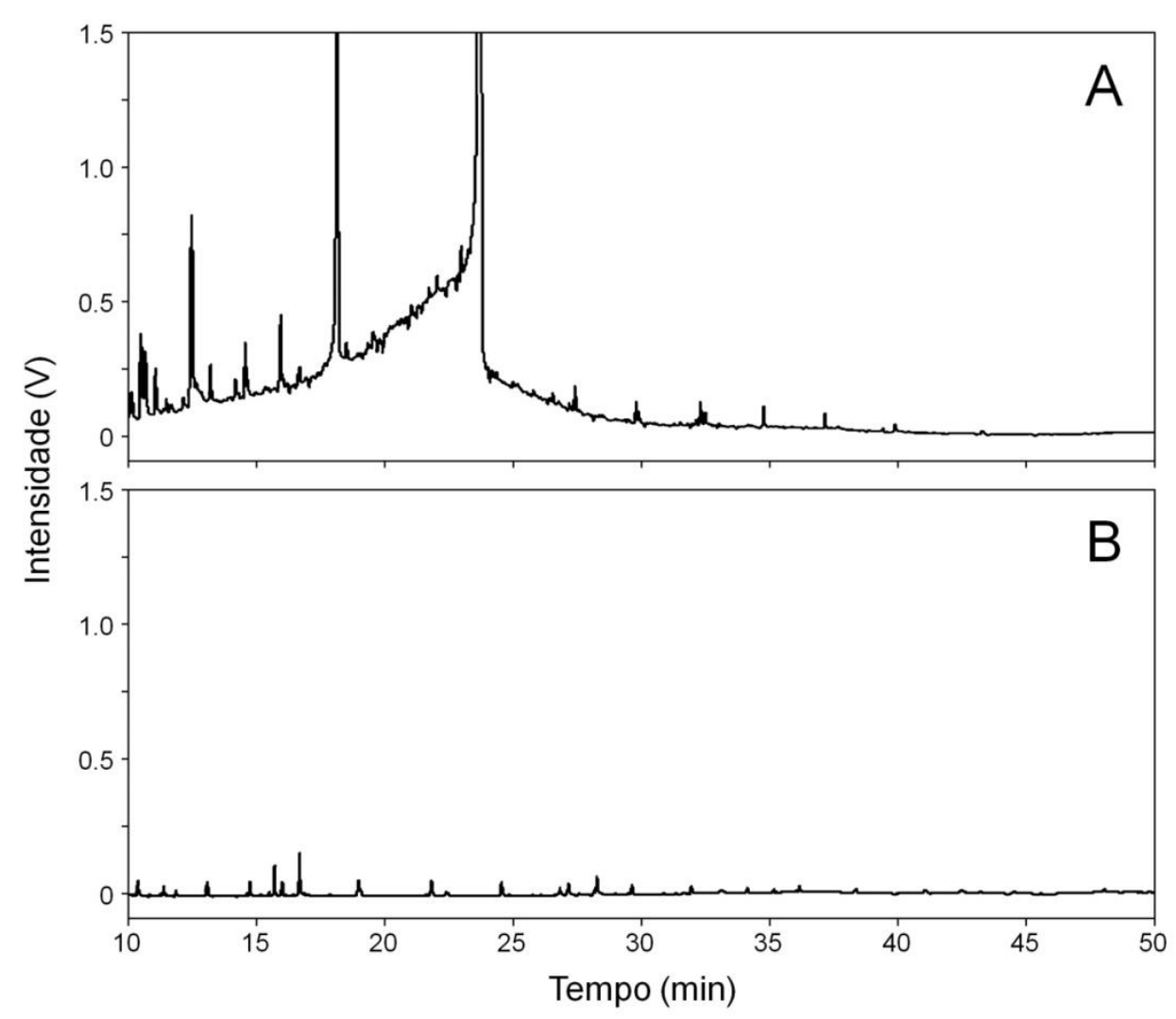

Figura 20. Cromatogramas de extratos de sedimento $(A)$ sem tratamento para remoção do enxofre e $(B)$ com tratamento para remoção do enxofre. 
Na Figura 20A é possível observar que ocorre um aumento considerável da linha base na presença de enxofre. Observa-se também que este aumento é responsável por sobrepor sinais analíticos, o que pode representar perdas significativas de informações inerentes à amostra. Ao submeter o extrato ao tratamento com cobre metálico, observa-se supressão (Figura 20B) da interferência, evitando-se assim problemas com a seletividade do método.

Além da remoção de enxofre, a realização de etapas de limpeza da amostra, ou seja, clean-up, torna-se indispensável para remoção de inúmeras substâncias coextraídas junto com os PBDE. Neste caso, a eficiência da remoção de interferentes, bem como a seletividade do método analítico, pode ser observada pela ausência de picos nos mesmos tempos de retenção dos congêneres.

A única exceção é o sinal observado em aproximadamente 27,5 min, presente em ambos os cromatogramas (Figura 21). Este sinal é, na verdade, um interferente halogenado, provavelmente o heptacloro epóxido, presente no solvente utilizado como keeper, portanto, ubíquo durante as análises. Mesmo assim, é importante mencionar que a presença deste sinal não é proveniente do extrato de sedimento e, igualmente, não representa interferência durante determinação dos PBDE, mesmo no caso do BDE-47, que elui em tempo de retenção próximo ao do interferente. 


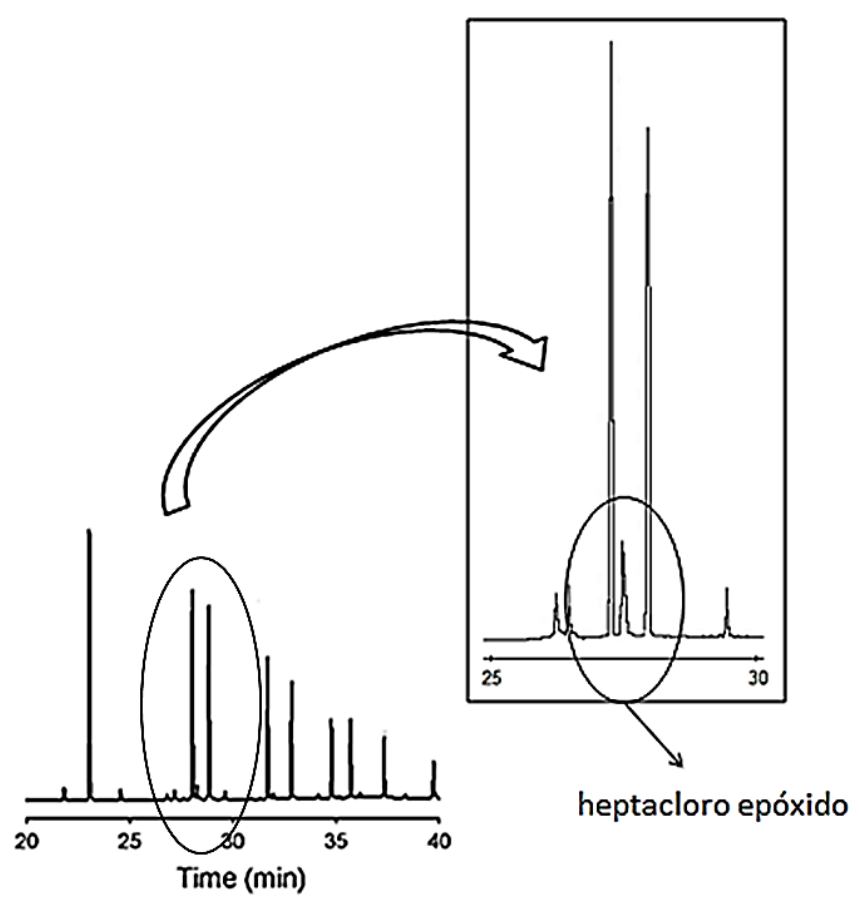

Figura 21. Cromatogramas indicando a presença do interferente halogenado heptacloro epóxido presente no solvente isoctano.

\subsubsection{Exatidão e precisão}

Os resultados dos ensaios de avaliação de recuperação e precisão do método, investigados utilizando MRC e sedimento fortificado, encontram-se dispostos na Tabela 9. Deste modo os percentuais de recuperação obtidos evidenciam exatidão para método proposto, uma vez que valores de recuperação variaram de $89,8 \pm 2,8 \%$ (BDE-138) a 98,5 $\pm 2,5 \%$ (BDE-28) para o sedimento fortificado, e de $87,7 \pm 6,6 \%$ (BDE-138) a $98,7 \pm 1,4 \%$ (BDE-28) para o MRC.

Tabela 9. Exatidão e precisão para o método proposto.

\begin{tabular}{|c|c|c|}
\hline Congêneres & 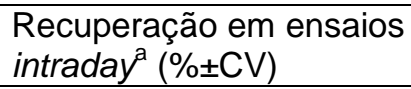 & $\begin{array}{l}\text { Recuperação em ensaios } \\
\text { inter day }(\%(\% \pm C V))\end{array}$ \\
\hline BDE-28 & $98.5 \pm 2.5$ & $\mathrm{Na}$ \\
\hline BDE-47 & $98.2 \pm 4.3$ & $98.7 \pm 1.4$ \\
\hline BDE-66 & $97.8 \pm 4.7$ & $\mathrm{Na}$ \\
\hline BDE-85 & $92.9 \pm 6.0$ & $\mathrm{Na}$ \\
\hline BDE-99 & $97.9 \pm 6.0$ & $97.1 \pm 2.3$ \\
\hline BDE-100 & $97.6 \pm 6.5$ & $96.5 \pm 6.1$ \\
\hline BDE-138 & $89.8 \pm 2.8$ & $\mathrm{Na}$ \\
\hline BDE-153 & $90.5 \pm 4.5$ & $87.7 \pm 6.6$ \\
\hline BDE-154 & $92.4 \pm 7.1$ & $91.9 \pm 3.7$ \\
\hline
\end{tabular}

${ }^{a}$ Sedimento fortificado $(\mathrm{n}=7) ;{ }^{\mathrm{b}} \mathrm{MRC}(\mathrm{n}=9) ; \mathrm{Na}=$ Não analisado (Não presentes no MRC) 
Esses resultados são expressivos e encontram-se próximos aos reportados por diferentes trabalhos, incluindo aqueles que utilizam métodos de extração considerados mais eficientes, como a extração acelerada por solventes (KLOSTERHAUS et al., 2012). São compatíveis também com resultados reportados em trabalhos que utilizam outras técnicas de quantificação e outras abordagens para o cálculo da recuperação. Dodder et al. (2012) obtiveram percentuais de recuperação de 80 a 120\%, empregando substâncias deuteradas como padrão surrogate, extração por líquido pressurizado e GC/MS. Neste caso, convém mencionar que um padrão surrogate consiste de uma substância representativa da classe estudada, na maioria das vezes deuterada, para qual os resultados dos ensaios de recuperação são extrapolados para os demais analitos da mesma classe, não existindo, portanto, uma avaliação individual de cada uma das substâncias investigadas. Klosterhaus et al. (2012), também empregaram padrões surrogate e obtiveram percentuais de recuperação entre 65 e 155\%, utilizando extração acelerada por solventes e determinação por GC/MS. A recuperação por fortificação da matriz isenta de PBDE também foi descrita por Cai et al. (2012), que realizaram ensaios a partir de extração Soxhlet e determinação por GC/MS. Os autores obtiveram recuperações entre 83,1 e 103,6\%.

Os resultados apresentados na Tabela 9 também revelam um ligeiro decréscimo nas percentagens de recuperação à medida que o número de átomos de bromo nas estruturas dos PBDE torna-se maior. Este comportamento pode ser uma consequência da degradação dos congêneres durante as análises cromatográficas, conforme apontado anteriormente. Ao mesmo tempo, com o aumento da bromação as estruturas também apresentam um aumento nas características apolares, afetando assim a eficiência da separação da mistura solvente durante a extração sólido-líquido.

A Figura 22 mostra que os percentuais de recuperação obtidos para 0 MRC e sedimento fortificado foram influenciadas pelas características apolares dos congêneres de PBDE. Neste caso, foram observados coeficientes de correlação linear significativos para ambos, com a diminuição dos percentuais de recuperação para valores mais elevados dos coeficientes de partição octanol/água ( $\left.\log K_{\text {ow }}\right)$. 


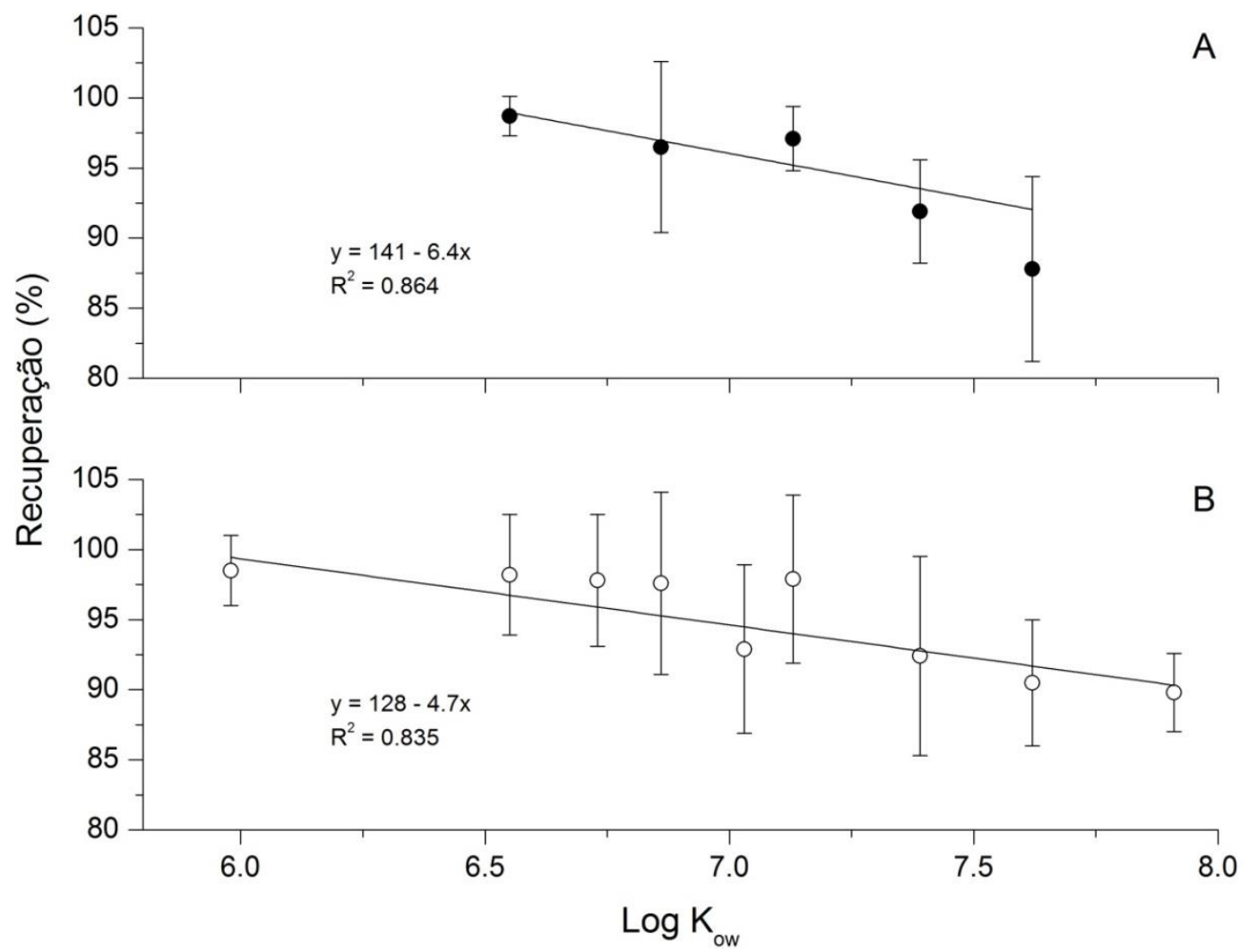

Figura 22. Correlação entre os percentuais de recuperação e Log $K_{o w}$ para: $(A) M R C$ e (B) sedimento fortificado.

Além disso, como o aumento do caráter apolar as interações hidrofóbicas entre matriz e os analitos tornam-se mais intensas reduzindo a eficiência da mistura de solventes usada durante a extração. Esta afinidade também foi observada por Liang et al. (2010) estudando biodisponibilidade de PBDE em solos. Os autores mostraram que compostos menos bromados foram moderadamente sorvidos pelas partículas do solo e, portanto, permaneceram mais disponíveis para biota. Teoricamente, um aumento no volume do solvente apolar poderia proporcionar melhores resultados de recuperação, bem como a utilização de outras técnicas como Soxhlet, ultrassom e ASE. Ambas as extrações do tipo sólido-líquido são empregadas em amostras de sedimento, sendo capazes de melhorar a quebra das fortes interações hidrófobas entre o analito e a matriz. No entanto a extração assistida por ultrassom utilizada neste trabalho forneceu recuperações (superiores a 88\%) comparáveis, ou mesmo melhor, do que outras técnicas utilizadas para a extração de PBDE em sedimentos aquáticos. 
Cabe ressaltar que a utilização de uma mistura solvente com caráter mais apolar poderia afetar a eficiência da extração de PBDE menos bromados, ocasionando também aumento na quantidade de matéria orgânica nos extratos intensificando os efeitos da matriz e a necessidade de uma limpeza mais eficiente. Outro aspecto que vale a pena ser considerado é a influência da etapa de concentração dos extratos em evaporador rotativo, apresentando ligeira redução nos percentuais de recuperações mesmo com a utilização de npentano em vez de $n$-hexano.

Por fim, os resultados também indicam que os percentuais de recuperação para MRC são comparáveis com os resultados obtidos para as amostras fortificadas. A Figura 23 mostra uma resposta linear significativa quando estes resultados são avaliados indicando que o procedimento de fortificação realizado foi eficiente. Este aspecto é importante porque as amostras fortificadas, preparadas em diferentes concentrações, podem ser produzidas de modo a conter outras substâncias que não estão presentes nos materiais de referência certificados.

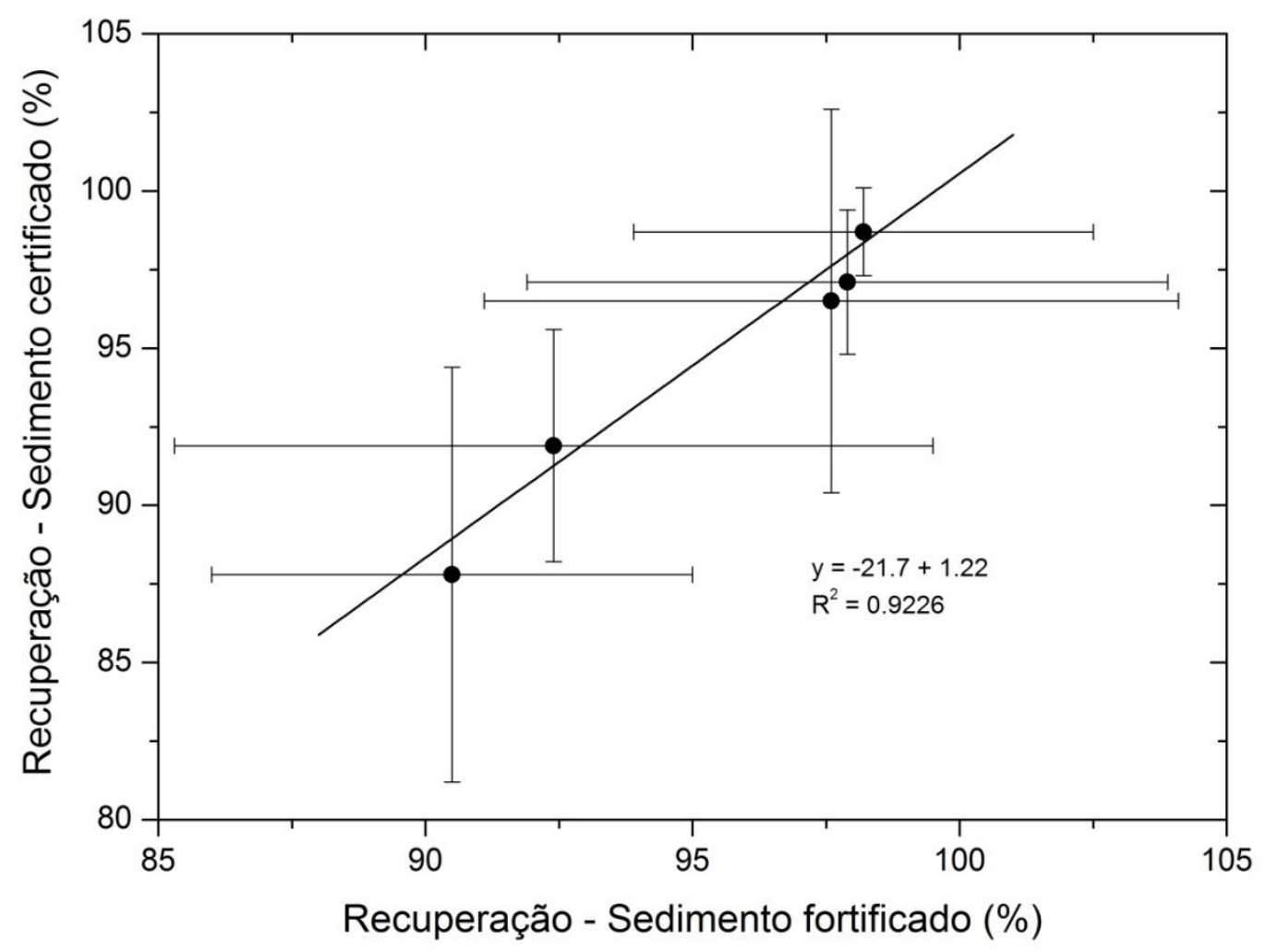

Figura 23. Correlação obtida entre os resultados de recuperação para material de referência certificado e sedimento fortificado 
Na Tabela 9 também se encontram os resultados de precisão associada aos percentuais de recuperação. Os coeficientes de variância (CV) que variaram de $2,5 \%$ a $7,1 \%$, foram observadas em ensaios intraday $(n=7)$, e de $1,4 \%$ a $6,6 \%$ para as experiências de inter day $(n=9)$.

De acordo com os valores obtidos, torna-se evidente que os resultados sofreram pequenas dispersões demonstrando que 0 método apresenta precisão. Assim, acredita-se que pode ser empregado para investigar PBDE em amostras de sedimentos aquáticos em experimentos que envolvam um grande conjunto de extratos e réplicas ao longo de dias de análises.

Até o melhor de nosso conhecimento, não existem critérios para a aceitabilidade de resultados de precisão envolvidos com a análise de PBDE ou de qualquer outro tipo de contaminante persistente em sedimentos Diante disso, nossos resultados foram comparados com critérios estabelecidos para outros contaminantes em outros tipos de matrizes igualmente complexas. Os resultados apresentados nesta Tese estão em conformidade com os critérios para a aceitação de repetitividade em métodos analíticos ( $C V<23,3 \%$ ) preconizados pelo (MAPA, 2011). Encontram-se também de acordo com o guia da Agência Nacional de Vigilância Sanitária para a validação de métodos analíticos e bioanalíticos, que consideram valores de CV abaixo de $15 \%$ satisfatórios para analitos em matrizes biológicas (ANVISA, 2003).

\subsection{Determinação de PBDE em sedimentos do Lago ParanoÁ}

Os resultados da determinação dos nove congêneres nos sedimentos do Lago Paranoá se encontram na Tabela 10. Desta forma, dos sete locais investigados, em quatro puderam ser observadas a ocorrência dos PBDE (ETS, CNB, ETN e BIC), evidenciando possíveis fontes de aporte desses no ambiente. 
Tabela 10. Concentrações (ng $\mathrm{g}^{-1}$ ) dos congêneres investigados em amostras de sedimento do Lago Paranoá.

\begin{tabular}{|c|c|c|c|c|c|c|c|}
\hline \multirow{2}{*}{ PBDE } & \multicolumn{7}{|c|}{ Pontos de amostragem } \\
\hline & ETS $^{a}$ & $\mathrm{CNB}^{\mathrm{a}}$ & $\mathrm{RGC}^{\mathrm{a}}$ & PJK $^{a}$ & $\mathrm{PBG}^{\mathrm{a}}$ & ETN $^{a}$ & $\mathrm{BIC}^{\mathrm{a}}$ \\
\hline BDE-28 & $0,143 \pm 0,005$ & $<L D$ & nd & $n d$ & nd & $0,67 \pm 0,04$ & $<\mathrm{LD}$ \\
\hline BDE-47 & $2,85 \pm 0,02$ & $0,70 \pm 0,06$ & nd & nd & nd & $1,65 \pm 0,09$ & $1,74 \pm 0,06$ \\
\hline BDE-66 & $8,1 \pm 0,4$ & $0,42 \pm 0,09^{*}$ & $n d$ & $n d$ & $n d$ & $1,33 \pm 0,09$ & $0,62 \pm 0,07^{*}$ \\
\hline BDE-85 & $1,72 \pm 0,6$ & $0,7 \pm 0,1^{*}$ & nd & nd & nd & $1,2 \pm 0,4$ & $1,38 \pm 0,09$ \\
\hline BDE-99 & $3,5 \pm 0,5$ & $1,44 \pm 0,05$ & nd & nd & nd & $2,25 \pm 0,09$ & $2,06 \pm 0,07$ \\
\hline BDE-100 & $2,5 \pm 0,9$ & $0,61 \pm 0,06$ & nd & nd & nd & $1,69 \pm 0,08$ & $1,53 \pm 0,08$ \\
\hline BDE-138 & $n d$ & $n d$ & $n d$ & $n d$ & nd & nd & $n d$ \\
\hline BDE-153 & $n d$ & $n d$ & $n d$ & nd & $n d$ & $n d$ & nd \\
\hline BDE-154 & $n d$ & $n d$ & $n d$ & nd & nd & nd & $n d$ \\
\hline$\sum_{9}$ PBDE & $19 \pm 2$ & $3,87 \pm 0,03$ & - & - & - & $8,79 \pm 0,03$ & $7,3 \pm 0,2$ \\
\hline$\sum T r i$ & $0,134 \pm 0,005$ & - & - & - & - & $0,67 \pm 0,04$ & - \\
\hline$\sum$ Tetra & $10,9 \pm 0,2$ & $1,12 \pm 0,01$ & - & - & - & $2,98 \pm 0,02$ & $2,36 \pm 0,01$ \\
\hline$\sum$ Penta & $7,7 \pm 1,0$ & $2,75 \pm 0,02$ & - & - & - & $5,14 \pm 0,2$ & $4,97 \pm 0,02$ \\
\hline$\sum_{\text {Tetra }} / \sum$ Penta & 1,4 & 0,4 & - & - & - & 0,5 & 0,6 \\
\hline BDE[47]/[99] & 0,8 & 0,5 & - & - & - & 0,7 & 0,8 \\
\hline
\end{tabular}

Pode-se observar que dos nove congêneres investigados, apenas seis foram identificados (BDE-28, BDE-47, BDE-66, BDE-85, BDE-99 e BDE-100), sendo o BDE-28 o único a não ser detectado nos quatro pontos afetados. Já o

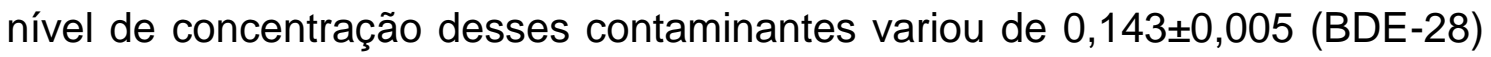
a $8,1 \pm 0,4 \mathrm{ng} \mathrm{g}^{-1}$ (BDE-66).

É possível verificar também as concentrações totais para cada ponto obtidas pelo somatório das concentrações dos nove congêneres ( $\sum_{9}$ PBDE). Como resultado o ETS $\left(19 \pm 2 \mathrm{ng} \mathrm{g}^{-1}\right)$ e ETN $\left(8,79 \pm 0,03 \mathrm{ng} \mathrm{g}^{-1}\right)$ tiveram maiores concentrações estando assim como os locais mais afetados.

Ainda na Tabela 10, a análise de perfil dos PBDE evidenciou que 0 BDE-99 contribui com os maiores percentuais para os valores de $\sum_{9}$ PBDE em CNB (37\%), ETN (26\%) e BIC (28\%). As concentrações desse congênere nesses locais tiveram uma variação de $1,44 \pm 0,05$ a 2,25 $\pm 0,09 \mathrm{ng} \mathrm{g}^{-1}$. Contudo, esse comportamento não foi observado em ETS, em que o BDE-66 foi o mais abundante com $8,1 \pm 0,4 \mathrm{ng} \mathrm{g}^{-1}$, valor esse que corresponde a $46 \%$ do $\sum_{9}$ PBDE. Nesse sentido, os dados também demostraram que o segundo e terceiro congêneres mais abundantes foram o BDE-47 e 100, respectivamente. 
A avaliação do perfil dos PBDE em função dos níveis de bromação foi obtida pela comparação entre as somatórias das concentrações dos congêneres tribromados ( $\left.\sum_{\text {Tri: }}\right)$, representado apenas pelo BDE-28, tetrabromados ( $\sum$ Tetra: BDE-47 + BDE-66) e pentabromados ( $\sum$ Penta: BDE-85 + BDE-99 + BDE-100).

Esses dados revelaram que houve maiores concentrações dos pentabromados em CNB $\left(2,75 \pm 0,02 \mathrm{ng} \mathrm{g}^{-1}\right)$, ETN $\left(5,14 \pm 0,2 \mathrm{ng} \mathrm{g}^{-1}\right)$ e BIC $\left(4,97 \pm 0,02 \mathrm{ng} \mathrm{g}^{-1}\right)$. Nesses locais a ordem de prevalência seguiu dos tetrabromados e tribromado. Contudo, em ETS os congêneres tetrabromados tiveram a maior concentração $\left(10,9 \pm 0,2 \mathrm{ng} \mathrm{g}^{-1}\right)$, seguida pelos pentabromados $\left(7,7 \pm 1,0 \mathrm{ng} \mathrm{g}^{-1}\right)$ e o tribromado $\left(0,134 \pm 0,005 \mathrm{ng} \mathrm{g}^{-1}\right)$.

As razões $\sum_{\text {tetra }} / \sum_{\text {penta }}$ foram estimadas para cada local a fim de estabelecer o perfil de concentração entre essas espécies. Os resultados entre CNB $(0,4)$, ETN $(0,5)$ e BIC $(0,6)$ tiveram valores bem próximos. Já em ETS a razão obtida foi de 1,4 .

Por fim, outro aspecto importante estimado na Tabela 10 foi a estimativa da razão entre as concentrações dos BDE-47 e BDE-99 (BDE[47]/[99]), haja vista que esses congêneres são os mais abundantes na formulação comercial pentaBDE. Os valores foram estimados para os quatro pontos tendo uma variação de 0,5 a 0,8 .

Portanto, os resultados evidenciam a presença dos PBDE nos sedimentos do Lago Paranoá, sendo feita através da Figura 24 uma comparação de níveis de concentração desse estudo, com outros de diversos locais pelo planeta. 


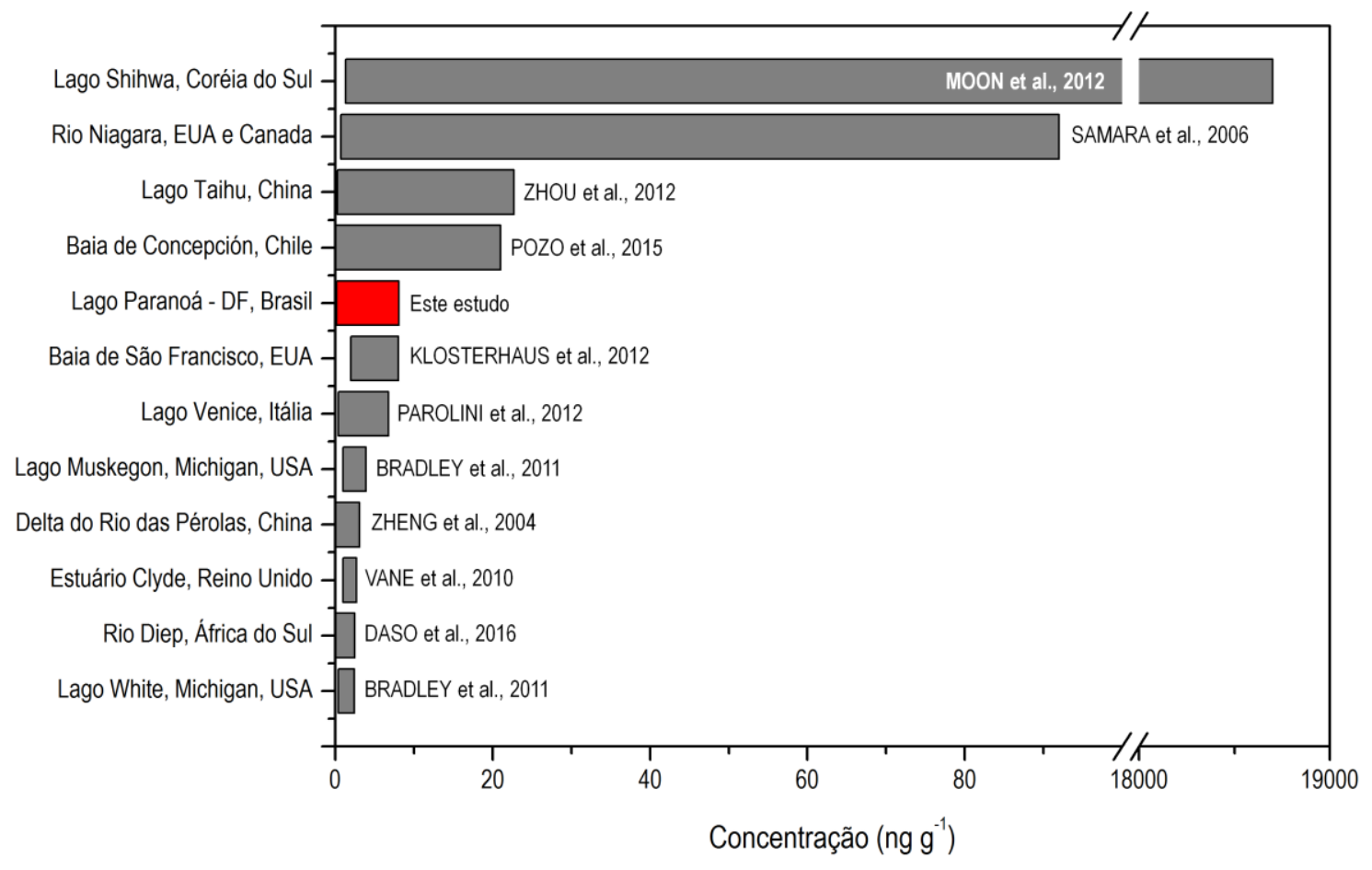

Figura 24. Comparativo dos níveis de concentração $\left(\sum \mathrm{PBDE}\right)$ em sedimentos aquáticos desse estudo, e de outros locais.

Pode-se notar através do gráfico da Figura 24, que os níveis com concentrações maiores que os detectados no Lago Paranoá $(0,143 \pm 0,005$ a $\left.8,1 \pm 0,4 \mathrm{ng} \mathrm{g}^{-1}\right)$ foram os do Lago Shihwa (1,3 a $18700 \mathrm{ng} \mathrm{g}^{-1}$ ), Rio Niágara $\left(0,72\right.$ a $\left.92 \mathrm{ng} \mathrm{g}^{-1}\right)$, Lago Taihu $\left(0,279\right.$ a 22,72 $\left.\mathrm{ng} \mathrm{g}^{-1}\right)$ e Baia de Concepción $\left(0,02\right.$ a $\left.21 \mathrm{ng} \mathrm{g}^{-1}\right)$.

O Lago Shihwa também é um reservatório artificial, com área de $56,5 \mathrm{~m}^{2}$ e população vizinha de 1 milhão de habitantes. Sua principal diferença com o Lago Paranoá é a presença de aproximadamente 13 mil indústrias de diversos setores como mecânica, eletroeletrônica, petroquímica, siderúrgica e têxtil. Essas são as principais responsáveis pelas elevadas concentrações de PBDE nesse local (MOON et al., 2012).

Já o rio Niágara, localizado entre os Estados Unidos e Canadá, foi durante anos afetado por descargas de efluentes domésticos e intensa atividade industrial da região. Segundo Samara et al. (2006) essa é a principal causa dos elevados níveis de PBDE e outros contaminantes orgânicos no corpo hídrico. 
Continuando a análise da Figura 24, se observa que o nível máximo do Lago Taihu, na China, é significativamente mais baixo que o dos dois anteriores. Contudo, é quase o triplo do determinado nesse estudo. De acordo com Zhou et al,. (2012), a contaminação dos recursos hídricos por POPs é muito comum naquele país devido à intensa atividade industrial.

Para os níveis de PBDE na baia de Concepción, o aporte nos sedimentos foi atribuído ao tsunami ocorrido na Indonésia em 2010. Os autores evidenciaram que os destroços do desastre foram transportados pelo oceano Pacífico até o Chile. Muitos desses materiais continham FR que, ao se desprenderem, depositaram nos sedimentos da região (POZO et al., 2015).

Nos demais estudos da Figura 24, os níveis máximos encontram-se abaixo do apresentado nesse estudo. No geral, esses locais tem como causa para o aporte dos PBDE nos sedimentos o lançamento de efluentes industriais e domésticos, tratados ou não (ZHENG et al., 2004; VANE et al., 2010; BRADLEY et al., 2011; KLOSTERHAUS et al., 2012; PAROLINI et al., 2012; DASO et al., 2016).

Há de se destacar que as maiores concentrações totais $\left(\sum_{9} \mathrm{PBDE}\right)$ no Lago Paranoá foram determinadas em pontos influenciados pelo lançamento de efluentes das ETE Brasília Sul (ETS) e Norte (ETN). De acordo com Deng et al., 2015, as ETE convencionais não possuem capacidade de remover toda carga de PBDE que chega no afluente. Assim, entre 21 e $45 \%$ desses são precipitados no lodo, e 52 a $80 \%$ lançados em corpos aquáticos através do efluente. As ETE são consideradas as principais fontes pontuais de aporte desses contaminantes no ambiente.

Nos pontos menos afetados (CNB e BIC) se encontram redes de drenagem urbana que foram implantadas há mais de 50 anos, estando atualmente em situação crítica por não receberem ampliação. Desta forma, com a crescente ocupação irregular do solo e o aumento de sua impermeabilização, essas não comportam mais o elevado volume das águas pluviais e lançamentos irregulares de esgoto bruto (CORREIO BRAZILIENSE, 2011).

Em outubro de 2013, nas redes próximas a Baia late Clube de Brasília (BIC) foram feitos lançamentos de óleo oriundo da caldeira do Hospital Regional da Asa Norte, localizado na região central de Brasília, atingindo uma 
área de $190 \mathrm{~m}^{2}$ do Paranoá (G1, 2013). Neste mesmo local em 2014, outro lançamento de óleo ocorreu, tendo desta vez como fonte uma caldeira do restaurante do Palácio do Planalto, sede da Presidência da República ( $O$ GLOBO, 2014). Em novembro de 2016 a CAESB, juntamente com a Agência Reguladora de Águas, Energia e Saneamento do Distrito Federal (ADASA) e o Instituto Brasília Ambiental (IBRAM), emitiu alerta de restrição do uso do Lago nas regiões próximas do ponto CNB. Nesses locais foi constatada a proliferação de cianobactérias que tiveram como causa o lançamento de esgoto bruto através das redes pluviais (G1, 2016). Logo, foi possível evidenciar o lançamento de esgoto bruto através das redes de águas pluviais das duas regiões, além de caracterizá-las como fontes difusas de aporte desses contaminantes.

A presença do BDE-99, BDE-47 e BDE-100, nos sedimentos do Paranoá, sugere que no Brasil o produto pentaBDE esteja aplicado em materiais de diversos bens de consumo. Isto se deve ao fato desses congêneres serem os principais PBDE da composição desse produto (de WIT et al., 2002; CHEN et al., 2012).

Deste modo, na Figura 25 é apresentado um gráfico dos percentuais de contribuição dos congêneres tribromado, tetrabromados e pentabromados em todos os pontos afetados, bem como do produto comercial pentaBDE, onde são somados os hexabromados e outros.

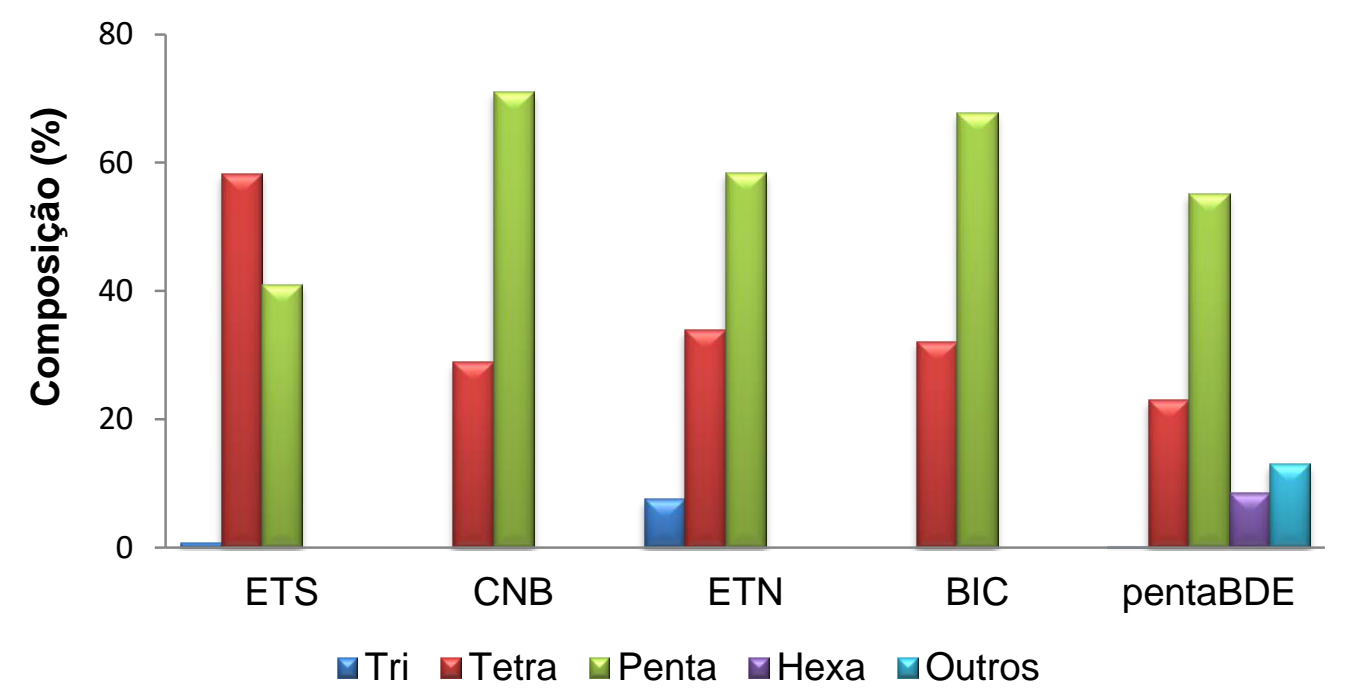

Figura 25. Composição percentual dos congêneres em ETS, CNB, ETN, BIC e produto pentaBDE (CHEN et al., 2012). 
Segundo a Figura 25, em CNB, ETN e BIC, as maiores contribuição foram das espécies pentabromadas (51 a 71\%), seguidas pelos tetrabromados (29 a 32\%) e do tribromado (7,6\%). Logo, considerando as baixas concentrações da espécie tribromada, apenas em ETS e ETN, e não detecção de espécies com seis ou mais átomos de bromo, os perfis para tetrabromados e pentabromados se assemelham ao da formulação comercial pentaBDE.

Esses resultados corroboram com a hipótese do emprego do pentaBDE no país, haja vista que sua composição é de $23 \%$ de tetrabromados e $55 \%$ de pentabromados (CHEN et al., 2012). Além disso, essa formulação é a única fonte de congêneres com esses níveis de bromação, à medida que não fazem parte das formulações octaBDE e decaBDE (de WIT et al., 2002; CHEN et al., 2012).

Assim, as razões $\sum$ Tetra / $\sum$ Penta da Tabela $10 \mathrm{em} \mathrm{CNB}(0,4)$, ETN $(0,5)$ e BIC $(0,6)$, quando comparadas a formulação pentaBDE $(0,4)$, confirmam a semelhança. Ou seja, indicam a maior prevalência de congêneres pentabromados, tanto no FR quanto nos pontos. Cabe ressaltar que nesses dois casos o BDE-99, maior representante dos congêneres com cinco átomos de bromo, é o de maior concentração. Deste modo torna-se evidente a utilização desse produto com FR no Brasil.

As distorções observadas em ETS tem como causa a elevada concentração do BDE-66, que superestimou o valor percentual dos congêneres com quatro átomos de bromo. Possivelmente, essa concentração pode estar relacionada ao fato de que os PBDE sofrem reações de desbromação redutiva, através de micro-organismos anaeróbicos, formando espécies menos bromadas (LEE et al., 2010; HUANG et al., 2014). Nesse sentido, estudo realizado por HUANG et al. (2014) em sedimento, propôs uma via de desbromação de BDE-209, identificando por HRGC/HRMS todos os congêneres intermediários até o produto final BDE-3.

Desta forma, conforme o esquema apresentado na Figura 26, em parte da via a ordem de desbromação vai do BDE-138 para o BDE-85, seguido do BDE-85 para o BDE-66 e, do BDE-66 para o BDE-28. Neste caso, como o BDE-138 não foi detectado no Paranoá, provavelmente a desbromação sugerida partiu do BDE-85, tendo como produto a formação do BDE-66 (HUANG et al., 2014). 


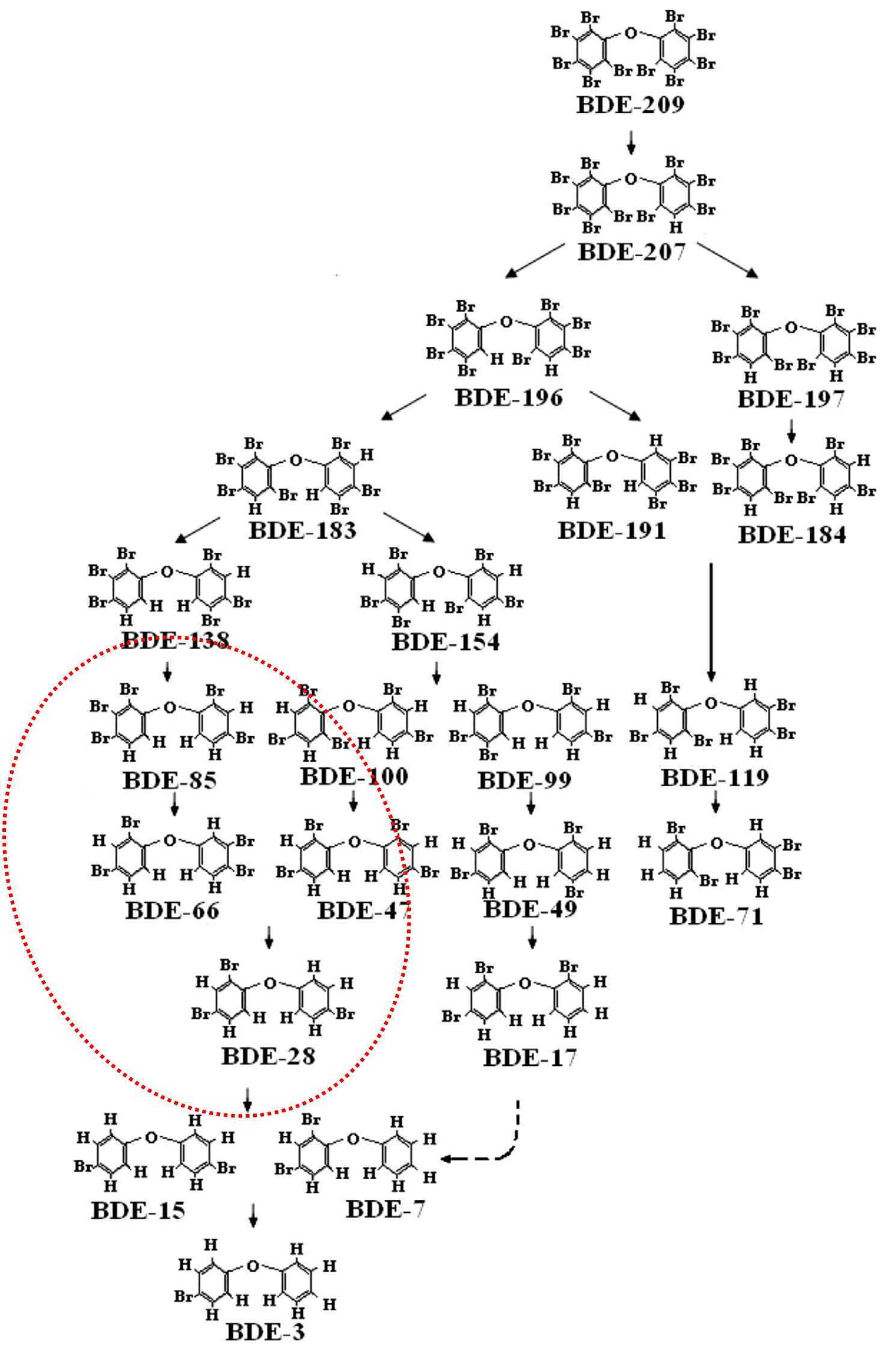

Figura 26. Rota de desbromação dos PBDE proposta por HUANG et al. (2014) 
Por outro lado, nos pontos onde o BDE-28 foi detectado, as concentrações de BDE-66 foram maiores que BDE-85, demonstrando a ocorrência de desbromação deste último. Portanto, parte dos BDE-66 presentes em ETS seriam produto da desbromação do BDE-85, que somados aos do sedimento aumentaram o valor de concentração.

Entretanto, mesmo diante de tais distorções, a avaliação da formulação pentaBDE empregada no Brasil revelou comportamento semelhante entre os quatro pontos. Há de se destacar que existem dois principais produtos comerciais, que são a formulação americana DE-71 e a européia Bromkal 705DE (QIU et al., 2010; ZHOU et al., 2012).

A diferença entre esses pode ser verificada através do cálculo entre as razões das concentrações de [BDE-47]/ [BDE-99], sendo o valor no produto americano de 0,8 e na europeia 1,0 (VANE et al., 2010; XIANG et al., 2013). Os dados aqui obtidos (Tabela 10) revelaram que possivelmente a formulação americana (DE-71) é a empregada no Brasil, em virtude das razões variarem de 0,5 a 0,8 nos quatro pontos.

Cabe ressaltar que essas misturas tiveram sua produção e uso banidos pela Convenção de Estocolmo, tendo em vista que os BDE-99 e 47, detectados nesse estudo, são persistentes no ambiente, além de causarem efeitos adversos à saúde humana (HALE et al., 2003; HOPPE et al., 2007; TALSNESS, 2008; MOON et al., 2007; WANG et al., 2011; WU et al., 2012; ZHOU et al., 2012).

Outros estudos no país detectaram esses congêneres em espécies de cetáceos (DORNELES et al.,2010) e arraias (ROSENFELDER et al., 2012) da região costeira do estado do Rio de Janeiro, cetáceos da região costeira de São Paulo (YOGUl et al., 2011), bem como em corvinas, golfinhos e peixesespada do Rio Paraíba do Sul, que cobre um extensa região dos estados de Minas Gerais, Rio de Janeiro e São Paulo (QUINETE et al.,2011).

Com efeito, os resultados indicam a contaminação dos sedimentos do Lago Paranoá por PBDE, através dos efluentes das ETE, bem como por meio do lançamento de esgoto bruto nas redes de águas de escoamento superficial. Os dados indicam que os congêneres detectados são os mesmos empregados na formulação DE-71 (pentaBDE) produzida nos EUA. 


\subsection{Estudo dA FUGACIDADE dos PBDE}

Neste estudo o software EQC Model foi utilizado em seu modelo avaliativo de Nível I (Level I), simulando uma distribuição no qual os PBDE atingem o equilíbrio num ambiente padrão, composto por ar, aerossol, água, sólidos em suspensão, peixe, sedimento e solo, em valores definidos de volume, densidade, carbono orgânico e fração lipídica.

Para isso, são fornecidos dados de entrada dos PBDE investigados, que consistem em nome químico, massa de emissão no ambiente e temperatura, massa molar, solubilidade em água, pressão de vapor e coeficiente de partição octanol/água. Os resultados são gerados pelo software na forma de tabelas e diagramas permitindo explorar a fugacidade geral no sistema, bem como as concentrações e massas em cada compartimento (Figura 27).

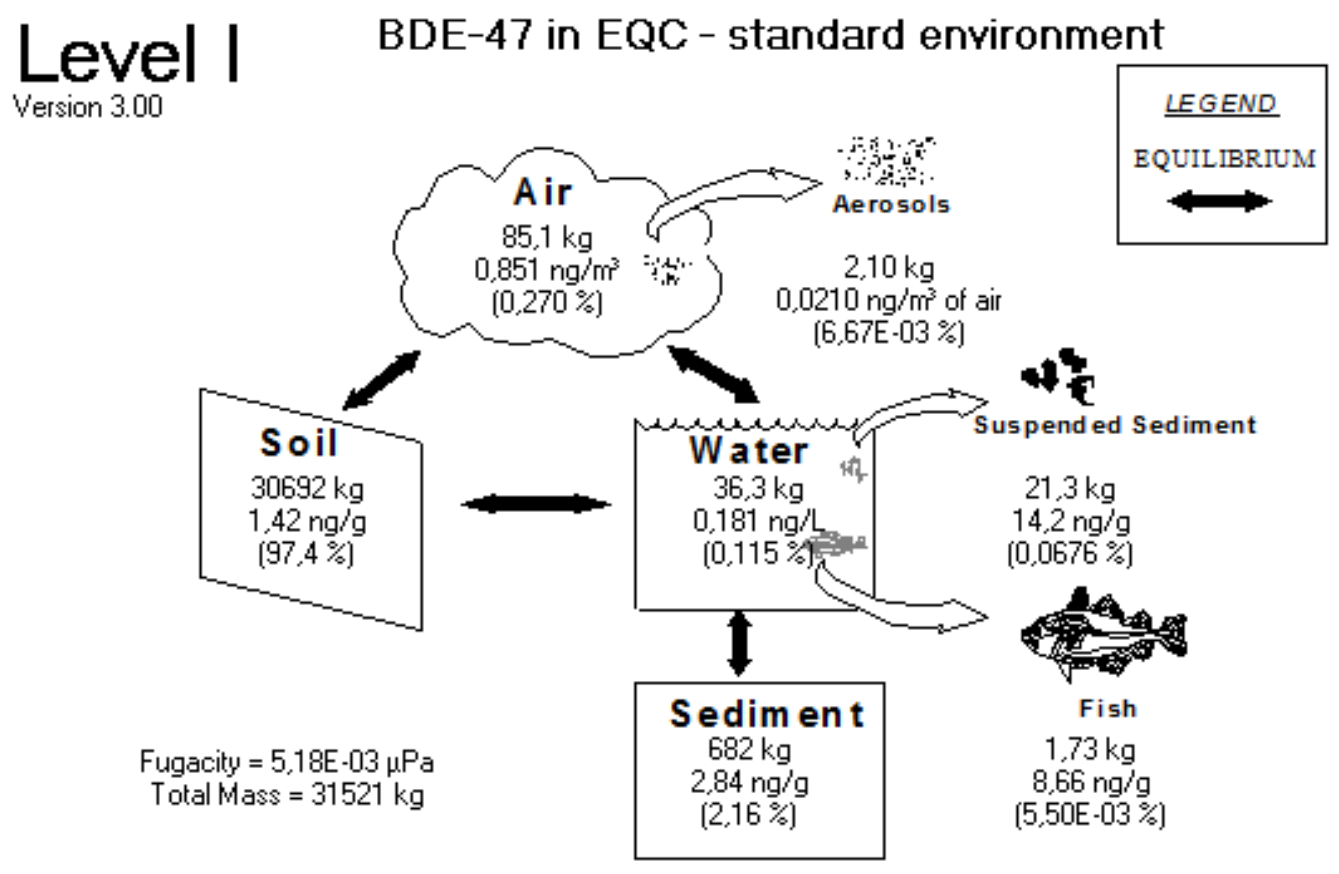

Figura 27. Diagrama de distribuição do BDE-47 nos compartimentos de um ambiente padrão segundo simulação do software EQC Model - Level I 
Neste estudo foram realizadas duas análises distintas. Na primeira, para obtenção da partição dos congêneres nos compartimentos e seus valores de percentual em massa, foi necessária a criação de um modelo de entrada (Model Input), conforme mostrado na Tabela 11, contendo dados de identificação da simulação (Simulation ID), propriedades químicas (Chemical Properties), propriedades ambientais (Environmental Properties) e emissões (Emissions).

Assim, cada congênere foi identificado pela sua nomenclatura básica, ou seja, BDE-28, BDE-47, BDE-66, BDE-85, BDE-99 e BDE-100. As propriedades químicas utilizadas foram massa molar $(\mathrm{g} / \mathrm{mol})$, temperatura dos dados $\left({ }^{\circ} \mathrm{C}\right)$, solubilidade em água $\left(\mathrm{g} / \mathrm{m}^{3}\right)$, pressão de vapor $(\mathrm{Pa})$, temperatura de fusão $\left({ }^{\circ} \mathrm{C}\right)$ e coeficiente de partição octanol/água ( $\log K_{\text {ow }}$ ).

Já as propriedades ambientais adotaram um modelo de ambiente padrão (EQC - Standard Environment) recomendado pelo software. Esses dados consistem em volumes $\left(\mathrm{m}^{3}\right)$ e densidades $\left(\mathrm{Kg} / \mathrm{m}^{3}\right)$ predeterminados para ar, aerossol, água, sólido em suspensão, peixe, solo e sedimento, bem como a fração lipídica de peixes $(\mathrm{g} / \mathrm{g})$ e o carbono orgânico $(\mathrm{g} / \mathrm{g})$ de sólidos em suspensão, solo e sedimento. 
Tabela 11. Dados de entrada utilizados no estudo da fugacidade empregando o software EQC Model - Level I

\begin{tabular}{lllllll}
\hline \multirow{2}{*}{ Prop. Químicas } & \multicolumn{5}{c}{ CONGÊNERES } \\
\cline { 2 - 7 } & BDE-28 & BDE-47 & BDE-66 & BDE-85 & BDE-99 & BDE-100 \\
\hline $\mathrm{MM}(\mathrm{g} / \mathrm{mol})$ & 407 & 486 & 486 & 565 & 565 & 565 \\
Temp. $\left({ }^{\circ} \mathrm{C}\right)$ & 25 & 25 & 25 & 25 & 25 & 25 \\
$\mathrm{~W}_{\mathrm{S}}\left(\mathrm{g} / \mathrm{m}^{3}\right)$ & 0,02 & 0,015 & 0,018 & 0,006 & 0,0094 & 0,04 \\
$\mathrm{~V}_{\mathrm{P}}(\mathrm{Pa})$ & $2,0 \times 10^{-3}$ & $1,86 \times 10^{-4}$ & $1,22 \times 10^{-4}$ & $9,86 \times 10^{-6}$ & $9,4 \times 10^{-3}$ & $2,9 \times 10^{-5}$ \\
$\mathrm{MP}\left({ }^{\circ} \mathrm{C}\right)$ & 64 & 83,5 & 83,5 & 119 & 92,5 & 102 \\
Log $K_{\text {ow }}$ & 5,98 & 6,55 & 6,73 & 7,03 & 7,13 & 6,86 \\
\hline
\end{tabular}

\begin{tabular}{lllll}
\hline \multicolumn{5}{c}{ PROPRIEDADES AMBIENTAIS (EQC Standard Environment) } \\
\hline Compartimentos & Volume $\left(\mathbf{m}^{3}\right)$ & $\begin{array}{l}\text { Densidade } \\
\left(\mathbf{K g} / \mathbf{m}^{3}\right)\end{array}$ & $\begin{array}{l}\text { Carbono } \\
\text { Orgânico } \mathbf{~ g / g ) ~}\end{array}$ & $\begin{array}{l}\text { Fração Lipídica } \\
(\mathbf{g} / \mathbf{g})\end{array}$ \\
\hline Ar & $1,0 \times 10^{14}$ & 1,18 & - & - \\
Aerossol & 2000 & 2000 & - & - \\
Água & $2,0 \times 10^{11}$ & 1000 & - & - \\
Sól. em & $1,0 \times 10^{6}$ & 1500 & 0,2 & - \\
Suspensão & $2,0 \times 10^{5}$ & 1000 & - & 0,05 \\
Peixe & $8,9 \times 10^{9}$ & 2400 & 0,02 & - \\
Solo & $1,0 \times 10^{8}$ & 2400 & 0,04 & - \\
Sedimento & & & & \\
\hline
\end{tabular}

As emissões de PBDE utilizadas nas avaliações iniciais empregando o software EQC model (Tabela 11) foram estimadas com base na produção mundial do produto comercial pentaBDE em 2006, ou seja, 7500 toneladas. Foram utilizados dados de 2006, pois esse ano foi último em que foram disponibilizados dados de produção do pentaPBDE em virtude do banimento deste produto, tanto pela Convenção de Estocolmo, quanto pelos produtores americanos.

Os valores para cada um dos congêneres foram, por sua vez, estimados com base na proporção média encontrada nestes produtos comerciais. Deste modo, considerando que o produto pentaBDE tem aproximadamente $0,23 \%$ de congêneres tribromados, $23,01 \%$ de tetrabromados e $55,1 \%$ de pentabromados, foram estimadas as seguintes cargas emitidas: $17,250 \mathrm{t}$ para $\mathrm{o}$ BDE-28 (tri), 1726 t para BDE-47 e BDE-66 (tetra), e 41325 t para BDE-85, BDE-99 e BDE-100 (penta). Essa mesma abordagem foi utilizada por Palm et al. (2002) em estudo de caso sobre destino dos PBDE empregando o software EQC Model. 
Ao utilizar os dados de entrada dispostos na Tabela 11, bem como os valores de carga emitida estimados para cada congênere, o software forneceu como respostas a simulação da distribuição percentual em massa dos congêneres em cada compartimento conforme apresentado na Tabela 12.

Tabela 12. Particionamento dos congêneres no ambiente segundo estimativa do EQC Model-Level I

\begin{tabular}{lllllll}
\hline \multirow{2}{*}{ Compartimentos } & \multicolumn{6}{c}{ Massa (\%) } \\
\cline { 2 - 7 } & BDE-28 & BDE-47 & BDE-66 & BDE-85 & BDE-99 & BDE-100 \\
\hline Ar & 0,3 & 0,04 & 0,01 & 0,002 & 0,001 & 0,001 \\
Água & 0,1 & 0,03 & 0,02 & 0,01 & 0,008 & 0,02 \\
Solo & 97,4 & 97,7 & 97,7 & 97,7 & 97,7 & 97,7 \\
Sedimento & 2,16 & 2,17 & 2,17 & 2,17 & 2,17 & 2,17 \\
Sólid. Susp. & 0,07 & 0,07 & 0,07 & 0,07 & 0,07 & 0,07 \\
Aerossol & 0,007 & 0,006 & 0,004 & 0,003 & 0,003 & 0,0009 \\
Peixe & 0,006 & 0,005 & 0,005 & 0,005 & 0,005 & 0,005 \\
\hline
\end{tabular}

Observa-se na Tabela 12, um perfil semelhante de fugacidade para os PBDE investigados, no qual cerca de $97 \%$ das emissões encontram o solo como destino, seguido de pouco mais de $2 \%$ para sedimentos. Esses dados confirmam a observação feita no subitem 2.4, no qual as características desses contaminantes fazem com que possuam tendência em se acumular em meios hidrofóbicos. Ou seja, ao serem transportados, se depositam no solo e, no caso de atingirem os corpos de água, sedimentam ou se acumulam em outros sítios hidrofóbicos como sólidos em suspensão e biota aquática (DE WIT, 2002; BRAEKEVELT et al., 2003; HARRAD et al., 2006; MACKAY et al., 2006; SAMARA et al., 2006; BARÓN et al., 2012; GORGY et al., 2013).

$\mathrm{Na}$ segunda análise, a porcentagem de cada um dos congêneres atribuída aos sedimentos (Tabela 12) foi utilizada para se estimar a carga de PBDE que aporta em cada ponto do Lago Paranoá. Para tanto, também foram utilizadas as concentrações de cada congênere obtidas nas amostras investigadas, conforme mostra a Equação 8.

$$
E_{B D E}=\frac{V_{\text {sed }} \times \rho_{\text {sed }} \times c_{B D E}}{f_{\%} \times 10^{12}}
$$


onde $E_{B D E}$ é a emissão em toneladas para cada congenere, $V_{\text {sed }}$ e $\rho_{\text {sed }}$ são o volume $\left(\mathrm{m}^{3}\right)$ e a densidade $\left(\mathrm{kg} / \mathrm{m}^{3}\right)$ de sedimento, respectivamente, conforme dados mostrados na Tabela 11, $c_{B D E}$ é a concentração do congenere determinada em cada ponto amostral e $f_{\%}$ representa a fração percentual de cada congenere atribuída ao sedimento, conforme dados mostrados na Tabela 12. Esse cálculo foi necessário para se conseguir um retrato mais fiel do ambiente estudado, uma vez que os valores de emissão utilizados para gerar os dados mostrados na Tabela 12 são baseados, unicamente, em informações sobre produção.

A partir da Equação 8, novos dados de emissão foram utilizados como parâmetros de entrada, juntamente com os dados disponíveis na Tabela 11, para se avaliar a fugacidade na área de estudo, bem como determinar possíveis concentrações em outros compartimentos adjacentes. Os diagramas obtidos para cada ponto amostral se encontram dispostos nos Anexos (Figuras 30 a 51), e os dados de concentração para ETS são apresentados na Tabela 13.

Tabela 13. Estimativas de concentração dos PBDE investigados no ponto amostral ETS.

\begin{tabular}{llllllll}
\hline & \multicolumn{7}{c}{ ETS - ETE Sul } \\
\cline { 2 - 8 } & BDE-28 & BDE-47 & BDE-66 & BDE-85 & BDE-99 & BDE-100 & $\sum_{9}$ PBDE \\
\hline Emissão (t) & 1,6 & 31,5 & 89,6 & 19 & 38,7 & 27,7 & 169,4 \\
$\operatorname{Ar}\left(\mathrm{ng} / \mathrm{m}^{3}\right)$ & 0,04 & 0,8 & 0,1 & 0,004 & 4,7 & 0,003 & 5,647 \\
Aerossol (ng/m $\left.{ }^{3}\right)$ & 0,001 & 0,02 & 0,03 & 0,005 & 9,5 & 0,003 & 9,559 \\
Água (ng/L) & 0,009 & 0,2 & 0,09 & 0,01 & 0,02 & 0,02 & 0,349 \\
Sólid. Susp. (ng/g) & 0,7 & 14,2 & 40,5 & 8,6 & 16,9 & 12,5 & 93,4 \\
Peixe (ng/g) & 0,437 & 8,66 & 24,7 & 5,25 & 10,3 & 7,6 & 56,947 \\
Solo (ng/g) & 0,07 & 1,4 & 4,1 & 0,9 & 1,7 & 1,3 & 9,47 \\
Sedimento (ng/g) & 0,143 & 2,85 & 8,1 & 1,72 & 3,5 & 2,5 & 18,813 \\
\hline
\end{tabular}

Observa-se na Tabela 13 valores individuais de emissão para cada um dos congeneres detectados no ponto ETS. Estes valores coincidem com aqueles empregados como parâmetros de entrada do modelo, conforme calculados pela Equação 8. A partir das emissões calculadas para cada um dos 
congeneres é possível estimar que a emissão total de PBDE para este ponto amostral que foi de 169,4 toneladas.

A Tabela 13 também faz uma estimativa para as concentrações de cada um dos congeneres em diferentes comparimenrtos ambientais. Obseva-se, por exemplo, que as concentrações de PBDE para o sedimento são exatamente iguais às obtidas empiricamente, evidenciando que as demais estimativas foram realizadas em conformidade com as características do ponto amostral investigado, levando-se em consideração o ambiente padrão (EQC - standard environment) adotado pelo modelo EQC, Nível I.

Observa-se também que a apresentação das concentrações de PBDE para cada compartimento é mais adequada para se compreender a distribuição dos contaminantes no ambiente, notadamente quando tais informações serão utilizadas para balizar a tomada de decisões em termos de saúde ambiental. Por exemplo, a concentração estimada de BDE-47 para o solo $\left(1,4 \mathrm{ng} \mathrm{g}^{-1}\right)$ é cerca da metade encontrada para o sedimento, ou seja, 2,85 $\mathrm{ng} \mathrm{g}^{-1}$, mesmo que a distribuição percentual mássica dos congeneres, mostrada na Tabela 12, indicasse a prevalência do solo como ambiente preferencial de acúmulo de PBDE. Obviamente, que os volumes e as densidades de cada compartimento serão essenciais para normalização dos dados em termos de concentração. Neste mesmo sentido, observa-se que a concentração de BDE-47 estimada para a biota em ETS $\left(8,66 \mathrm{ng} \mathrm{g}^{-1}\right)$ é relevanmte e pode servir como padrão para comparação com outros estudos dedicados a este tipo de matriz de interesse ambiental.

Finalmente, observam-se na Tabela 13, concentrações elevadas de todos os congeneres estimadas para os sólidos em suspensão na coluna de água. Neste caso, cabe mencionar que tais partículas em suspensão serão as precursoras para o enriquecimento de sedimentos, além de serem importantes fontes de mobilidade de substâncias hidrofóbicas, como os PBDE, em ambientes aquáticos naturais. Ainda, é importante ponderar que tais valores podem estar superestimados, pois o ambiente padrão (EQC - standard environment) utilizado nos cálculos pode diferir do ambiente lacustre investigado neste trabalho em termos de concentração de sólidos em suspensão. Nas Tabelas 14 a 16, trazem as estimativas para os demais pontos amostrais investigados. 
Tabela 14. Estimativas de concentração dos PBDE investigados no ponto amostral CNB.

\begin{tabular}{lllllll}
\hline & \multicolumn{6}{c}{ CNB - Clube Nipo Brasileiro } \\
\cline { 2 - 7 } & BDE-47 & BDE-66 & BDE-85 & BDE-99 & BDE-100 & [9PBDE \\
\hline Emissão (Kg) & 7,7 & 4,6 & 7,7 & 15,9 & 6,7 & 42,8 \\
Ar $\left(\mathrm{ng} / \mathrm{m}^{3}\right)$ & 0,2 & 0,01 & 0,001 & 0,002 & 0,001 & 0,214 \\
Aerossol (ng/m $\left.{ }^{3}\right)$ & 0,005 & 0,002 & 0,002 & 0,004 & 0,001 & 0,014 \\
Água (ng/L) & 0,04 & 0,005 & 0,004 & 0,007 & 0,005 & 0,061 \\
Sólid. Susp. (ng/g) & 3,5 & 2,1 & 3,5 & 7,2 & 3,1 & 11,8 \\
Peixe (ng/g) & 2,1 & 1,3 & 2,1 & 4,4 & 1,9 & 0,1 \\
Solo (ng/g) & 0,3 & 0,2 & 0,4 & 0,7 & 0,3 & 0,2 \\
Sedimento (ng/g) & 0,7 & 0,4 & 0,7 & 1,4 & 0,6 & 0,01 \\
\hline
\end{tabular}

Tabela 15. Estimativas de concentração dos PBDE investigados no ponto amostral ETN.

\begin{tabular}{llllllll}
\hline & \multicolumn{7}{c}{ ETN - ETE Norte } \\
\cline { 2 - 7 } & BDE-28 & BDE-47 & BDE-66 & BDE-85 & BDE-99 & BDE-100 & $\sum_{9}$ PBDE \\
\hline Emissão (t) & 7,4 & 18,2 & 14,7 & 13,3 & 24,9 & 18,7 & 97,3 \\
Ar $\left(\mathrm{ng} / \mathrm{m}^{3}\right)$ & 0,2 & 0,5 & 0,2 & 0,003 & 0,003 & 0,002 & 0,908 \\
Aerossol (ng/m $\left.{ }^{3}\right)$ & 0,005 & 0,012 & 0,005 & 0,004 & 0,006 & 0,002 & 0,034 \\
Água (ng/L) & 0,04 & 0,1 & 0,02 & 0,007 & 0,01 & 0,01 & 0,187 \\
Sólid. Susp. (ng/g) & 3,4 & 8,2 & 6,7 & 6,0 & 11,3 & 8,5 & 44,0 \\
Peixe (ng/g) & 2,1 & 5,0 & 4,1 & 3,7 & 6,9 & 5,2 & 26,8 \\
Solo (ng/g) & 0,3 & 0,8 & 0,7 & 0,6 & 1,1 & 0,8 & 4,4 \\
Sedimento (ng/g) & 0,7 & 1,7 & 1,3 & 1,2 & 2,3 & 1,7 & 8,8 \\
\hline
\end{tabular}

Tabela 16. Estimativas de concentração dos PBDE investigados no ponto amostral BIC.

\begin{tabular}{|c|c|c|c|c|c|c|}
\hline & \multicolumn{6}{|c|}{ BIC - Baia do late Clube de Brasília } \\
\hline & BDE-47 & BDE-66 & BDE-85 & BDE-99 & BDE-100 & $\sum_{9}$ PBDE \\
\hline Emissão (Kg) & 19,2 & 6,9 & 15,3 & 22,8 & 16,9 & 81,1 \\
\hline $\operatorname{Ar}\left(n g / m^{3}\right)$ & 0,5 & 0,009 & 0,003 & 0,003 & 0,002 & 0,517 \\
\hline Aerossol (ng/m $\left.{ }^{3}\right)$ & 0,01 & 0,002 & 0,004 & 0,01 & 0,002 & 0,027 \\
\hline Água (ng/L) & 0,1 & 0,01 & 0,01 & 0,01 & 0,01 & 0,15 \\
\hline Sólid. Susp. (ng/g) & 8,7 & 3,1 & 6,9 & 10,3 & 7,7 & 36,7 \\
\hline Peixe (ng/g) & 5,3 & 1,9 & 4,2 & 6,3 & 4,7 & 22,4 \\
\hline Solo (ng/g) & 0,9 & 0,3 & 0,7 & 1,0 & 0,8 & 3,7 \\
\hline Sedimento (ng/g) & 1,7 & 0,6 & 1,4 & 2,1 & 1,5 & 7,3 \\
\hline
\end{tabular}


É possível ver nas Tabelas 13 a 16, que se somados as emissões de cada ponto ( $\left.\Sigma_{9} \mathrm{PBDE}\right)$, é possível chegar a um valor correspondente à carga total aportada no Lago Paranoá, ou seja, 221,2 t de PBDE. Os maiores aportes ocorreram na ETS (169,4 t) e ETN (97,3 t), corroborando com as informações de que as ETE contribuem de forma acentuada para o lançamento desses contaminantes no ambiente (XIANG et al., 2013; DENG et al., 2015).

Além disso, os dados demonstram que foram estabelecidos níveis de concentração nos compartimentos ar $\left(0,009\right.$ a $\left.0,5 \mathrm{ng} \mathrm{m}^{-3}\right)$, aerossol $(0,001$ a $\left.0,012 \mathrm{ng} \mathrm{m}^{-3}\right)$, água $\left(0,004\right.$ a $\left.0,2 \mathrm{ng} \mathrm{L}^{-1}\right)$, sólidos em suspensão $(0,7$ a 40,5 $\mathrm{ng}$ $\left.\mathrm{g}^{-1}\right)$, peixes $\left(0,437\right.$ a $\left.24,7 \mathrm{ng} \mathrm{g}^{-1}\right)$ e solos $\left(0,07\right.$ a $\left.4,1 \mathrm{ng} \mathrm{g}^{-1}\right)$, evidenciando a distribuição dos PBDE no ambiente investigado.

Com base nesses níveis, foi possível estabelecer uma comparação com estudos realizados no país. Neste sentido, Quinete et al. (2011) obtiveram níveis de concentração em peixe-espada $\left(0,98\right.$ a 1,47 $\left.\mathrm{ng} \mathrm{g}^{-1}\right)$, corvina $(1,52 \mathrm{a}$ $\left.1,93 \mathrm{ng} \mathrm{g}^{-1}\right)$ e golfinhos $\left(0,77\right.$ a $\left.11 \mathrm{ng} \mathrm{g}^{-1}\right)$, semelhantes aos simulados para os peixes do Lago Paranoá $\left(0,437\right.$ a $\left.24,7 \mathrm{ng} \mathrm{g}^{-1}\right)$. Esse trabalho foi realizado no Rio Paraíba do Sul, cuja extensão abrange os estados de Minas Gerais, Rio de Janeiro e São Paulo. Em outro estudo, os níveis (13,84 a 36,94 $\mathrm{ng} \mathrm{g}^{-1}$ ) desses poluentes foram determinados em amostras de fígado de golfinhos da região costeira do Estado do Rio de Janeiro (LAVANDIER et al. 2016).

\subsection{Avaliação de risco}

A avaliação de risco dos PBDE à biota aquática do Lago Paranoá foi realizada de forma simplificada através da razão entre as concentrações preditas no ambiente (Predicted Environmental Concentration - PEC) e a concentração de efeito não previsto (Predicted No Effect Concentration PNEC) (EC, 2003).

Logo, se razão PEC/PNEC apresentar valores menores que 0,1 , a avaliação indicará que os PBDE não oferecem riscos à biota. Se os valores estiverem entre 0,1 e 1, é provável que haja risco, necessitando novos estudos. Valores superiores a 1 indicam risco à biota (KOMORI et al., 2013). 
Os valores de PEC utilizados foram as concentrações de PBDE na coluna d'água do Lago Paranoá, obtidas através de simulação pelo software EQC Model - Level I. Para os sedimentos, os valores correspondem às concentrações desses contaminantes em água intersticial. Já os valores de PNEC foram obtidos através da Equação 9.

$$
\text { PNEC }=\frac{\text { end point }}{f}
$$

sendo PNEC a concentração de efeito não previsto, o end point a concentração que causa efeito adverso a biota, obtida através de ensaios ecotoxicológicos ( $\mathrm{LC}_{50}$, EC $\mathrm{E}_{50}$, NOAEL, LOAEL e etc), e $f$ um fator de segurança para minimizar as incertezas envolvidas na extrapolação de dados de toxicidade (10 a 10000) (EC, 2003).

As concentrações end point foram obtidas através do banco de dados do software ECOSAR (Ecological Structure Activity Relationships), disponibilizado gratuitamente pela EPA (EPA, 2016), sendo utilizados os LD $_{50}$ dos congêneres na coluna d'água para Daphnia Magna, em fator de segurança 10000.

Para estimativa do risco da presença de PBDE em sedimentos do Lago Paranoá, os valores de PNEC na coluna d'água foram utilizados devido a escassez de dados de toxicidade em sedimento. Assim, levando em consideração o particionamento água/sedimento dos PBDE e os dados de toxicidade desses na coluna d'água, pode-se ter um valor extrapolado para 0 PNEC.

O particionamento água/sedimento dependerá da fração de carbono orgânico da matriz, que quanto maior, maior terá a capacidade de sorção dos PBDE, diminuindo assim sua concentração na água intersticial. Desta forma, a estimativa dos valores de MEC foi feita através da concentração dos PBDE em água intersticial, conforme Equação 10 (DI TORO et al., 1991).

$$
C_{i w}=\frac{C_{s}}{K_{o c} \times f_{o c}}
$$


sendo $C_{i w}$ a concentração de PBDE em água intesticial estimada para cada ponto, $C_{s}$ a concentração de PBDEem sedimento, $K_{o c}$ o coeficiente de partição carbono orgânico do PBDE e $f_{o c}$ a fração de carbono orgânico no sedimento.

Os valores de $K_{o c}$ foram obtidos para todos os congêneres investigados a partir do ACD / Labs Percepta Platform - PhysChem, disponibilizado gratuitamente pela Advanced Chemistry Development, Inc. (ACD / Labs).

A estimativa de $f_{o c}$ segue o padrão estabelecido pelo EQC - Standard Environment do software EQC Model - Level l, para sedimento, cujo valor para sedimentos é de 0,04. Esse dado padrão foi utilizado devido a impossiblidade de realização dos ensaios de carbono orgânico nas amostras do Lago Paranoá.Todos os dados acima decritos são apresentados na Tabela 17

Tabela 17. Dados para cálculo da concentração de PBDE em água intersticial e estimativa da razão PEC/PNEC para os congêneres nos pontos amostrais.

\begin{tabular}{lcclllll}
\hline \multirow{2}{*}{ PBDE } & \multirow{2}{*}{$\boldsymbol{K}_{o c}$} & \multirow{2}{*}{$\boldsymbol{f}_{o c}$} & \multirow{2}{*}{ PNEC $(\mu \mathrm{g} / \mathrm{L})$} & \multicolumn{4}{c}{$\boldsymbol{C}_{i w}(\mu \mathrm{g} / \mathrm{L})$} \\
\cline { 5 - 8 } & & & & ETS & CNB & ETN & BIC \\
\hline BDE-28 & 14678,8 & 0,04 & 0,1 & 0,0002 & 0 & 0,001 & 0 \\
BDE-47 & 83195,8 & 0,04 & 0,008 & 0,0009 & 0,0002 & 0,0005 & 0,0005 \\
BDE-66 & 94311,1 & 0,04 & 0,02 & 0,0021 & 0,0001 & 0,0004 & 0,0002 \\
BDE-85 & 186885,6 & 0,04 & 0,01 & 0,0002 & 0,0001 & 0,0002 & 0,0002 \\
BDE-99 & 190871,8 & 0,04 & 0,003 & 0,0005 & 0,0002 & 0,0003 & 0,0003 \\
BDE-100 & 142278,8 & 0,04 & 0,011 & 0,0004 & 0,0001 & 0,0003 & 0,0003 \\
\hline$\Sigma$ & ---- & --- & 0,2 & 0,004 & 0,001 & 0,003 & 0,001 \\
\hline
\end{tabular}

Assim, foi possível estabelecer as razões entre PEC/PNEC, levando em consideração que para as avaliações de risco em sedimentos aquáticos, os valores de PEC são representados pela $C_{i w}$. Na Figura 28 são apresentados de riscos para o Lago Paranoá. 


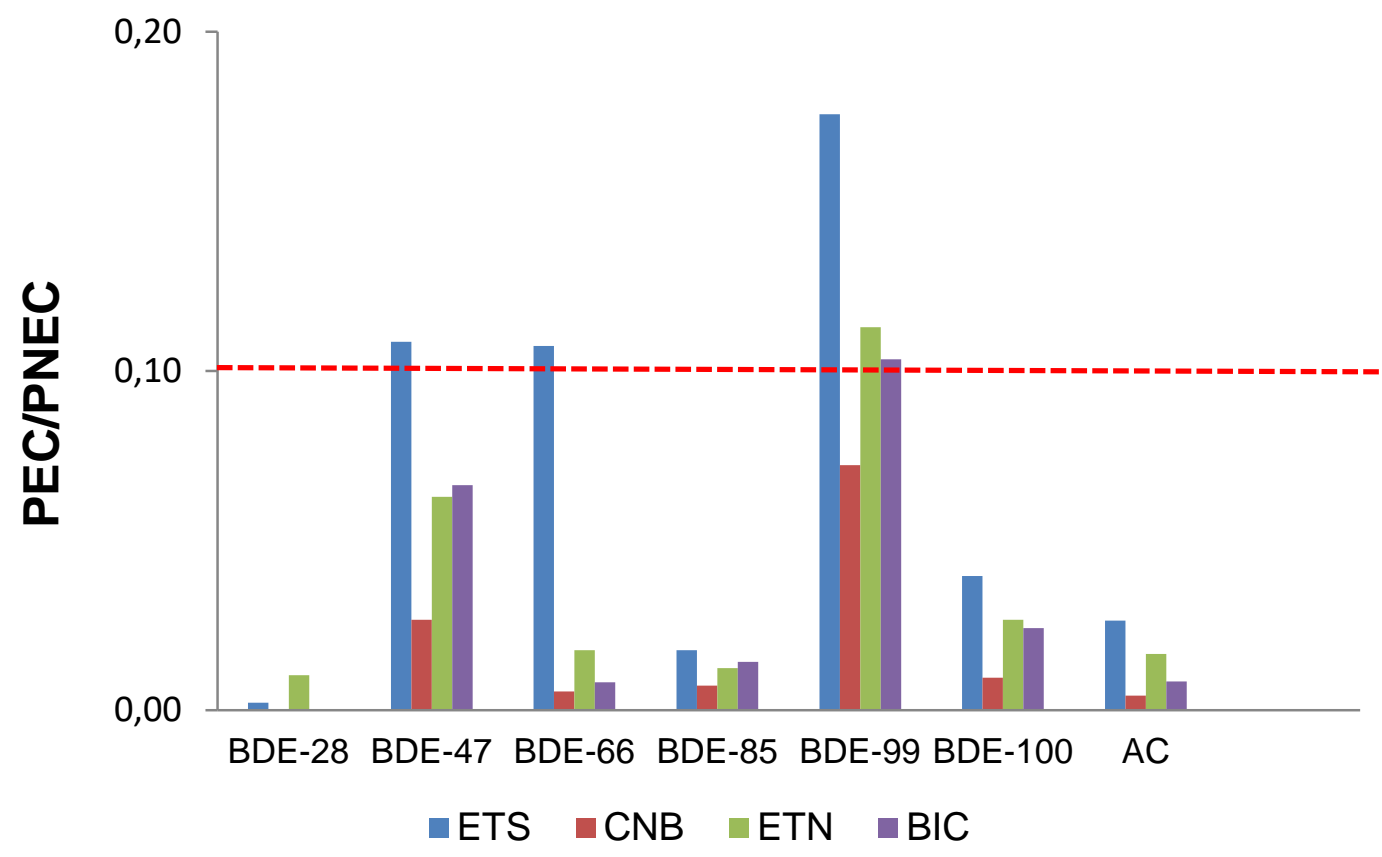

Figura 28. Razão PEC/PNEC em água intersticial para os congêneres nos pontos amostrais.

De acordo com a Figura 28, pode-se observar que todas as razões se encontram abaixo de 1, ou seja, os PBDE não apresentam nenhum risco a este ambiente. Contudo, na ETS os BDE-47 $(0,11)$, BDE-66 $(0,11)$ e BDE-99 $(0,18)$ tiveram valores superiores a linha vermelha tracejada, ou ceja, acima de 0,10 . Esse fato também ocorreu com o BDE-99 na $\operatorname{ETN}(0,11)$ e BIC $(0,103)$. Segundo Komori et al, (2013), isto sugere um provável risco, porém necessitando maiores investigações.

De volta a Tabela 17, é possível perceber que também foram obtidas as somatórias dos PNEC e $C_{i w}$. Esses dados foram utilizados para avaliar uma adição de concentração, ou seja, os riscos de uma mistura de congêneres, conforme Equação 11.

$$
A C=\frac{\sum P E C}{\sum P N E C}
$$

sendo $A C$ a adição de concentração, $\sum P E C$ o somatório das $C_{i w}$ dos PBDE num dado ponto e $\sum P N E C$ o somatório das PNEC dos PBDE. Na Figura 28 se observa que em todos os pontos os congêneres detectados no Lago Paranoá não constituem risco por adição de concentração. 
Para avaliação de risco dos PBDE na coluna d'água, as concetrações dos congêneres nesse ambiente serviram como valores de PEC. Vale lembrar que essas concentrações foram obtidas através de simulação do software $E Q C$ Model, conforme abordado no estudo fugacidade dos PBDE. Os valores de PNEC são os mesmo utilizados para avaliação em sedimento. Os dados estão na Tabela 18.

Tabela 18. Dados de concentração dos congêneres na coluna d'água, simulados através do software EQC Model, para estimativa das razões PEC/PNEC nos pontos amostrais.

\begin{tabular}{lllll}
\hline \multirow{2}{*}{ PBDE } & \multicolumn{4}{c}{ PEC $(\boldsymbol{\mu g} / \mathbf{L})$} \\
\cline { 2 - 5 } & ETS & CNB & ETN & ETS \\
\hline BDE-28 & 0,000009 & 0 & 0,00004 & 0 \\
BDE-47 & 0,0002 & 0,000045 & 0,0001 & 0,0001 \\
BDE-66 & 0,00009 & 0,000005 & 0,00003 & 0,000007 \\
BDE-85 & 0,00001 & 0,000004 & 0,000007 & 0,000008 \\
BDE-99 & 0,00002 & 0,000007 & 0,00001 & 0,00001 \\
BDE-100 & 0,00002 & 0,000005 & 0,00001 & 0,00001 \\
\hline$\Sigma$ & 0,0003 & 0,00006 & 0,0002 & 0,0002 \\
\hline
\end{tabular}


Com as informações da Tabela 18 as razões PEC/PNEC puderam ser estabelecidas e os riscos avaliados. Os resultados são apresentados na Figura 29.

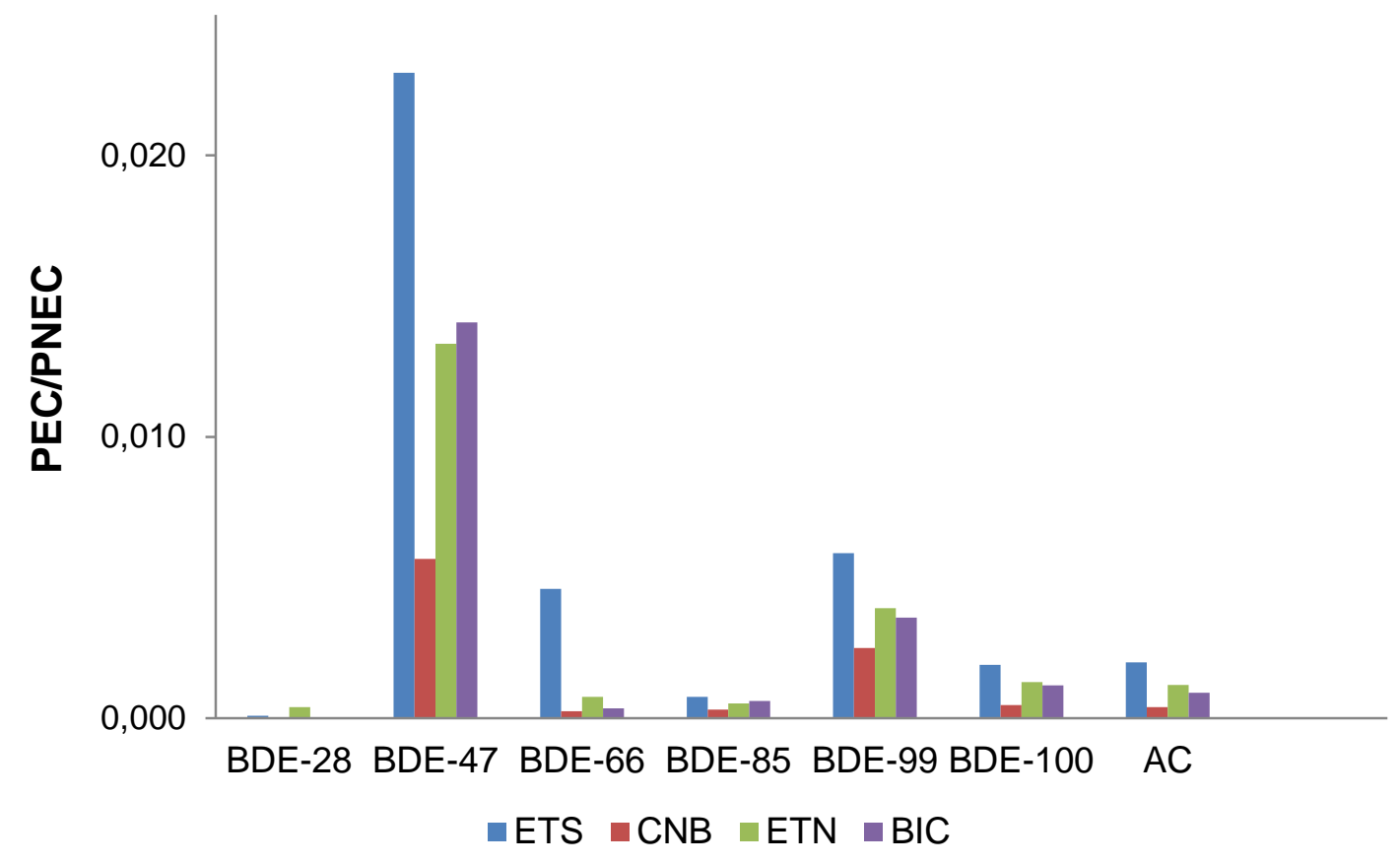

Figura 29. Razão PEC/PNEC na coluna d'água para os congêneres nos pontos amostrais.

De acordo com os resultados apresentados na Figura 29, é possivel ver que nenhum dos congêneres apresentou riscos, ou prováveis riscos, à biota por meio da coluna d'água do Lago Paranoá. A avaliação da adição de concentração $(\mathrm{AC})$ também não demosntrou risco em nenhum dos pontos investigados.

Esses resultados podem estar relacionado às baixas solubilidades em apresentadas pelos congêneres nessa matriz (MACKAY et al., 2006). No entanto, ao avaliar os perigos dos PBDE a biota aquática, deve-se também considerar que esses ocorrem por processos como biomagnificação e bioacumulação. Ou seja, esses contaminantes tendem a se acumular tanto ao longo da cadeia alimentar, quanto ao longo do tempo (ALAEE et al., 2003; LOKENSGARD, 2013). 


\section{CONCLUSÃo}

Através desse trabalho foi possível desenvolver e validar um método analítico para determinação de PBDE em sedimentos aquáticos, tendo-se em vista que no país os dados sobre estes contaminantes são escassos. O método consiste na extração assistida por ultrassom, clean-up para remoção dos interferentes e determinação por CG-ECD.

Assim, a GC-ECD se mostrou satisfatória na separação e detecção, sendo obtidos cromatogramas com picos não sobrepostos e seletivos para os nove congêneres investigados (BDE-28, BDE-47, BDE-66, BDE-85, BDE-99, BDE-100, BDE-138, BDE-153 e BDE-154).

Os coeficientes de correlação $(R)$ das curvas analíticas apresentaram valores superiores a 0,9967 , demonstrando linearidade. Os valores de LOD e $\mathrm{LOQ}$ do método variaram de 0,03 a $0,32 \mathrm{ng} \mathrm{g}^{-1}$ a 0,1 a $1,1 \mathrm{ng} \mathrm{g}^{-1}$, respectivamente.

A exatidão ficou evidenciada nos valores de recuperação analítica entre $89,8 \pm 2,8 \%$ (BDE-138) e $98,5 \pm 2,5 \%$ (BDE-28) para a amostra de sedimento fortificado, e de $87,7 \pm 6,6 \%$ (BDE-138) a $98,7 \pm 1,4 \%$ (BDE-28) para o MRC. A correlação $(R=0,9815)$ entre os valores de recuperação entre MRC e sedimento fortificado, para cada um dos analitos, demonstrou que fortificação de sedimento é uma alternativa frente ao uso de MRC.

A precisão, investigada em ensaios intra-day e inter-day, apresentou valores de CV abaixo de 7\%, comprovando o não comprometimento do método em longos períodos de análises.

As recuperações obtidas em MRC e sedimento fortificado apresentaram significativa correlação $\left(R^{2}\right.$ 0,9226), demonstrando a eficácia do método utilizado para fortificação de amostras, podendo ser utilizado para avaliar recuperações de outras substâncias que não estão presentes nos MRC, em diferentes concentrações.

Enfim, o método apresentado demostrou ser capaz de determinar PBDE em sedimentos aquáticos com elevado grau de confiança, em tempo relativamente curto, com pequena quantidade de amostra, baixos volumes de solventes orgânicos e pouca geração de resíduos tóxicos. 
A aplicação do método nos sedimentos do Lago Paranoá revelaram a ocorrência de PBDE em quatro dos sete locais investigados (ETS, CNB, ETN e

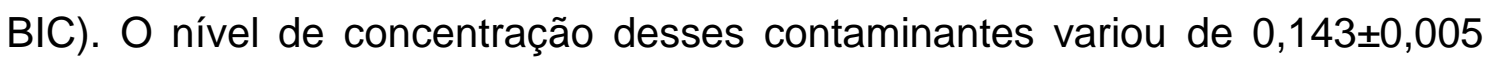
(BDE-28) a 8,1 $\pm 0,4 \mathrm{ng} \mathrm{g}^{-1}$ (BDE-66).

Os pontos mais afetados foram ETS $\left(19 \pm 2 \mathrm{ng} \mathrm{g}^{-1}\right)$ e ETN $\left(8,79 \pm 0,03 \mathrm{ng} \mathrm{g}^{-1}\right)$, influenciados pelo lançamento de efluentes das Estações de Tratamento de Esgoto Sul e Norte, respectivamente. As ETE são consideradas as principais fontes pontuais de aporte desses contaminantes em ambientes aquáticos.

Nos demais pontos, localizados os próximos ao Clube Nipo Brasileiro (CNB) e Baia do late Clube de Brasília (BIC), foi possível evidenciar o lançamento de esgoto bruto através das redes de águas pluviais, caracterizando como fontes difusas de aporte desses contaminantes no Lago Paranoá.

A semelhança entre os perfis de concentração dos congêneres tetrabromados e pentabromado com a formulação comercial pentaBDE, sugere que no Brasil esse retardante de chamas esteja aplicado em materiais de diversos bens de consumo. As razões entre as concentrações de BDE-47 e BDE-99 também revelaram que possivelmente esse produto seja o DE-71, de fabricação americana.

O estudo da fugacidade, no qual se utilizou o software EQC Model, foi capaz de simular e mensurar a distribuição dos congêneres nos compartimentos ambientais e biota, baseados em algumas de suas características. Com essas simulações foram estabelecidos para o Lago Paranoá níveis de concentração em ar $\left(0,009\right.$ a $\left.0,5 \mathrm{ng} \mathrm{m}^{-3}\right)$, aerossol $(0,001$ a $\left.0,012 \mathrm{ng} \mathrm{\textrm {m } ^ { - 3 }}\right)$, água $\left(0,004\right.$ a $\left.0,2 \mathrm{ng} \mathrm{L}^{-1}\right)$, sólidos em suspensão $\left(0,7\right.$ a 40,5 $\left.\mathrm{ng} \mathrm{g}^{-1}\right)$, peixes $\left(0,437\right.$ a $\left.24,7 \mathrm{ng} \mathrm{g}^{-1}\right)$ e solos $\left(0,07\right.$ a $\left.4,1 \mathrm{ng} \mathrm{g}^{-1}\right)$.

A avaliação de risco na coluna d'água e sedimento mostrou que as concentrações de PBDE não apresentam efeito a biota. Contudo nos pontos ETS (BDE-47, BDE-66 e BDE-99), ETN (BDE-99) e BIC (BDE-99), os resultados sugerem provável risco, porém, necessitando maiores investigações. 
Portanto, esses são os primeiros registros de PBDE numa matriz abiótica no país, podendo os resultados orientar o estabelecimento de indicadores de qualidade mais condizentes com o cenário atual, à medida que ainda são desconhecidos os níveis de concentração desses contaminantes no Brasil. Podem também ser o ponto de partida para outros estudos, em diferentes matrizes, haja vista que a avaliação de fugacidade revelou a presença em outros compartimentos ambientais. Os resultados aqui apresentados servem de alerta para a criação de programas de gestão de resíduos e de poluentes orgânicos persistentes no Brasil. 


\section{BIBLIOGRAFIA}

ALAEE, M. et al. An overview of commercially used brominated flame retardants, their applications, their use patterns in different countries/regions and modes of release. Environment International, v. 29, p. 683-689, 2003.

ANVISA, AGÊNCIA NACIONAL DE VIGILÂNCIA SANITÁRIA. Guia para validação de métodos analíticos e bioanalíticos. [S.I.]: [s.n.], 2003.

BALLSCHMITER, K.; ZELL, M. Analysis of Polychlorinated Biphenyls (PCB) by Glass Capillary Gas Chromatography: Composition of Technical Aroclor and Clophen PCB Mixtures. Fresenius Zeitschrift für Analytische Chemie, v. 302, p. 20-31, 1980.

BARÓN, E.; ELJARRAT, E.; BARCELÓA, D. Analytical method for the determination of halogenated norbornene flame retardants in environmental and biota matrices by gas chromatography coupled to tandem mass spectrometry. Journal of Chromatography A, v. 1248, p. 154-160, 2012.

BATTERMAN, S. et al. Brominated flame retardants in offices in Michigan, U.S.A. Environment International, v. 36, p. 548-556, 2010.

BENDICHO, C. et al. Ultrasound-assisted pretreatment of solid samples in the context of green analytical chemistry. Trends in Analytical Chemistry, v. 31, p. 50-60, 2012.

BESIS, A. et al. Concentrations of polybrominated diphenyl ethers (PBDEs) in central air-conditioner filter dust and relevance of non-dietary exposure in occupational indoor environments in Greece. Environmental Polluition, v. 188, p. 64-70, May 2014.

BESIS, A.; SAMARA, C. Polybrominated diphenyl ethers (PBDEs) in the indoor and outdoor environments - A review on occurrence and human exposure. Environmental Pollution, v. 169, p. 217-229, October 2012.

BILA, D. M.; DEZOTTI, M. Pharmaceutical drugs in the environment. Química Nova, v. 26, p. 523-530, 2003.

BJÖRKLUND, J. A. et al. Indoor Air is a Significant Source of Tridecabrominated Diphenyl Ethers to Outdoor Air via Ventilation 
Systems. Environmental Science \& Technology, v. 46, p. 5876-5884, 2012.

BORGHI, A. A.; PALMA, M. S. A. Tetracycline: production, waste treatment and environmental impact assessment. Brazilian Journal of Pharmaceutical Science, v. 50, p. 25-40, 2014.

BRADLEY, P. W. et al. PBDEs and methoxylated analogues in sediment cores from two Michigan, USA, inland lakes. Environmental Toxicology and Chemistry, v. 30, n. 6, p. 236-1242, 2011.

BRAEKEVELT, E.; TITTLEMIER, S. A.; TOMY, G. T. Direct measurement of octanol-water partition coefficients of some environmentally relevant brominated diphenyl ether congeners. Chemosphere, v. 51, p. 563567, 2003.

BRASIL. Decreto no 5.472, DE 20 de junho de 2005. Promulga o texto da Convenção de Estocolmo sobre Poluentes Orgânicos Persistentes, adotada, naquela cidade, em 22 de maio de 2001, 2005. Disponivel em: <https://www.planalto.gov.br/ccivil_03/_Ato20042006/2005/Decreto/D5472.htm>. Acesso em: 21 Novembro 2016.

CAESB. Estações de Tratamento de Esgoto. Companhia de Saneamento Ambiental do Distrito Federal, 2017. Disponivel em: $<$ http://atlascaesb.maps.arcgis.com/apps/MapJournal/index.html?appid $=9 \mathrm{babae} 05 \mathrm{a} 8 \mathrm{a} 1444180 \mathrm{cdf} 3 \mathrm{df} 83 \mathrm{f} 67 \mathrm{fb} 7>$. Acesso em: 2017 Fevereiro 20.

CAI, M. G. et al. Distribution of polybrominated diphenyl ethers and decabromodiphenylethane in surface sediments from the Bering Sea, Chukchi Sea, and Canada Basin. Deep-SeaResearchll, v. 81-84, p. 95101, 2012.

CAMEL, V. Microwave-assisted solvent extraction of environmental samples. Trends in analytical chemistry, v. 19, n. 4, p. 229-248, 2000.

CASTRO, M. D. L. D.; PRIEGO-CAPOTE, F. Soxhlet extraction: Past and present panacea. Journal of Chromatography A, v. 1217, p. 23832389, 2010.

CBHP. Bacia Hidrográfica do Rio Paranoá. Comitê da Bacia do Rio Paranoá, 2017.

em: 
$<$ http://www.recursoshidricos.df.gov.br/cbh_paranoa/bacia_paranoa.asp >. Acesso em: 3 Março 2016.

CEMC, CENTRE FOR ENVIRONMENTAL MODELLING AND CHEMISTRY. Level I Model. Trent University, 2004. Disponivel em: <http://www.trentu.ca/academic/aminss/envmodel/models/L1300.html>. Acesso em: 2016 Novembro 12.

CETESB, C. A. D. E. D. S. P. Guia nacional de coleta e preservação de amostras: água, sedimento, comunidades aquáticas e efluentes líquidos. São Paulo: CETESB, 2011.

CHEN, L. et al. Concentration Levels, Compositional Profiles, and Gas-Particle Partitioning of Polybrominated Diphenyl Ethers in the Atmosphere of an Urban City in South China. Environmental Science and Technology, v. 40, n. 4, p. 1190-1196, March 2006.

CHEN, L. et al. In- and outdoor sources of polybrominated diphenyl ethers and their human inhalation exposure in Guangzhou, China. Atmosphere Environment, v. 42, n. 1, p. 78-86, January 2008.

CHEN, Y. et al. Polybrominated diphenyl ethers fate in China: A review with an emphasis on environmental contamination levels, human exposure and regulation.. The Journal of Environmental Management, v. 113, p. 22-30, 2012.

CHEN, Z.-J. et al. Polybrominated diphenyl ethers (PBDEs) in human samples of mother-newborn pairs in South China and their placental transfer characteristics. Environment International , v. 73 , p. 77-84, 2014.

CINCINELLI, A. et al. PBDEs in Italian sewage sludge and environmental risk of using sewage sludge for land application. Environmental Pollution, v. 161, p. 229-234, 2012.

COLLINS, C. H.; BRAGA, G. L.; BONATO, P. S. Fundamentos de cromatografia. Campinas: Editora da Unicamp, 2006.

CORREIO BRAZILIENSE. Rede de captação e escoamento de água pluvial está há anos sem investimento. Correio Braziliense, 2011. Disponivel em:

<http://www.correiobraziliense.com.br/app/noticia/cidades/2011/04/12/in terna_cidadesdf,247364/rede-de-captacao-e-escoamento-de-agua- 
pluvial-esta-ha-anos-sem-investimento.shtml>. Acesso em: 12 Fevereiro 2016.

COTTA, J. A. O.; REZENDE, M. O. O.; LANDGRAF, M. D. Evaluation of solvent extraction by ultrasound by using high performance liquid chromatography for the determination of polycyclic aromatic hydrocarbons in contaminated soils. Química Nova, v. 32, p. 20262033, 2009.

CRUZ, L. P. S.; CAMPOS, V. P. AMOSTRAGEM PASSIVA DE POLUENTES ATMOSFÉRICOS. APLICAÇÃO AO SO2. Química Nova, v. 25, n. 3, p. 406-411, May 2002.

DASO, A. P.; FATOKI, O. S.; ODENDAAL, J. P. Polybrominated diphenyl ethers (PBDEs) and hexabromobiphenyl in sediments of the Diep and Kuils Rivers in South Africa. International Journal of Sediment Research, v. 31, n. 1, p. 61-70, 2016.

DE WIT, C. A. An overview of brominated flame retardants in the environment. Chemosphere, v. 46, p. 583-624, 2002.

DEAN, J. R. Extraction techniques in analytical sciences. Chichester: John Wiley \& Sons, 2009.

DENG, D.; CHEN, H.; TAM, N. F. Temporal and spatial contamination of polybrominated diphenyl ethers (PBDEs) in wastewater treatment plants in Hong Kong. Science of The Total Environment, v. 502, p. 133-142, 2015.

DENG, W. J. et al. Distribution of PBDE in air particles an eletronic waste recycling site compared with Guangshou and Hong Kong, South China. Environment International, v. 33, n. 8, p. 1063-1069, November 2007.

DHAGE, S. S. et al. Marine water quality assessment at Mumbai West Coast. Environment International, v. 32, p. 149-158, 2006.

DI TORO, D. M. et al. Technical basis for establishing sediment quality criteria for nonionic organic chemicals using equilibrium partitioning. Environmental Toxicology and Chemistry, v. 10, p. 1541-1583, 1991.

DODDER, N. G. et al. Distribution and sources of polybrominated diphenyl ethers in the Southern California Bight. Environmental Toxicology and Chemistry, v. 31, p. 2239-2245, 2012. 
DORNELES, P. R. et al. Anthropogenic and naturally-produced organobrominated compounds in marine mammals from Brazil. Environment International, v. 36, p. 60-67, 2010.

EC (EUROPEAN COMMISSION). Technical Guidance Document on Risk Assessment. Luxemburg: [s.n.], v. Part II, 2003.

EPA. United States Environmental Protection Agency. Ecological Structure Activity Relationships (ECOSAR) Predictive Model, 2016. Disponivel

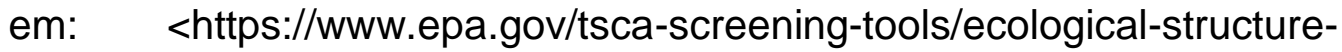
activity-relationships-ecosar-predictive-model>. Acesso em: 2017 Janeiro 9.

EPA, U. S. E. P. A. Method 3550B: Ultrasonic Extraction - Organics. Environmental Protection Agency, 1996. Disponivel em: $<$ https://www.epa.gov/sites/production/files/201512/documents/3550c.pdf>. Acesso em: 10 Agosto 2012.

EPA, U. S. E. P. A. Method 3550C: Ultrasonic Extraction (non or semi-volatile). Environmental Protection Agency, 1999. Disponivel em: $<$ https://www.epa.gov/sites/production/files/201512/documents/3550c.pdf>. Acesso em: 10 Agosto 2012.

EPA, U. S. E. P. A. Method 1614: Brominated Diphenyl Ethers in Water, Soil, Sediment, and Tissue by HRGC/HRMS. U.S. Environmental Protection Agency, Washington, 2007. Disponivel em: <https://nepis.epa.gov/Exe/ZyNET.exe/P10070D4.TXT?ZyActionD=ZyD ocument\&Client=EPA\&Index $=2006+$ Thru+2010\&Docs $=\&$ Query=\&Time $=\&$ EndTime $=\&$ SearchMethod $=1 \&$ TocRestrict $=$ n\&Toc $=\&$ TocEntry $=\& Q F i$ eld $=\& Q$ Field Year $=\& Q F i e l d M o n t h=\& Q F i e l d D a y=\& I n t Q F i e l d O p=0 \& E x t Q F$ ieldOp=0\&XmlQuery=>. Acesso em: 10 Agosto 2012.

FEITOSA, R. S.; SODRÉ, F. F.; MALDANER, A. O. Drogas de abuso em águas naturais e residuárias urbanas: ocorrência, determinação e aplicação forense. Química nova, v. 36, n. 2, p. 2013, 2013.

FIDALGO-USED, N.; BLANCO-GONZÁLEZ, E.; SANZ-MEDEL, A. Sample handling strategies for the determination of persistent trace organic contaminants from biota samples. Analytica Chimica Acta, v. 590, n. 1, p. 1-16, 2007. 
FROMME et al. PCBs, PCDD/Fs, and PBDEs in blood samples of a rural population in South Germany. International Journal of Hygiene and Environmental Health, v. 218, p. 41-46, 2015.

FULONG, C. R. P.; ESPINO, M. P. B. Decabromodiphenyl ether in indoor dust from different microenvironments in a university in the Philippines. Chemosphere, v. 90, p. 42-48, 2013.

G1. Óleo que desceu ao fundo de lago em Brasília atingiu área de 190m². G1 Distrito Federal, 2013. Disponivel em: <http://g1.globo.com/distritofederal/noticia/2013/10/oleo-que-desceu-ao-fundo-de-lago-em-brasiliaatingiu-area-de-190m.html>. Acesso em: 20 Outubro 2013.

G1. GDF suspeita que esgoto clandestino contaminou trecho do Lago Paranoá. G1 - Distrito Federal, 2016. Disponivel em: <http://g1.globo.com/distrito-federal/noticia/2016/11/gdf-suspeita-queesgoto-clandestino-contaminou-trecho-do-lago-paranoa.html>. Acesso em: 24 Novembro 2016.

GALLO, J. B.; AGNELLI, J. A. M. Aspectos do Comportamento de Polímeros em Condições de Incêndio. Polímeros: Ciência e Tecnologia, v. 8, p. 23-38, 1998.

GAO, Z. et al. Polybrominated diphenyl ethers (PBDEs) in aquatic biota from the lower reach of the Yangtze River, East China. Chemosphere, v. 75, n. 9, p. 1273-1279, 2009.

GARRISON, T. Fundamentos de oceanografia. 4a . ed. São Paulo: Cengage Learning, 2010.

GASCON, M. et al. Effects of pre and postnatal exposure to low levels of polybromodiphenyl ethers on neurodevelopment and thyroid hormone levels at 4 years of age. Environment International, v. 37 , p. 605-611, 2011.

GORGY, T. et al. An Exploratory Investigation on the Mobility of Polybrominated Diphenyl Ethers (PBDEs) in Biosolid-Amended Soil. Water, Air, \& Soil Pollution, v. 223, p. 2297-2309, 2012.

GORGY, T. et al. Migration of polybrominated diphenyl ethers in biosolidsamended soil. Environmental Pollution, v. 172, p. 124-130, 2013. 
GUZZELLA, L. et al. Organic persistent toxic substances in soils, waters and sediments along an altitudinal gradient at Mt. Sagarmatha, Himalayas, Nepal. Environmental Pollution, v. 159, p. 2552e2564, 2011.

HARA, E. L. Y. Protocolo analítico para determinação de éteres difenílicos polibromados (PBDE) em sedimentos de Rios por GC-MS. Dissertação de Mestrado - Programa de Pós-Graduação em Química da Universidade Federal do Paraná, p. 83p, 2014.

HARRAD, S.; HAZRATI, S.; IBARRA, C. Concentrations of Polychlorinated Biphenyls in Indoor Air and Polybrominated Diphenyl Ethers in Indoor Air and Dust in Birmingham, United Kingdom: Implications for Human Exposure. Environmental Science \& Technology, v. 40, p. 46334638, 2006.

HUANG, H.-W.; CHANG, B.-V.; LEE, C.-C. Reductive debromination of decabromodiphenyl ether by anaerobic microbes from river sediment. International Biodeterioration \& Biodegradation, v. 87, p. 60-65, 2014.

INMETRO. Instituto Nacional de Metrologia, Normalização e Qualidade Industrial; Orientações sobre Validação de Métodos de Ensaios Químicos. [S.I.]: DOQ-CGCRE-008, 2011.

JIANG, Y. et al. Occurrence, compositional patterns, and possible sources of polybrominated diphenyl ethers in agricultural soil of Shanghai, China. Chemosphere, v. 89, p. 936-943, 2012.

JUGAN, M.; LEVI, Y.; BLONDEAU, J. Endocrine disruptors and thyroid hormone physiology. Biochemical Pharmacology, v. 79, p. 939-947, 2010.

KALANTZI, O. I. et al. Polybrominated diphenyl ethers and polychlorinated biphenyls in human breast adipose samples from Brazil. Environment International , v. 35 , p. 113-117, 2009.

KANG, Y. et al. Polybrominated diphenyl ethers (PBDEs) in indoor dust and human hair. Atmospheric Environment, v. 45, n. 14, p. 2386-2393, May 2011.

KEFENI, K. K.; OKONKWO, J. O. Analysis of major congeners of polybromobiphenyls and polybromodiphenyl ethers in office dust using 
high resolution gas chromatography-mass spectrometry. Chemosphere, v. 87, p. 1070-1075, 2012.

$\mathrm{KIM}, \mathrm{M}$. et al. Review of contamination of sewage sludge and amended soils by polybrominated diphenyl ethers based on meta-analysis. Environmental Pollution, v. 220, n. Part B, p. 753-765, 2017.

KLOSTERHAUS, S. L. et al. Brominated and chlorinated flame retardants in San Francisco Bay sediments and wildlife. Environment International, v. 47 , p. 56-65., 2012.

KOMORI, K. et al. Occurrence of selected pharmaceuticals in river water in Japan and assessment of their environmental risk. Environmental Monitoring and Assessment, v. 185, p. 4529-4536, 2013.

KRÓL, S.; NAMIESNIK, J.; ZABIEGAłA, B. Occurrence and levels of polybrominated diphenyl ethers (PBDEs) in house dust and hair samples from Northern Poland; an assessment of human exposure. Chemosphere, v. 110 , p. 91-96, 2014.

LANÇAS, F. M. Validação de métodos cromatográficos de análise. São Carlos: RiMa, 2004.

LAVANDIER, R. et al. Polychlorinated biphenyls (PCBs) and Polybrominated Diphenyl ethers (PBDEs) in three fish species from an estuary in the southeastern coast of Brazil. Chemosphere, v. 90, n. 9, p. 2435-2443, 2013.

LAVANDIER, R. et al. An assessment of PCB and PBDE contamination in two tropical dolphin species from the Southeastern Brazilian coast. Marine Pollution Bulletin, v. 101, n. 2, p. 947-953, 2015.

LAVANDIER, R. et al. PCB and PBDE levels in a highly threatened dolphin species from the Southeastern Brazilian coast. Environmental Pollution, v. 208, n. Part B, p. 442-449, 2016.

LEE, I.-S. et al. Evaluation of mono- to deca-brominated diphenyl ethers in riverine sediment of Korea with special reference to the debromination of DeBDE209. Science of the Total Environment, v. 432, p. 128-134, 2012.

LEE, L. K.; HE, J. Reductive Debromination of Polybrominated Diphenyl Ethers by Anaerobic Bacteria from Soils and Sediments. Applied and environmental microbiology, v. 76, n. 3, p. 794-802, 2010. 
LI, F. et al. Contamination by persistent toxic substances in surface sediment of urban rivers in Chaohu City, China. Journal of Environmental Sciences, v. 24 , p. 1934-1941, 2012.

$\mathrm{LI}, \mathrm{Q}$. et al. Occurrence and levels of polybrominated diphenyl ethers (PBDEs) in recent sediments and marine organisms from Xiamen offshore areas, China. Marine Pollution Bulletin, v. 60, p. 464-469., 2010.

$\mathrm{LI}$, Y. et al. Polybrominated diphenyl ethers (PBDEs) in sediments of the coastal East China Sea: Occurrence, distribution and mass inventory. Environmental Pollution, v. 171, p. 155-161, 2012.

LI, Y. et al. Study of PCBs and PBDEs in King George Island, Antarctica, using PUF passive air sampling. Atmospheric Environment, v. 51, May 2012.

LIANG, X. et al. Bioaccumulation and bioavailability of polybrominated diphenyl ethers [corrected] (PBDEs) in soil. Environmental Pollution, v. 158, n. 7, p. 2387-2392, 2010.

LIN, S.-M. et al. Negative associations between PBDE levels and thyroid hormones in cord blood. International Journal of Hygiene and Environmental Health, v. 214, p. 115-120, 2011.

LIU, L.-Y. et al. Persistent organic pollutants in coastal sediment off south china in relation to the importance of anthropogenic inputs. Environmental Toxicology and Chemistry, v. 31, p. 1194-1201, 2012.

LOKENSGARD, E. Plásticos Industriais: Teoria e Aplicações. 5a. ed. São Paulo: Cengage Learning, 2013.

MACHADO, M. T. D. S.; BAPTISTA, G. M. D. M. Sensoriamento remoto como ferramenta de monitoramento da qualidade da água do Lago Paranoá (DF). Engenharia Sanitaria e Ambiental, v. 21, n. 2, p. 357-365, 2016. MACKAY, D. Multimedia Ecological Models: The Fugacity Approach. New York: CRC Press LLC, 1991.

MACKAY, D. et al. Handbook of Physical-Chemical Properties and Environmental Fate for Organic Chemicals. 2 ${ }^{\mathrm{a}}$. ed. Boca Raton: CRC Press, 2006.

MANAHAN, S. E. Química ambiental. 9a - ed. Porto Alegra: Bookman, 2013.

MANDALAKIS, M.; BESIS, A.; STEPHANOU, E. G. Particle-size distribution and gas/particle partitioning of atmospheric polybrominated diphenyl 
ethers in urban areas of Greece. Environmental Pollution, v. 157, n. 4, april 2009. ISSN 1227-1233.

MAPA, MINISTERIO DA AGRICULTURA, PECUARIA E ABASTECIMENTO. Manual de garantia da qualidade analitica. [S.I.]: [s.n.], 2011.

MARIANI, G. et al. Atmospheric input of POPs into Lake Maggiore (Northern Italy): PBDE concentrations and profile in air, precipitation, settling material and sediments. Chemosphere, v. 73, p. S114-S121, 2008.

MECHLINSKA, A.; WOLSKA, L.; NAMIESNIK, J. Removal of sulfur from a solvent extract. Trends in Analytical Chemistry, v. 31, p. 129-133, 2012.

MINISTÉRIO DO DESENVOLVIMENTO, I. E. C. M. Importação de éter decabromo difenílino. Aliceweb, 2016. Disponivel em: $<$ http://aliceweb.desenvolvimento.gov.br>. Acesso em: 11 Novembro 2016.

MÖLLER, A. et al. Polybrominated diphenyl ethers (PBDEs) and alternative brominated flame retardants in air and seawater of the European Arctic. Environmental Pollution , v. 159, p. 1577-1583, 2011.

MOON, H.-B. et al. Polybrominated diphenyl ethers (PBDEs) in marine sediments from industrialized bays of Korea. Marine Pollution Bulletin, v. 54, p. 1402-1412, 2007.

MOON, H.-B. et al. Contamination and potential sources of polybrominated diphenyl ethers (PBDEs) in water and sediment from the artificial Lake Shihwa, Korea. Chemosphere, v. 88, p. 837-843, 2012.

MOZETO, A. A.; UMBUZEIRO, G. D. A.; JARDIM, W. D. F. Métods de coleta, análises físico-químicas e ensaios biológicos e ecotoxicológicos de sedimentos de água doce. 1a. ed. São Carlos: Cubo Multimídia, 2006.

$\mathrm{NI}$, H. et al. Incidence of polybrominated diphenyl ethers in central air conditioner filter dust from a new office building. Environmental Pollution, v. 1962, n. 7, p. 1957, July 2011.

O GLOBO. Palácio do Planalto será multado por vazar óleo que contaminou Lago Paranoá. 0 Globo, 2014. Disponivel em: <http://oglobo.globo.com/brasil/palacio-do-planalto-sera-multado-por- 
vazar-oleo-que-contaminou-lago-paranoa-11370543>. Acesso em: 22 Janeiro 2014.

PALM, A. et al. Assessing the environmental fate of chemicals of emerging concern: a case study of the polybrominated diphenyl ethers. Environmental Pollution, v. 117, n. 2, p. 195-213, 2002.

PAPACHLIMITZOU, A. et al. A review of the analysis of novel brominated flame retardants. Journal of Chromatography A , v. 1219, p. 15-28, 2012.

PAROLINI, M. et al. New evidences in the complexity of contamination of the lagoon of Venice: polybrominated diphenyl ethers (PBDEs) pollution. Environmental Monitoring and Assessment, v. 184, p. 2001-2015, 2012.

PAROLINI, M. et al. Polybrominated diphenyl ether contamination in soil, vegetation, and cow milk from a high-mountain pasture in the Italian Alps. Archives of Environmental Contamination and Toxicology, v. 63, p. 29-44., 2012.

PENTEADO, J. C. P.; VAZ, J. M. O legado das bifenilas policloradas (PCBs). Química Nova, v. 24, p. 390-398, 2001.

$\mathrm{PI}, \mathrm{N}$. et al. Effects of tidal flushing regimes on mangrove roots receiving wastewater contaminated with PAHs and PBDEs. Regional Studies in Marine Science, v. 8, p. 51-58, 2016.

POZO, C. et al. Polybrominated Diphenyl Ethers (PBDEs) in Concepción Bay, central Chile after the 2010 Tsunami. Marine Pollution Bulletin, v. 96, n. 1, p. 480-483, 2015.

QIU, X.; ZHU, T.; HU, J. Polybrominated diphenyl ethers (PBDEs) and other flame retardants in the atmosphere and water from Taihu Lake, East China. Chemosphere, v. 80, n. 10, p. 1207-1212, 2010.

QUINETE, N. et al. Specific profiles of polybrominated diphenylethers (PBDEs) and polychlorinated biphenyls (PCBs) in fish and tucuxi dolphins from the estuary of Paraíba do Sul River, Southeastern Brazil. Marine Pollution Bulletin, v. 62, p. 440-446, 2011.

RAHMAN, F.; LANGFORD, K. H. S. M. D.; LESTER, J. N. Polybrominated diphenyl ether (PBDE) flame retardants.. The Science of the Total Environment, v. 275, p. 1-17, 2001. 
RÍOS, J. M. et al. Use of wild trout for PBDE assessment in freshwater environments: Review and summary of critical factors. Emerging Contaminants, v. 1, p. 54-63, 2015.

ROCHA, J. C.; ROSA, A. H.; CARDOSO, A. A. Introdução à química ambiental. $2^{\mathrm{a}}$. ed. Porto Alegre: Bookman, 2009.

ROSENFELDER, N. et al. Thorough analysis of polyhalogenated compounds in ray liver samples off the coast of Rio de Janeiro, Brazil. Environmental Science and Pollution Research, v. 19, p. 379-389, 2012.

SAGIV, S. K. et al. Prenatal and childhood polybrominated diphenyl ether (PBDE) exposure and attention and executive function at 9-12 years of age. Neurotoxicology and Teratology, v. 52, Part B, p. 151-161, 2015.

SAHLSTRÖM, L.; SELLSTRÖM, U.; WIT, C. A. D. Clean-up method for determination of established and emerging brominated flame retardants in dust. Analytical and Bioanalytical Chemistry, v. 404, p. 459-466, 2012.

SAKAI, S.-I. et al. Combustion of brominated ${ }^{-}$ame retardants and behavior of its byproducts. Chemosphere, v. 42, p. 519 $\pm 531,2001$.

SAMARA, F.; TSAI, C. W.; AGA, D. S. Determination of potential sources of PCBs and PBDEs in sediments of the Niagara River. Environmental Pollution, v. 139, p. 489-497, 2006.

SÁNCHEZ-BRUNETE, C.; MIGUEL, E.; TADEO, J. L. Determination of polybrominated diphenyl ethers in soil by ultrasonic assisted extraction and gas chromatography mass spectrometry. Talanta, v. 70, p. 10511056, 2006.

SHIN, M.; SVOBODA, M. L.; FALLETTA, P. Microwave-assisted extraction (MAE) for the determination of polybrominated diphenylethers (PBDEs) in sewage sludge. Analytical and Bioanalytical Chemistry, v. 387, p. 2923-2929, 2007.

SHOEIB, M. et al. Legacy and current-use flame retardants in house dust from Vancouver, Canada. Environmental Polluition, v. 169, p. 175-182, 2012. 
SIDDIQUE, S. et al. Levels of dechlorane plus and polybrominated diphenylethers in human milk in two Canadian cities. Environment International , v. 39 , p. 50-55, 2012.

SJODIN, A. et al. Concentration of polybrominated diphenyl ethers (PBDEs) in household dust from various countries. Chemosphere, v. 73, p. S131S136, 2008.

SOLOMONS, T. W. G.; FRYHLE, C. B. Química orgânica. 9å. ed. Rio de Janeiro: LTC, v. I, 2001.

STASINSKA, A. et al. Concentrations of polybrominated diphenyl ethers (PBDEs) in residential dust samples from Western Australia. Chemosphere, v. 91, p. 187-193, 2013.

STASINSKA, A. et al. Polybrominated diphenyl ether (PBDE) concentrations in plasma of pregnant women from Western Australia. Science of the Total Environment, v. 493, p. 554-561, 2014.

TAKIGAMI, $\mathrm{H}$. et al. Brominated flame retardants and other polyhalogenated compounds in indoor air and dust from two houses in Japan. Chemosphere, v. 76, n. 2, p. 270-277, June 2009.

TALSNESS, C. E. Overview of toxicological aspects of polybrominated diphenyl ethers: A flame-retardant additive in several consumer products. Environmental Research, v. 108, p. 158-167, 2008.

TAN, J. et al. Polybrominated diphenyl ethers in house dust in Singapore. Chemosphere, v. 66, n. 6, p. 985-992, January 2007.

TITTLEMIER, S. A. et al. Vapor pressures, aqueous solubilities, and Henry's law constants of some brominated flame retardants. Environmental Toxicology and Chemistry, v. 21, p. 1804-1810, 2002.

TOKARZ, J. A. et al. Reductive debromination of polybrominated diphenyl ethers in anaerobic sediment and a biomimetic system. Environmental Science \& Technology, v. 42, n. 4, p. 1157-1164, 2008.

TOLLBÄCK, P.; BJÖRKLUND, J.; ÖSTMAN, C. Large-volume programmedtemperature vaporiser injection for fast gas chromatography with electron capture and mass spectrometric detection of polybrominated diphenyl ethers. Journal of Chromatography A , v. 991, p. 241-253, 2003. 
VALENTE, A. L. P.; DA ROCHA, E. C.; PINI, G. F. Avaliação da Otimização do Desempenho de um Detector por Captura de Elétrons. Química Nova, v. 19, p. $668-670,1996$.

VANE, C. $H$. et al. Increasing polybrominated diphenyl ether (PBDE) contamination in sediment cores from the inner Clyde Estuary, UK. Environmental Geochemistry and Health , v. 32, p. 13-21, 2010.

VONDERHEIDE, A. P. A review of the challenges in the chemical analysis of the polybrominated diphenyl ethers. Microchemical Journal , v. 92 , p. 49-57, 2009.

WANG, G. et al. Polybrominated diphenyl ethers in sediments from the Southern Yellow Sea: Concentration, composition profile, source identification and mass inventory. Chemosphere, v. 144, p. 2097-2105, 2016.

WANG, J. et al. Polybrominated diphenyl ethers in water, sediment, soil, and biological samples from different industrial areas in Zhejiang, China. Journal of Hazardous Materials, v. 197, p. 211-219., 2011.

WANG, P. et al. Evaluation of Soxhlet extraction, accelerated solvent extraction and microwave-assisted extraction for the determination of polychlorinated biphenyls and polybrominated diphenyl ethers in soil and fish samples. Analytica Chimica Acta, v. 663, n. 1, p. 43-48, 2010.

WANG, W. et al. Health risk assessment of exposure to polybrominated diphenyl ethers (PBDEs) contained in residential air particulate and dust in Guangzhou and Hong Kong. Atmospheric Environment, v. 89, p. 786-796, June 2014.

WANG, $X$. et al. Characterization, treatment and releases of PBDEs and PAHs in a typical municipal sewage treatment plant situated beside an urban river, East China. Journal of Environmental Sciences, v. 25, n. 7, p. 1281-1290, 2013.

WANG, X.-T. et al. Occurrence, profiles, and ecological risks of polybrominated diphenyl ethers (PBDEs) in river sediments of Shanghai, China. Chemosphere, v. 133, p. 22-30, 2015. 
WANG, $Y$. et al. Characterization of the exchange of PBDEs in a subtropical paddy field of China: A significant inputs of PBDEs via air-foliage exchange. Environmental Pollution, v. 205, p. 1-7, October 2015.

WARD, J.; MOHAPATRA, S. P.; MITCHELL, A. An overview of policies for managing polybrominated diphenyl ethers (PBDEs) in the Great Lakes basin. Environment International, v. 34, p. 1148-1156, 2008.

WATKIMS, D. J. et al. Associations between PBDEs in office air, dust, and surface wipes. Environment International, v. 59, p. 124-132, September 2013.

XIANG, N. et al. Polybrominated diphenyl ethers (PBDEs) in a conventional wastewater treatment plant (WWTP) from Shanghai, the Yangtze River Delta: Implication for input source and mass loading. Science of The Total Environment, v. 461-462, p. 391-396, 2013.

XIE, Z.; EBINGHAUS, R. Analytical methods for determination of emerging organic contaminats in the atmosphere. Analytica Chimica Acta, v. 610, n. 2, p. 156-178, March 2008.

$X U$, P. et al. Effects of PCBs and PBDEs on thyroid hormone, lymphocyte proliferation, hematology and kidney injury markers in residents of an ewaste dismantling area in Zhejiang, China. Science of the Total Environment, v. 536 , p. 215-222, 2015.

YANG, R. et al. Emerging Brominated Flame Retardants in the Sediment of the Great Lakes. Environmental Science \& Technology, v. 46, p. 31193126, 2012.

YOGUI, G. T. et al. PBDEs in the blubber of marine mammals from coastal areas of São Paulo, Brazil, southwestern Atlantic. Marine Pollution Bulletin, v. 62, p. 2666-2670, 2011.

YOGUI, G. T.; SERICANO, J. L. Polybrominated diphenyl ether flame retardants in the U.S. marine environment:A review. Environment International , v. 35, p. 655-666, 2009.

$\mathrm{YU}, \mathrm{M}$. et al. Bioaccumulation and trophic transfer of polybrominated diphenyl ethers (PBDEs) in biota from the Pearl River Estuary, South China. Environment International, v. 35, n. 7, p. 1090-1095, 2009. 
YUAN, G.-L. et al. Altitudinal distribution of polybrominated diphenyl ethers (PBDEs) in the soil along Central Tibetan Plateau, China. Science of the Total Environment, v. 433, p. 44-49, 2012.

ZHANG, C. C. Fundamentals of environmental sampling and analysis. New Jersey: John Wiley \& Sons, 2007.

ZHAO, X. et al. Polybrominated diphenyl ethers in sediments of the Daliao River Estuary, China: Levels, distribution and their influencing factors. Chemosphere, v. 82, p. 1262-1267, 2011.

ZHENG, G. J. et al. Concentrations of polybrominated diphenyl ethers (PBDEs) inPearl River Delta sediments. Baseline / Marine Pollution Bulletin, v. 49, p. 514-524, 2004.

ZHENG, $X$. et al. Distribution of PCBs and PBDEs in soils along the altitudinal gradients of Balang Mountain, the east edge of the Tibetan Plateau. Environmental Pollution, v. 161, p. 101-106, 2012.

ZHOU, P. et al. Distribution of polybrominated diphenyl ethers in the surface sediments of the Taihu Lake, China. Chemosphere, v. 88, p. 13751382, 2012. 


\section{ANEXOS}

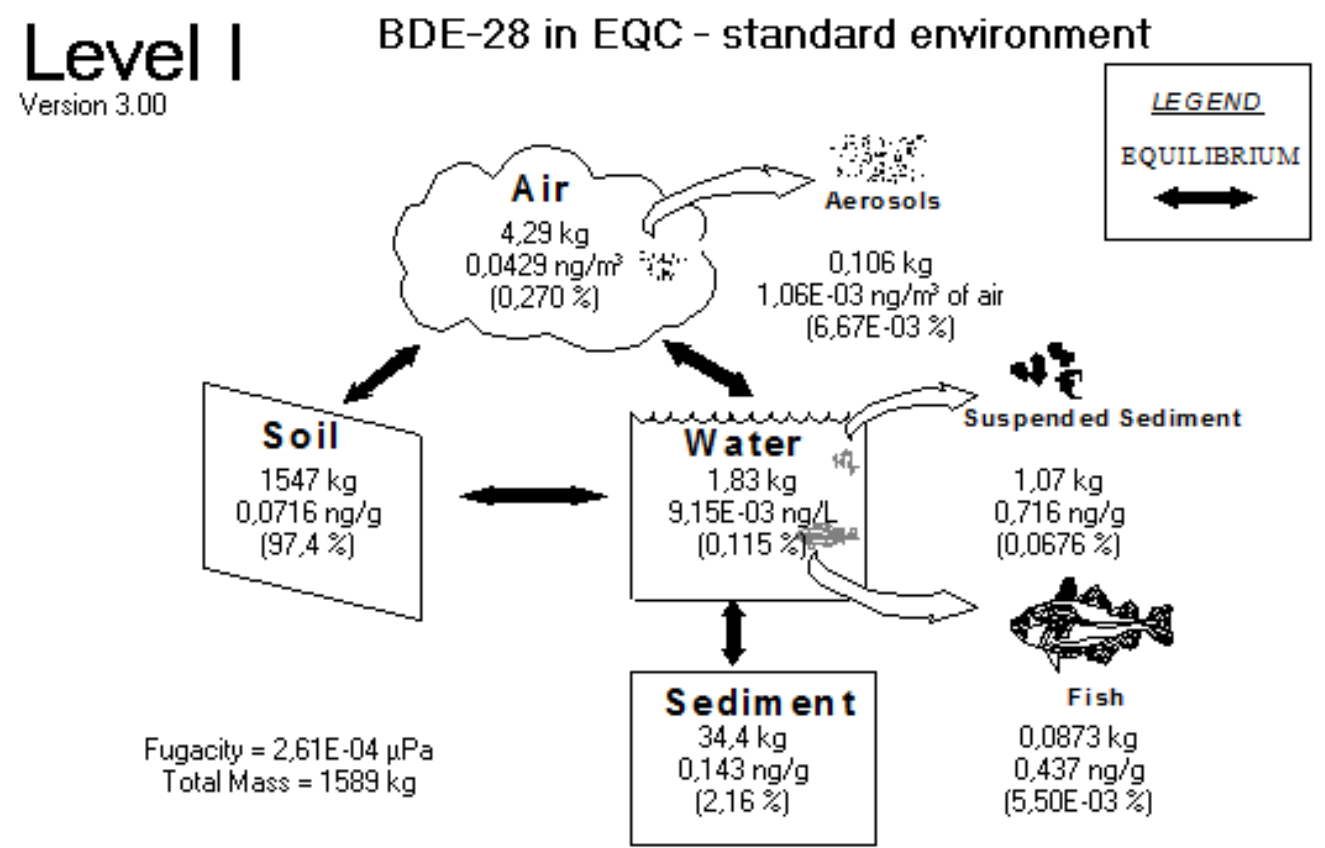

Figura 30. Diagrama de fugacidade do BDE-28 no ponto ETS

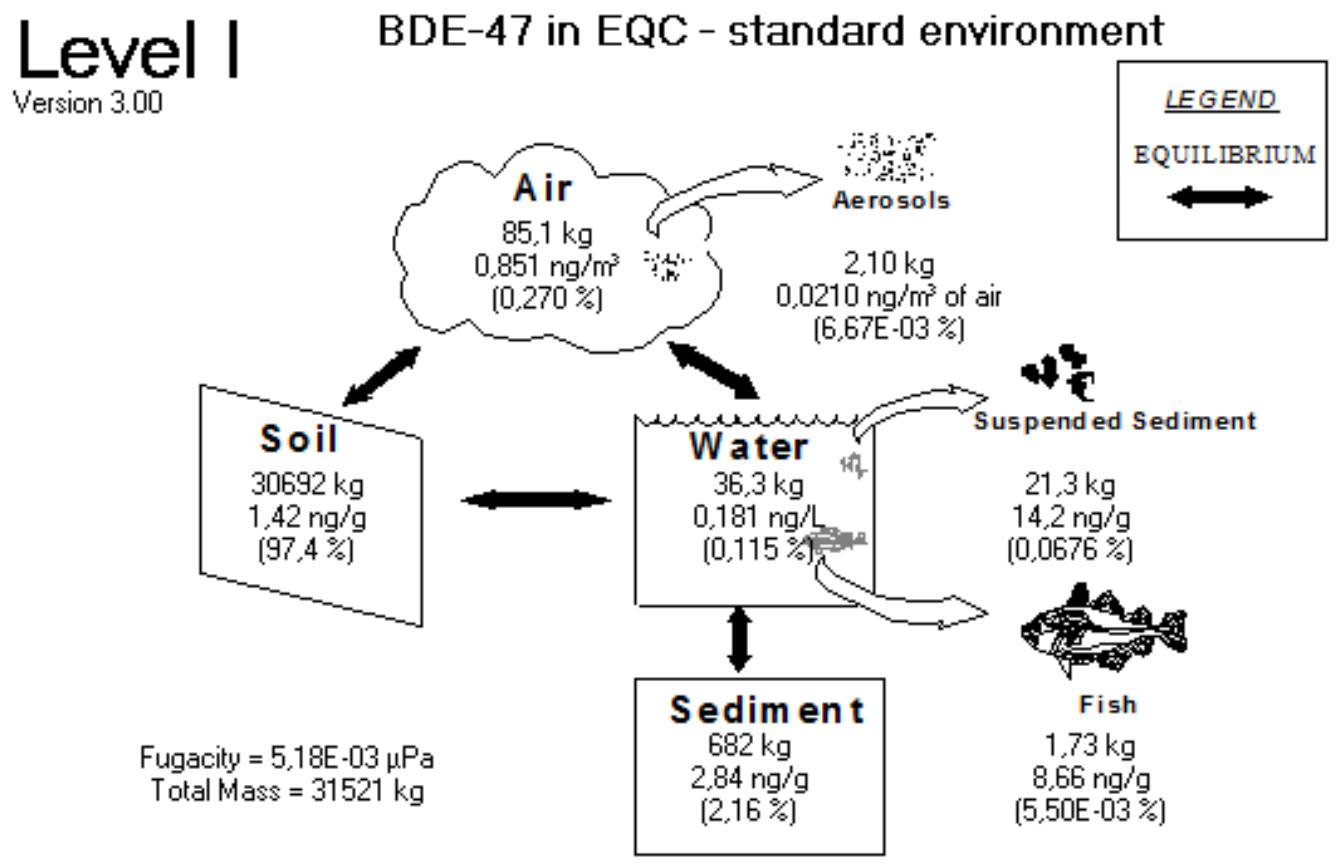

Figura 31. Diagrama de fugacidade do BDE-47 no ponto ETS 


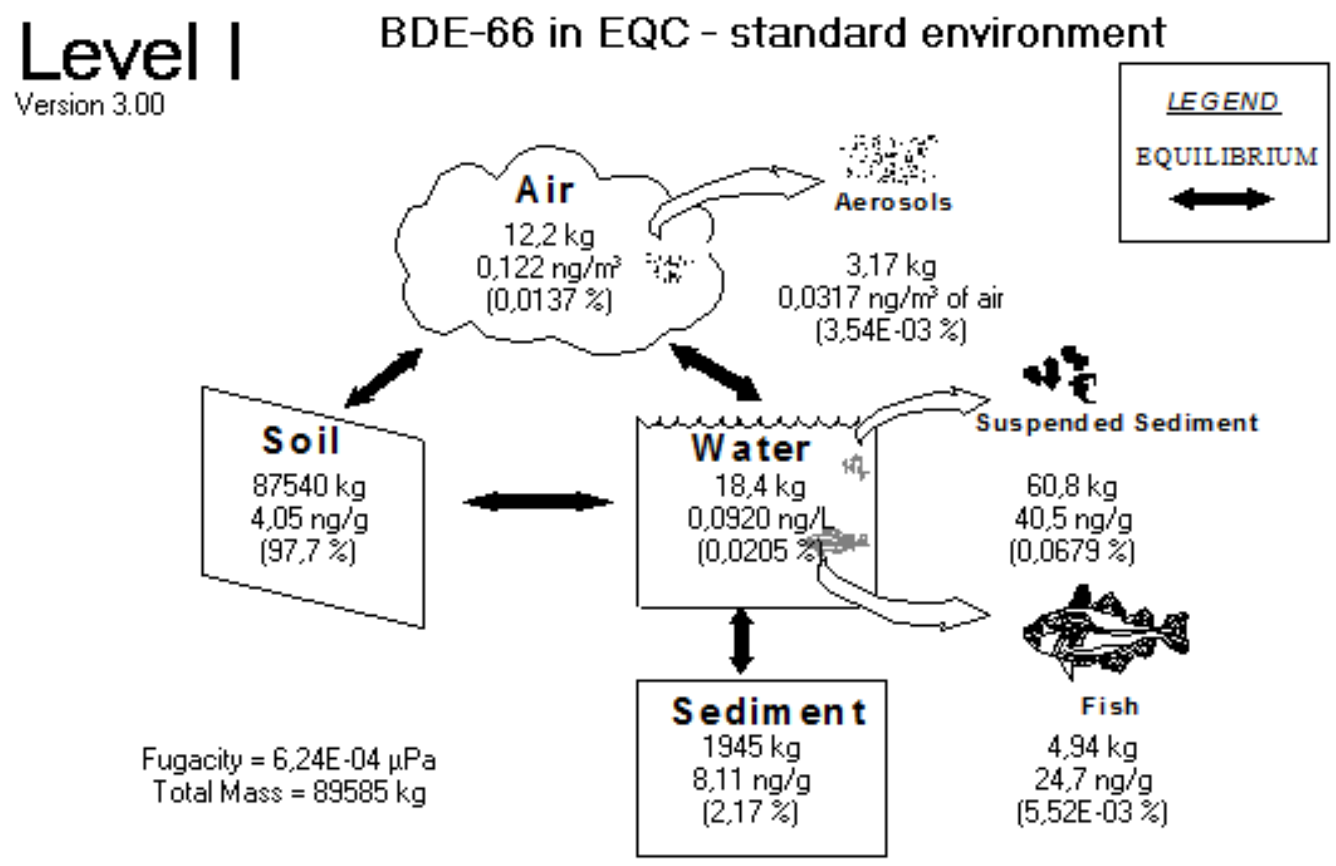

Figura 32. Diagrama de fugacidade do BDE-66 no ponto ETS

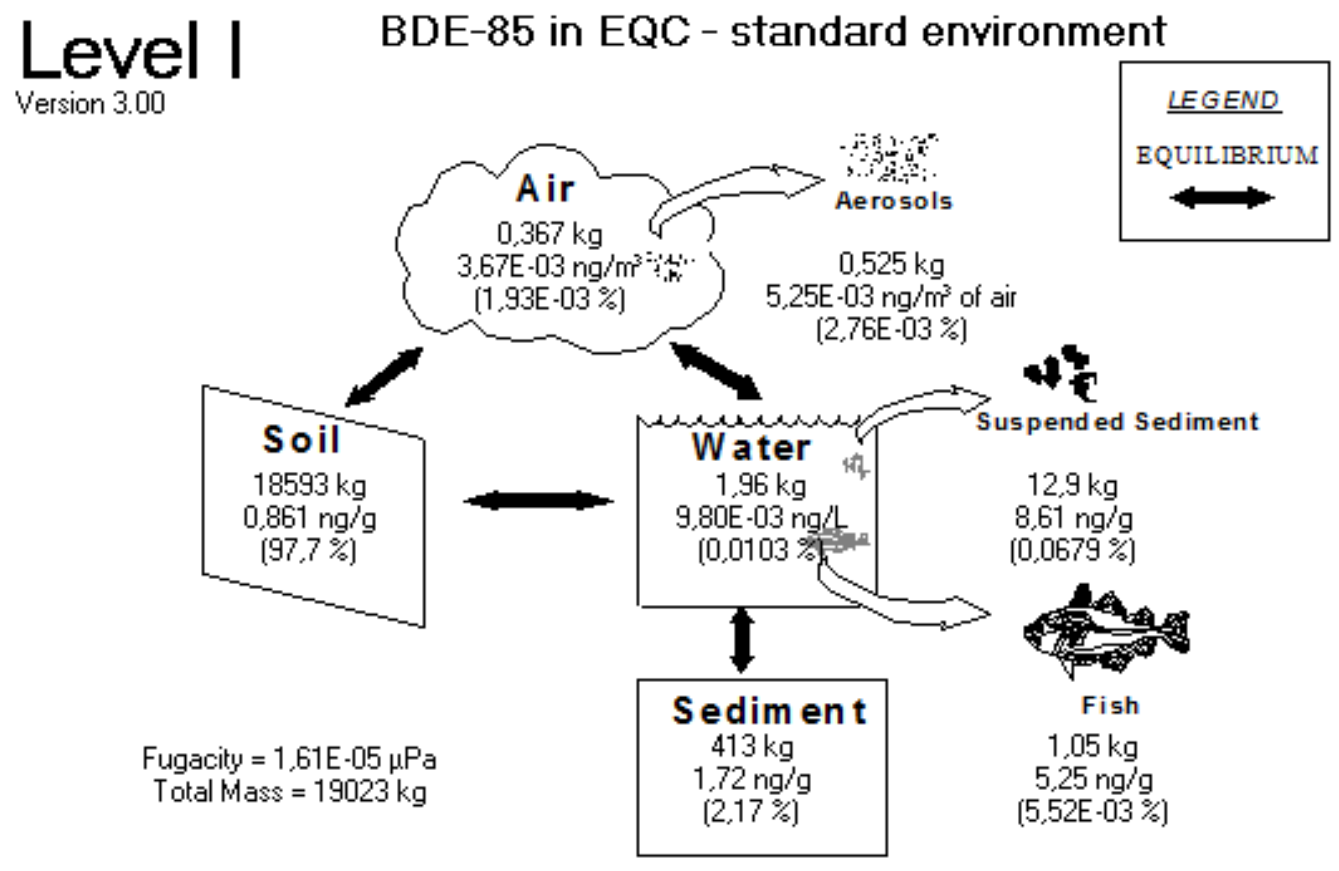

Figura 33. Diagrama de fugacidade do BDE-85 no ponto ETS 


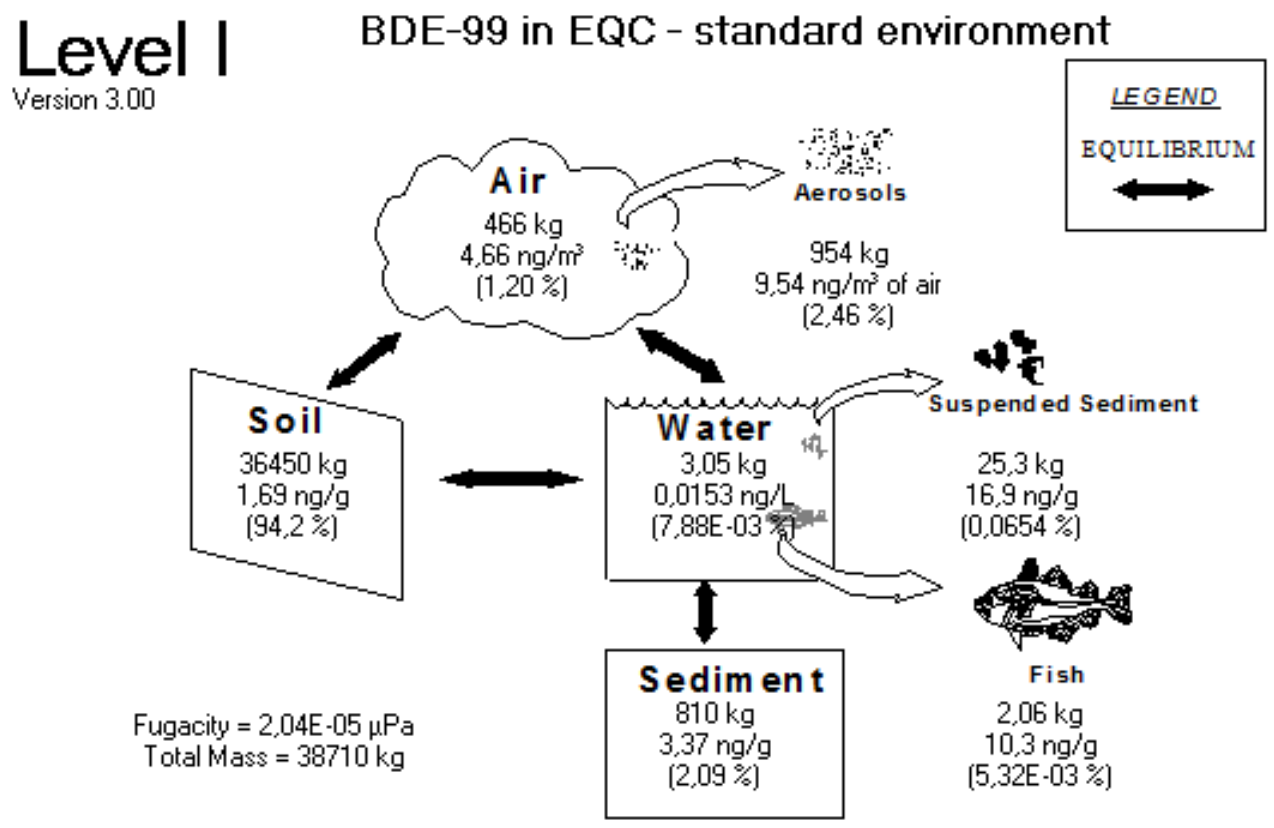

Figura 34. Diagrama de fugacidade do BDE-99 no ponto ETS

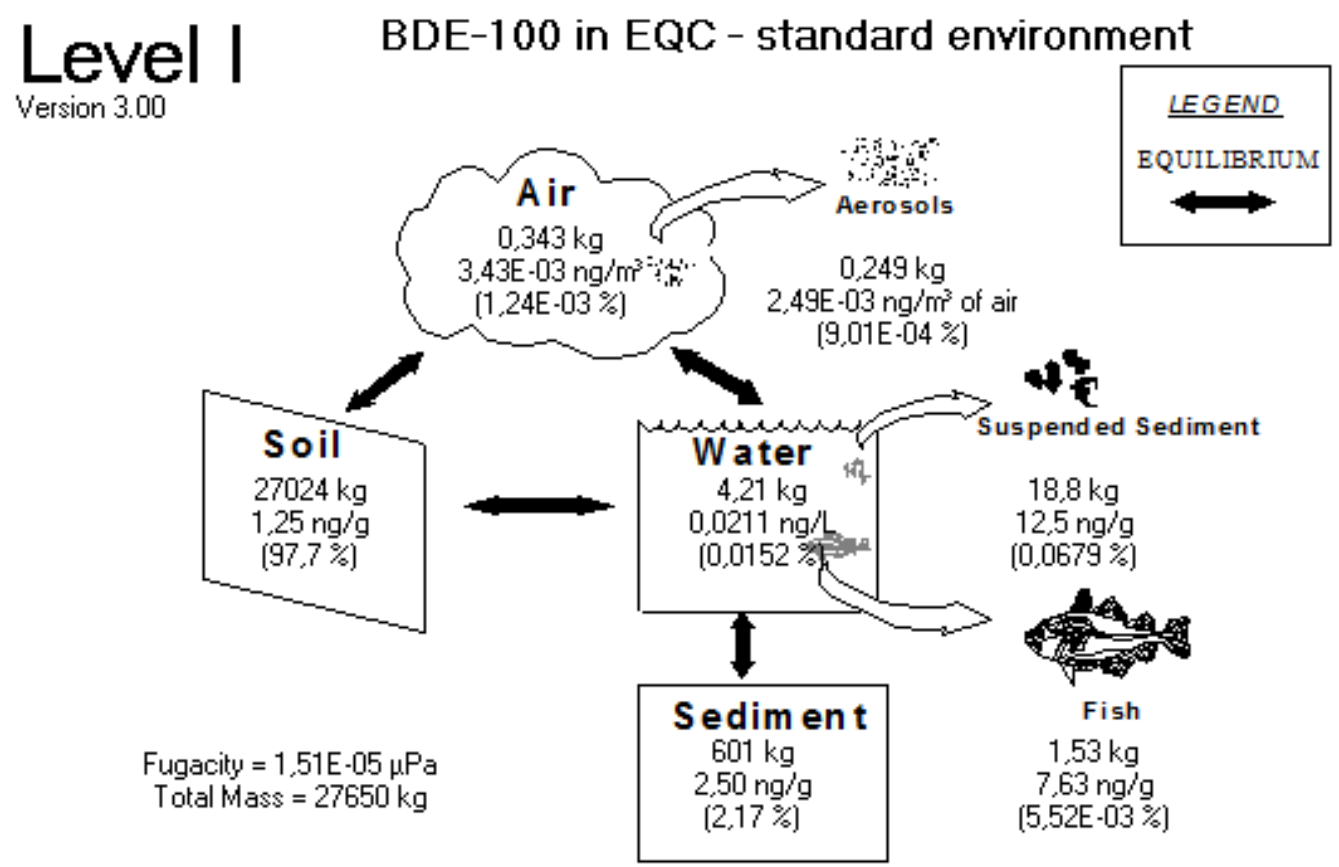

Figura 35. Diagrama de fugacidade do BDE-100 no ponto ETS 


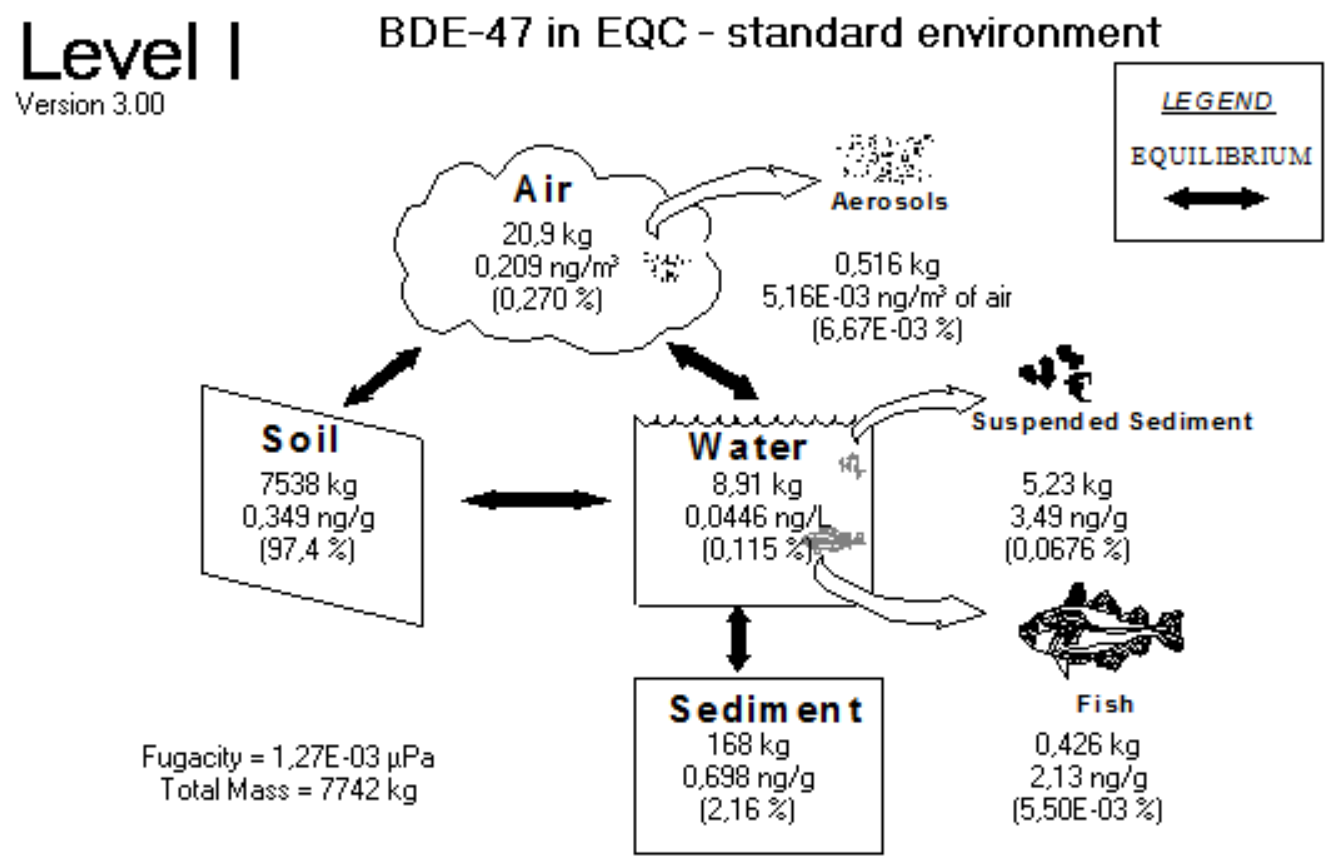

Figura 36. Diagrama de fugacidade do BDE-47 no ponto CNB

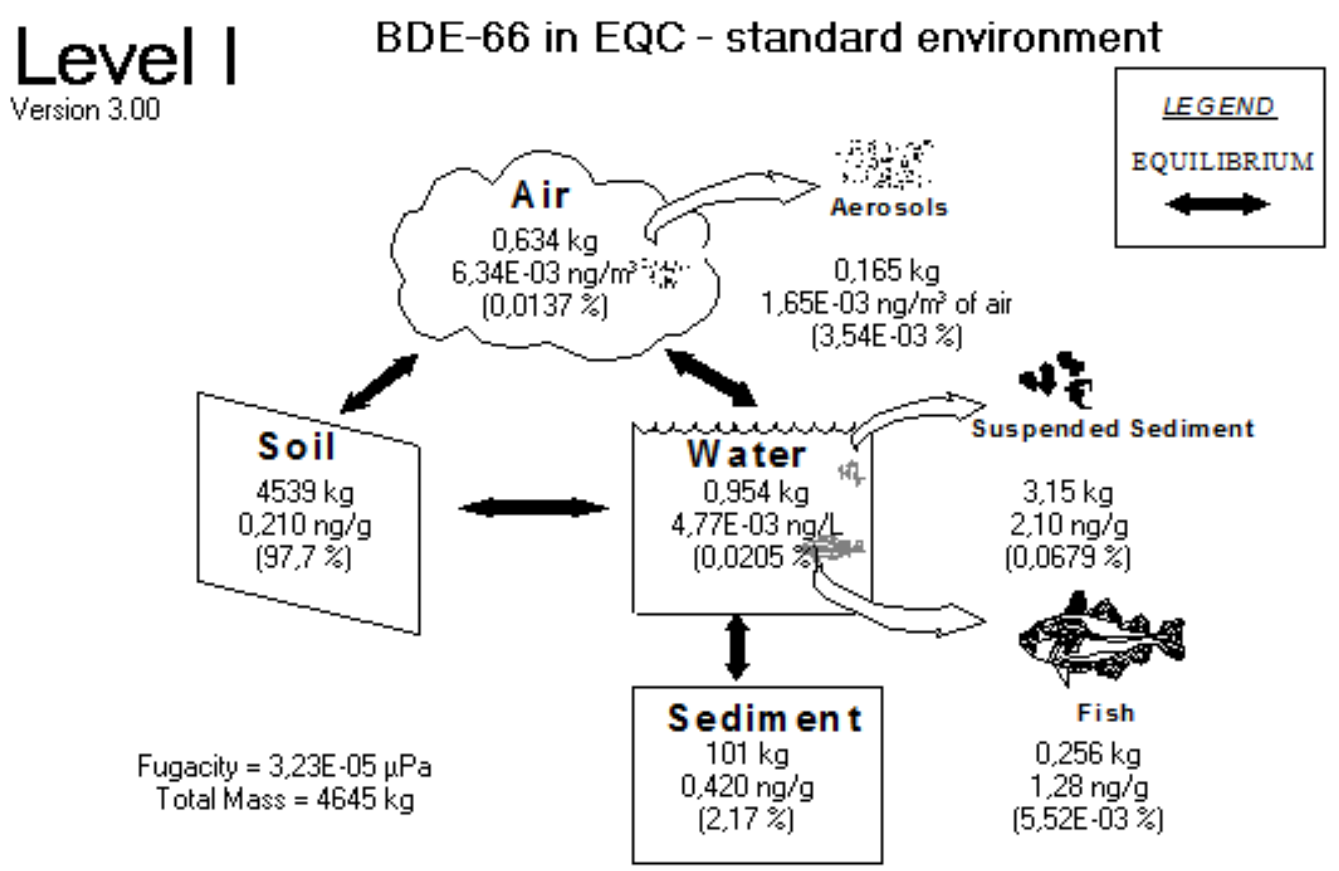

Figura 37. Diagrama de fugacidade do BDE-66 no ponto CNB 


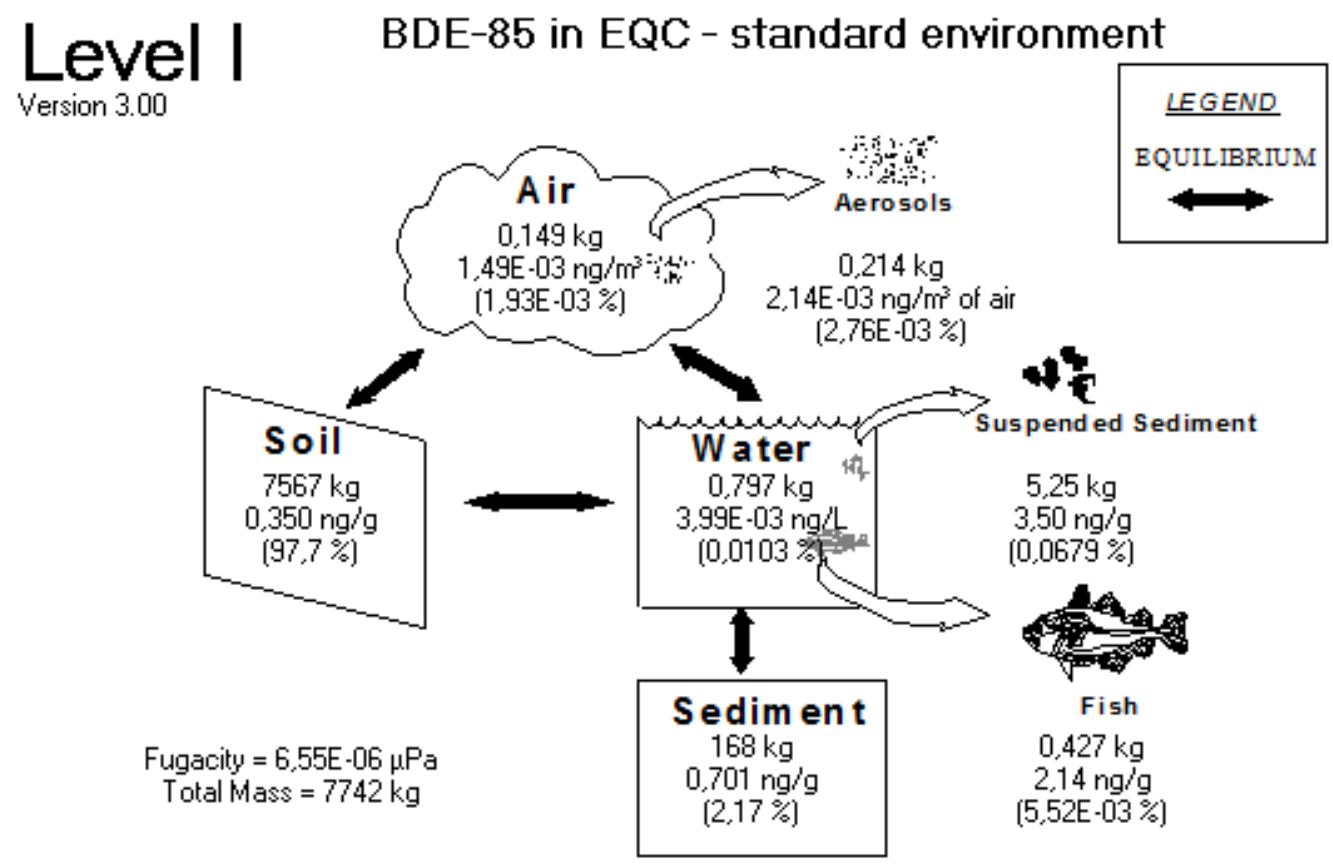

Figura 38. Diagrama de fugacidade do BDE-85 no ponto CNB

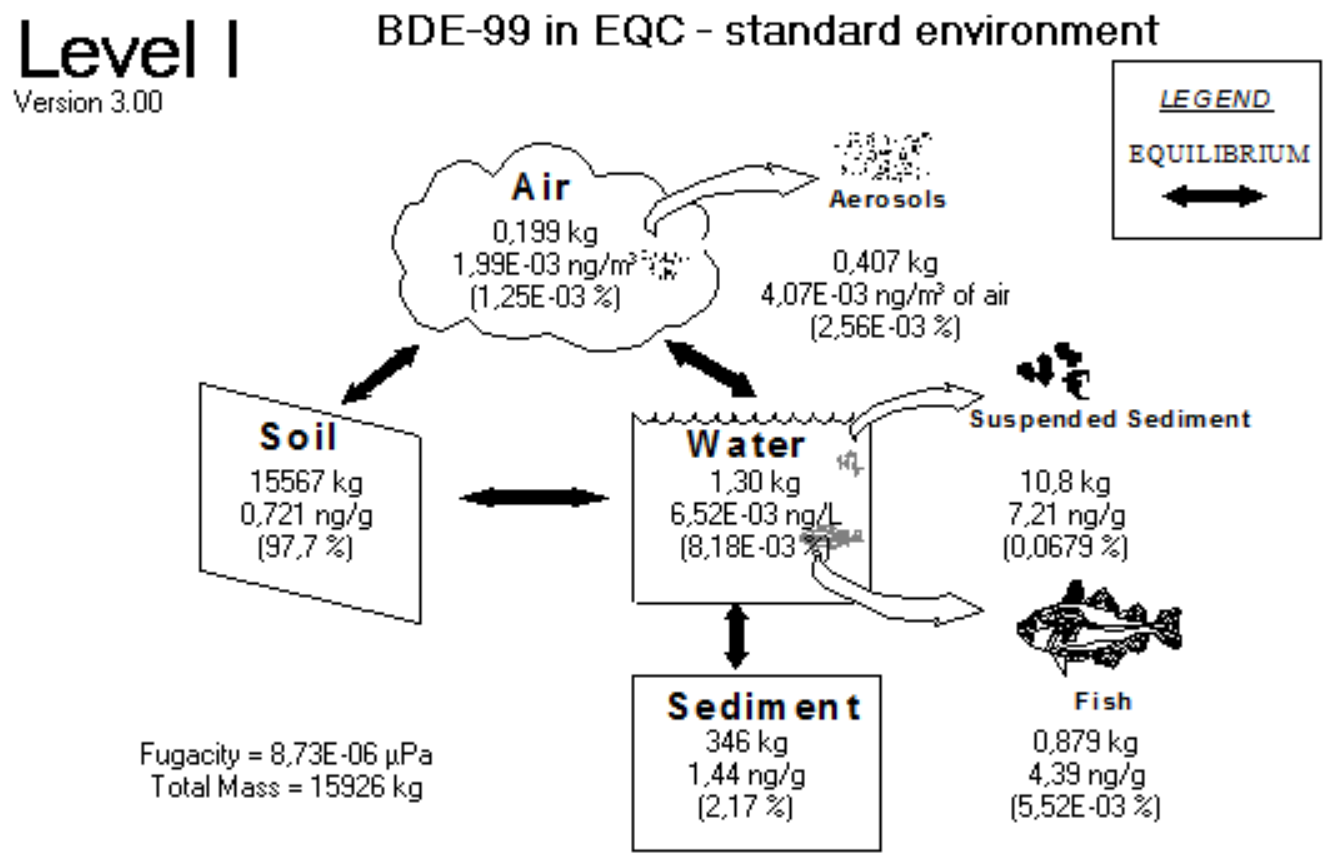

Figura 39. Diagrama de fugacidade do BDE-99 no ponto CNB 


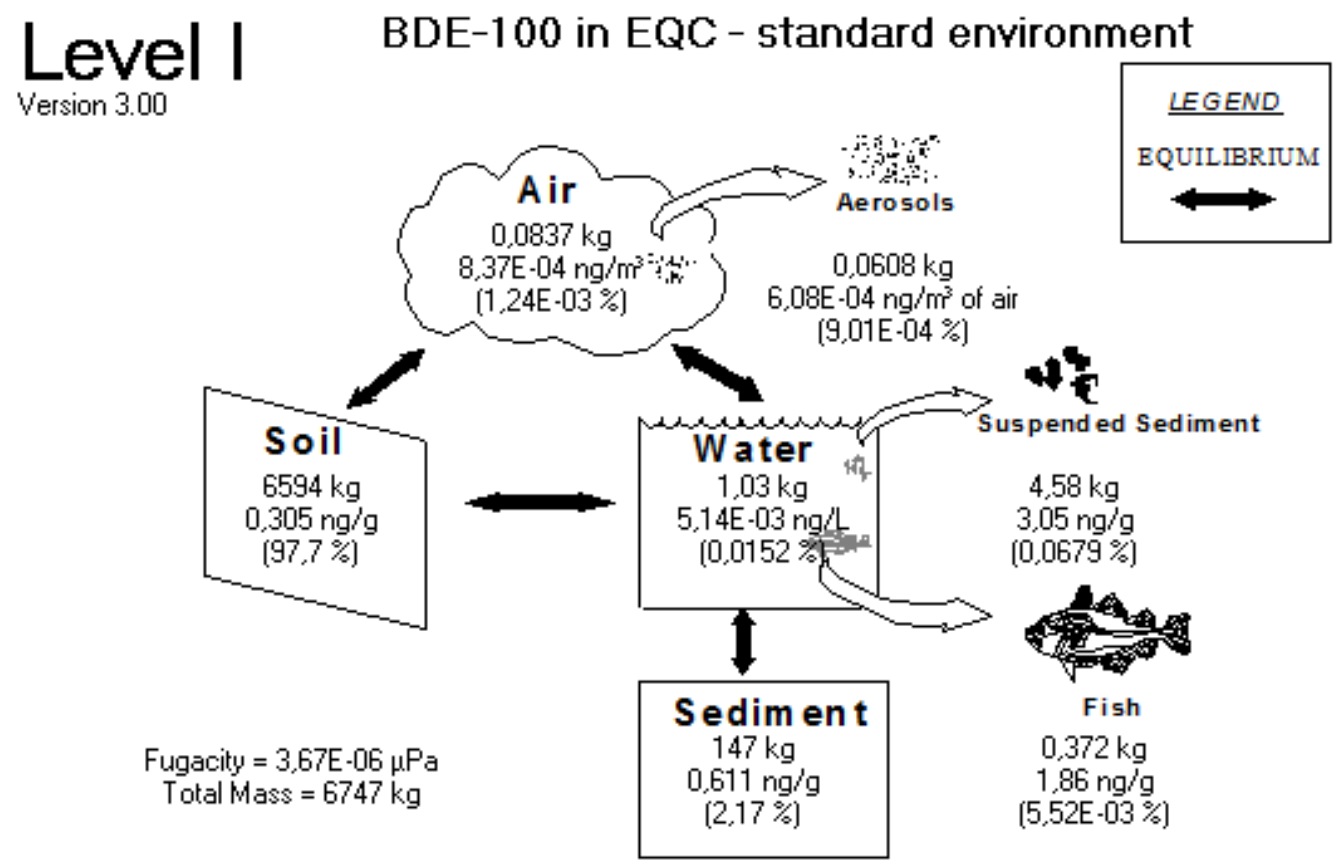

Figura 40. Diagrama de fugacidade do BDE-100 no ponto CNB

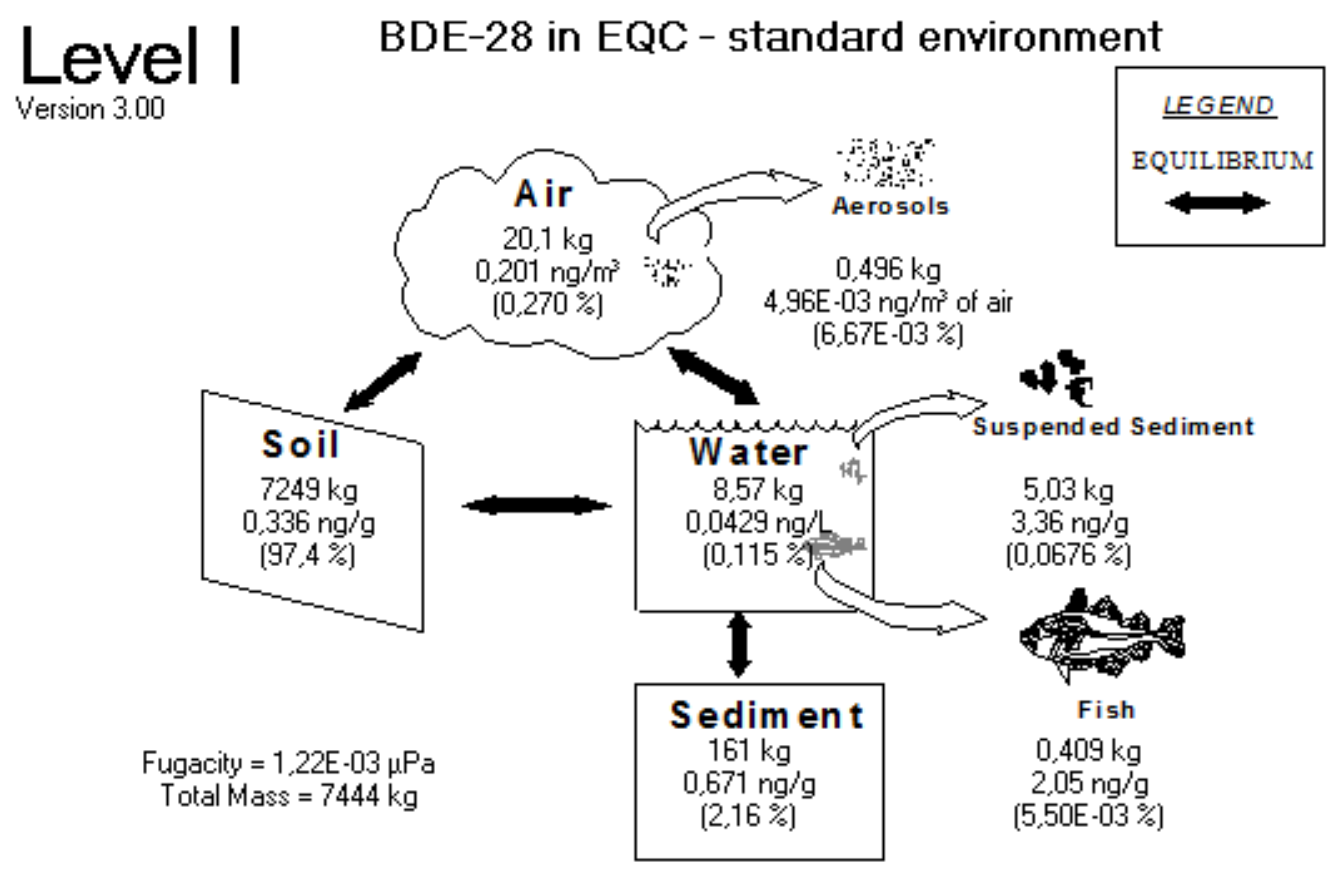

Figura 41. Diagrama de fugacidade do BDE-28 no ponto ETN 


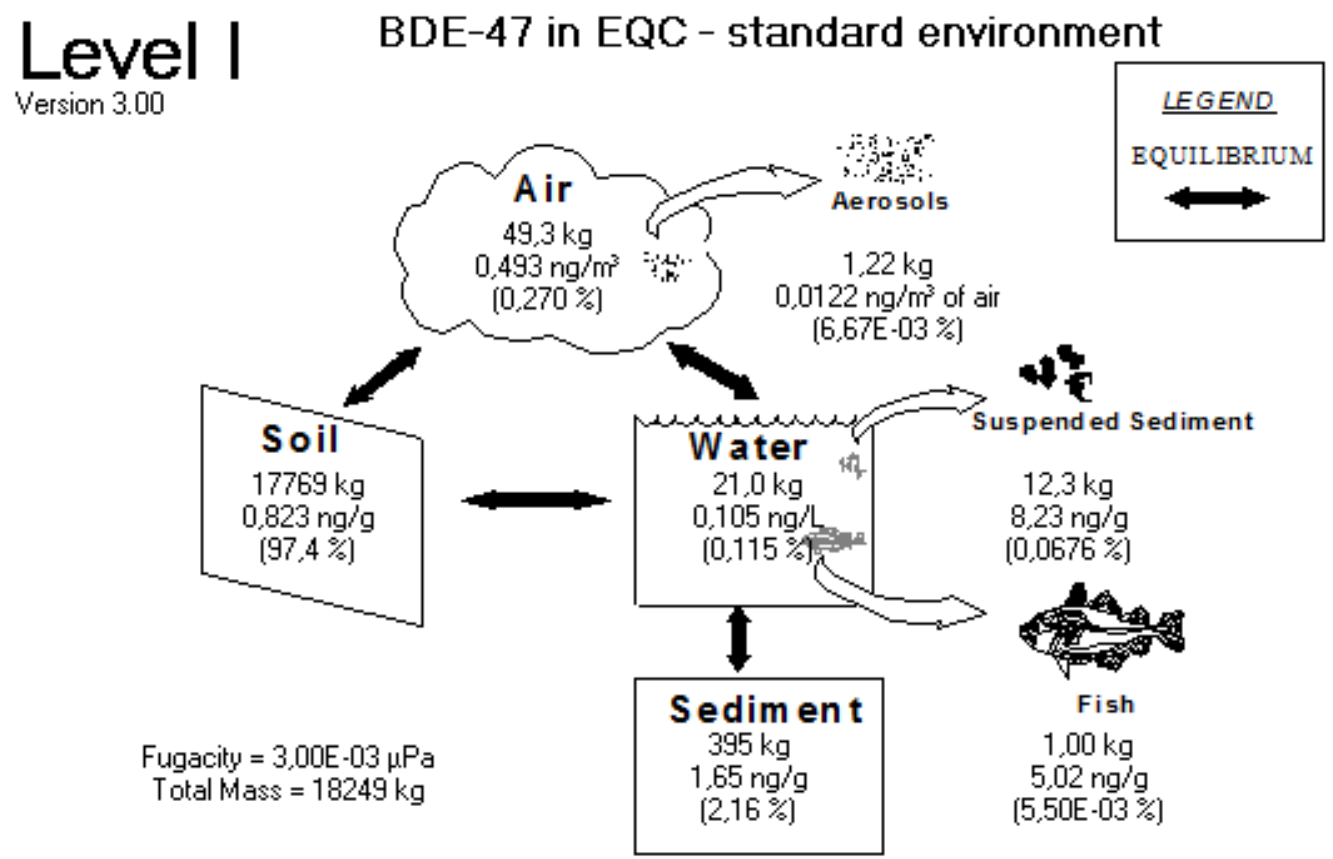

Figura 42. Diagrama de fugacidade do BDE-47 no ponto ETN

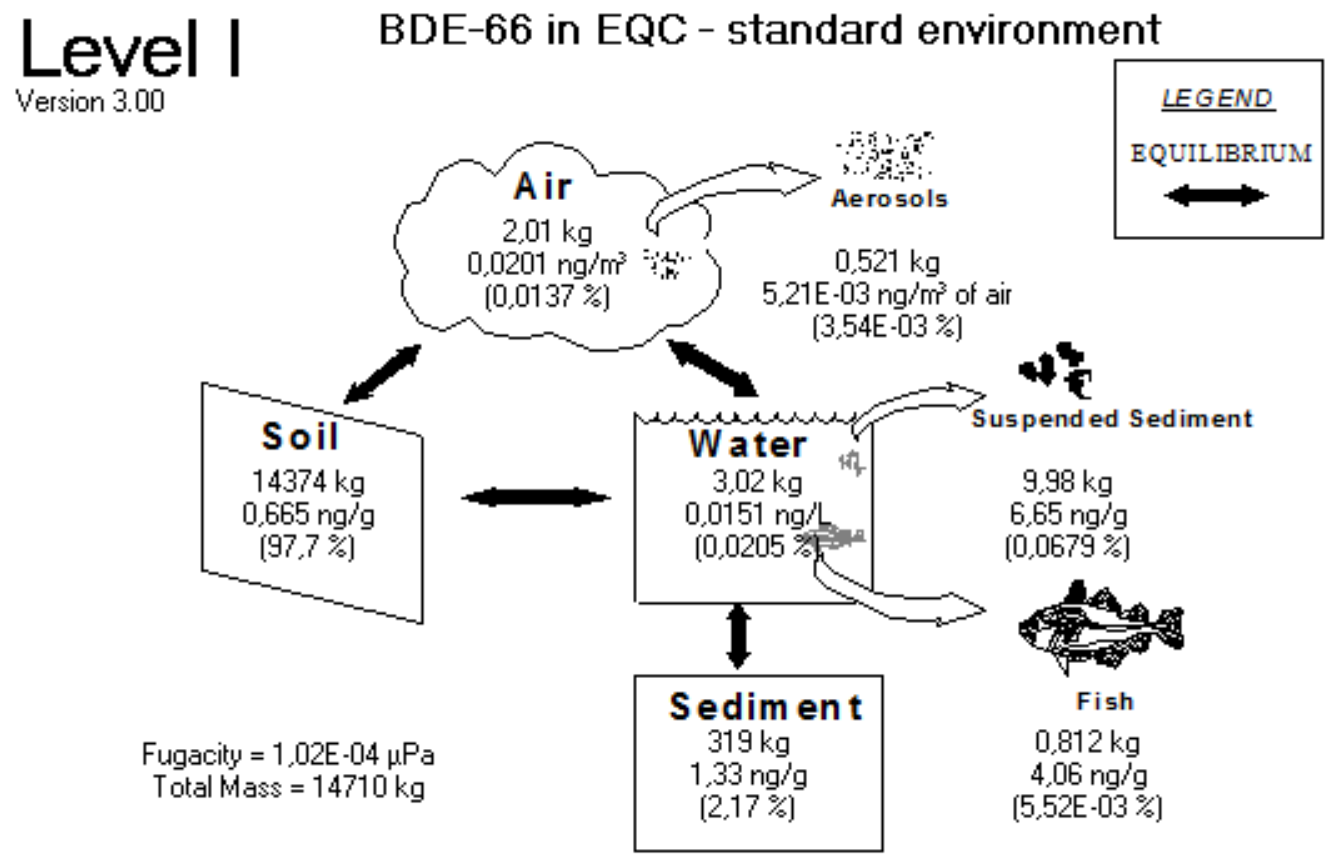

Figura 43. Diagrama de fugacidade do BDE-66 no ponto ETN 


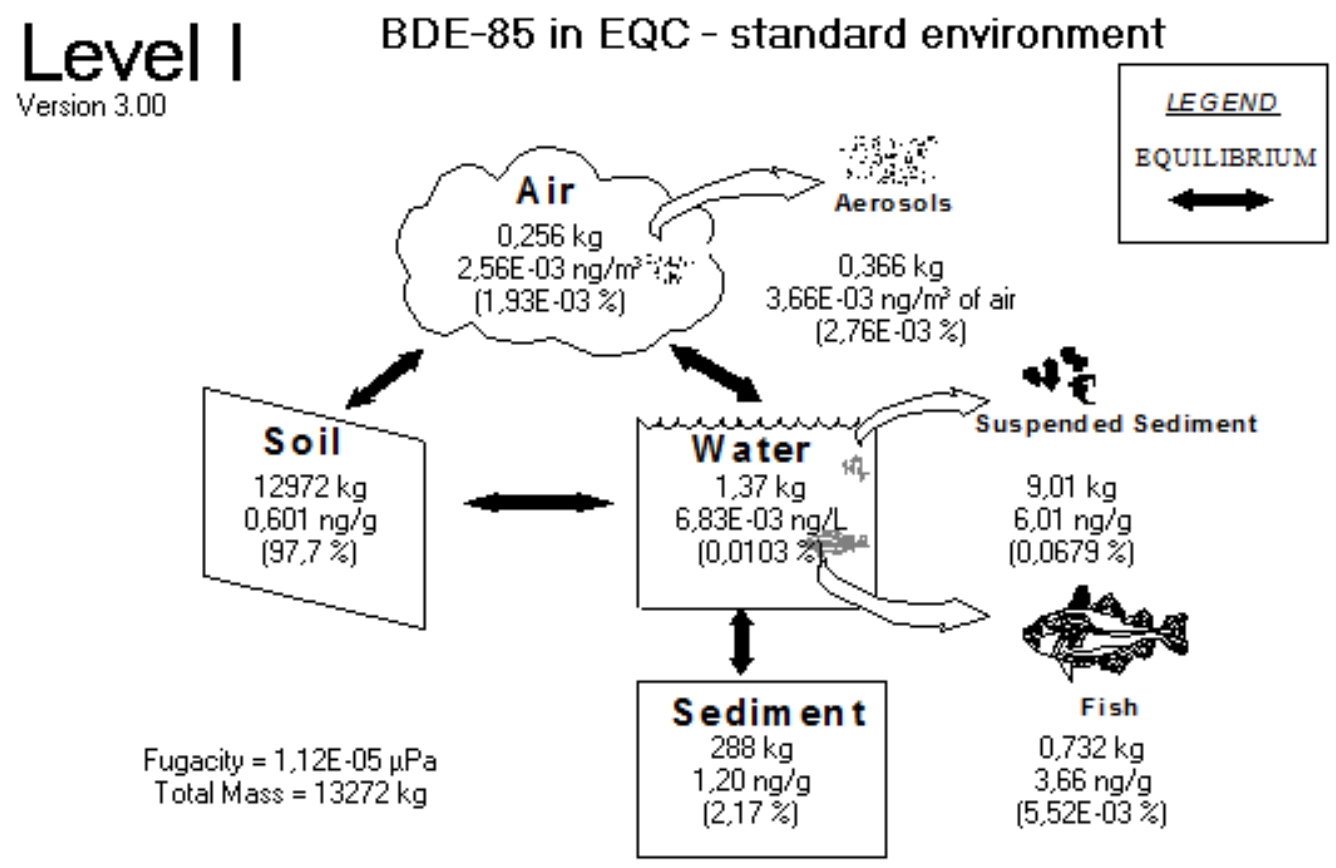

Figura 44. Diagrama de fugacidade do BDE-85 no ponto ETN

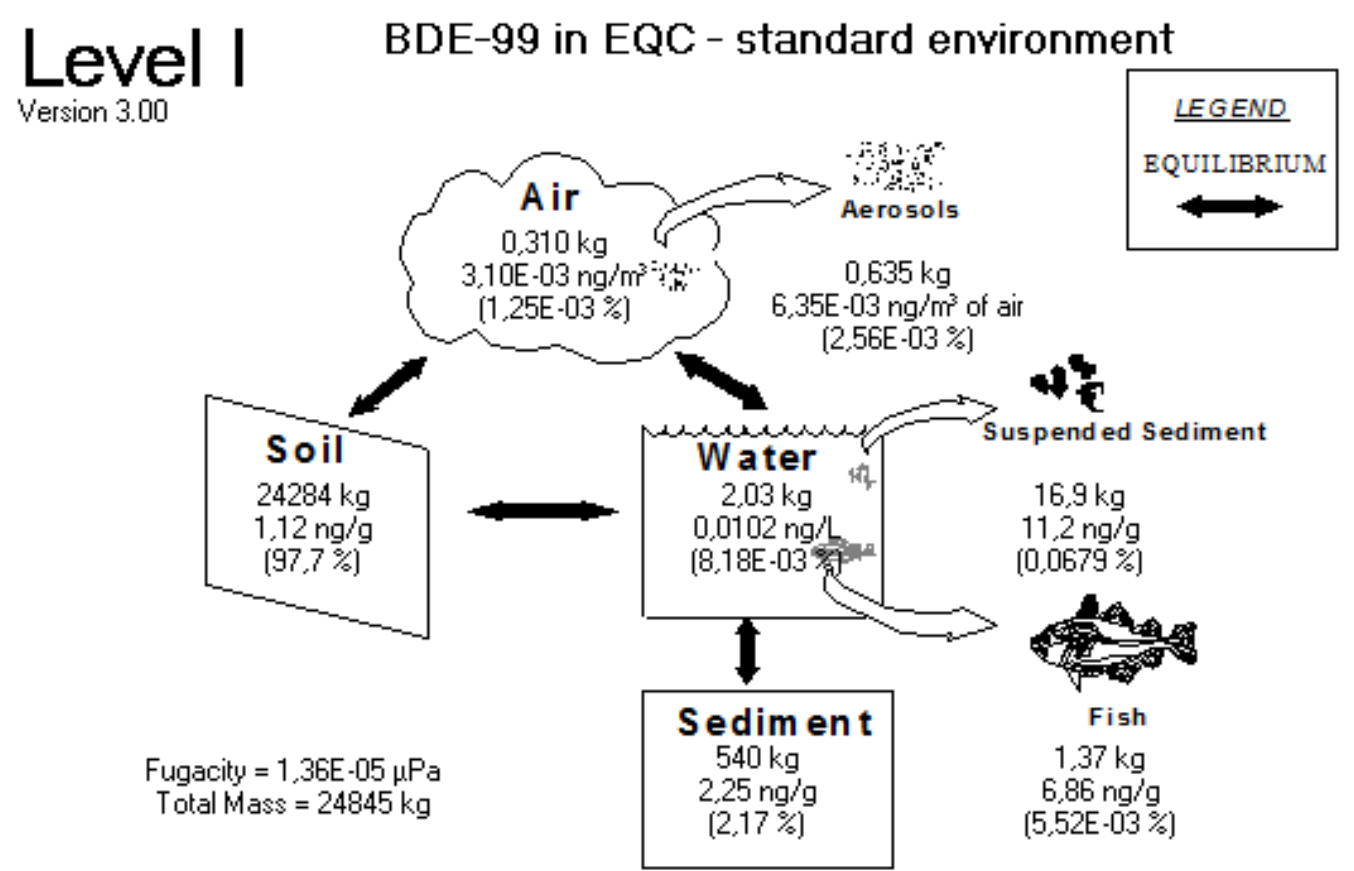

Figura 45. Diagrama de fugacidade do BDE-99 no ponto ETN 


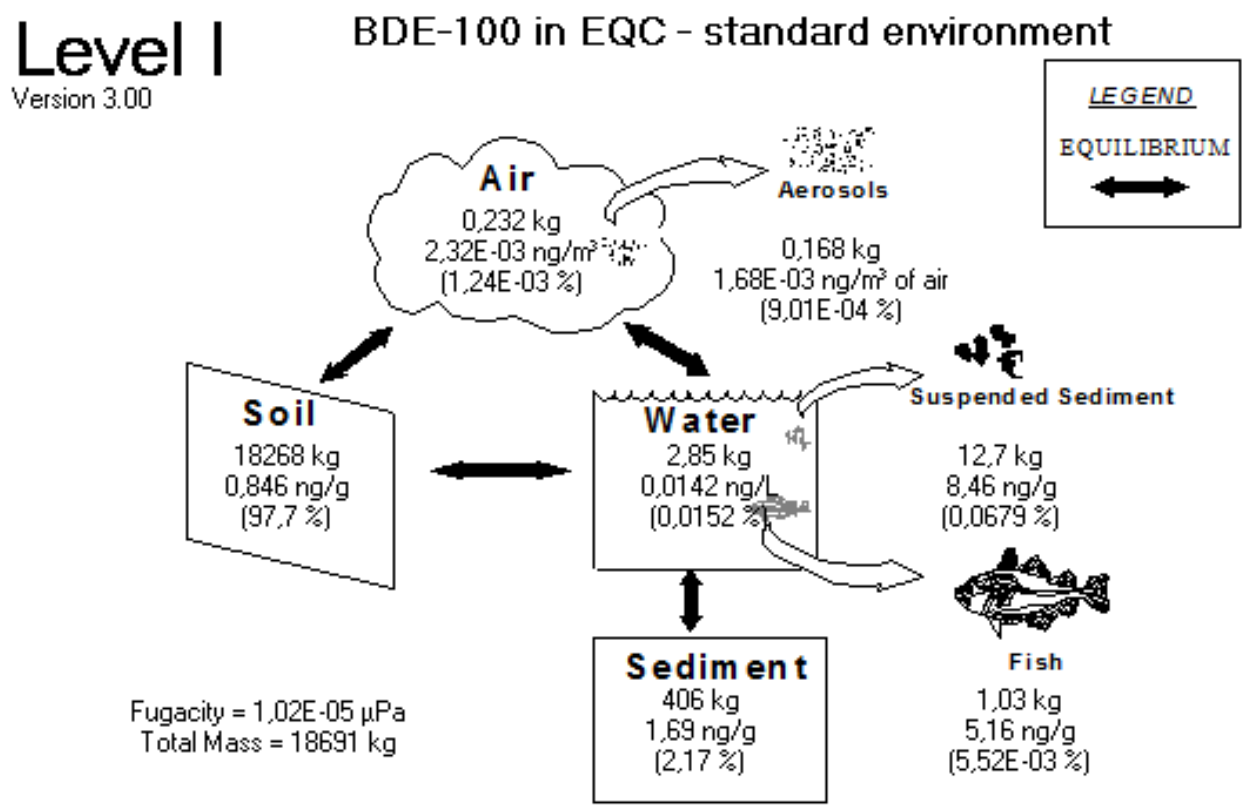

Figura 46. Diagrama de fugacidade do BDE-100 no ponto ETN

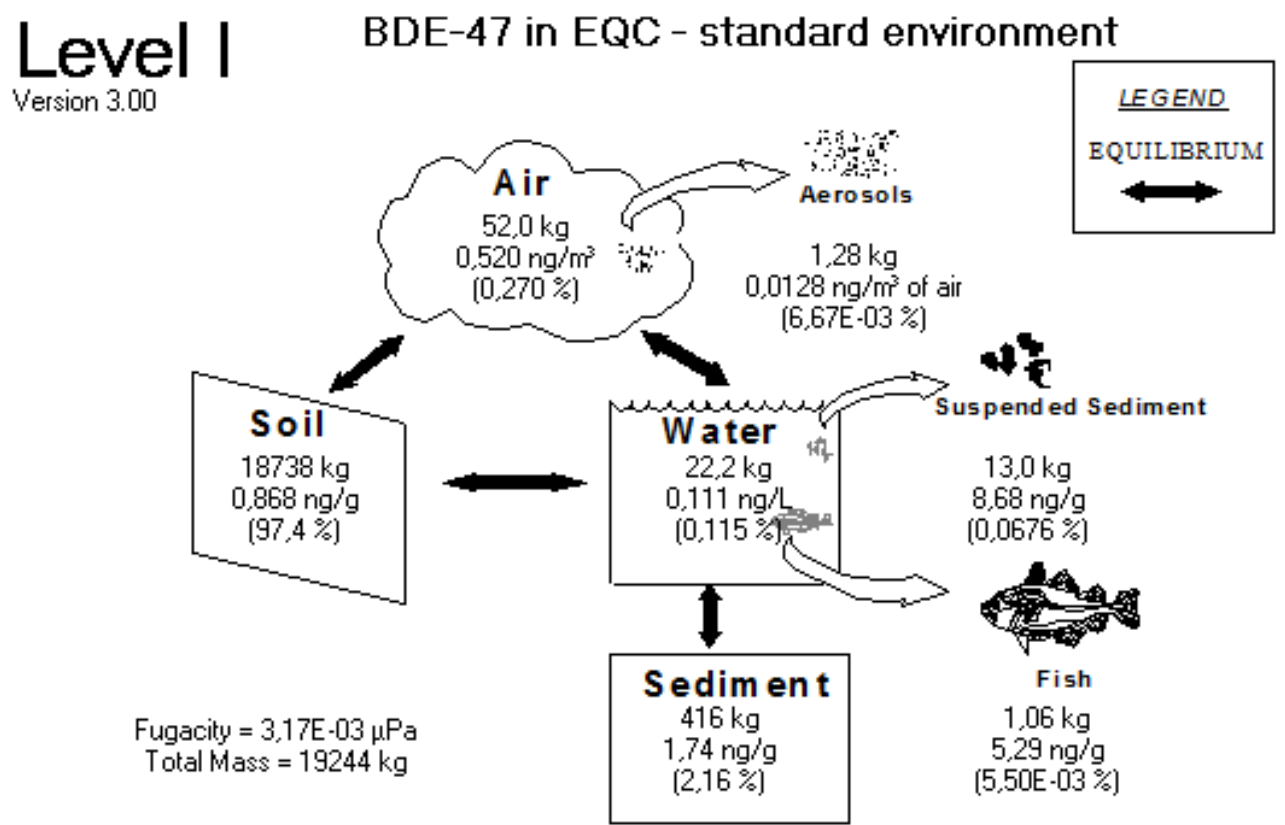

Figura 47. Diagrama de fugacidade do BDE-47 no ponto BIC 


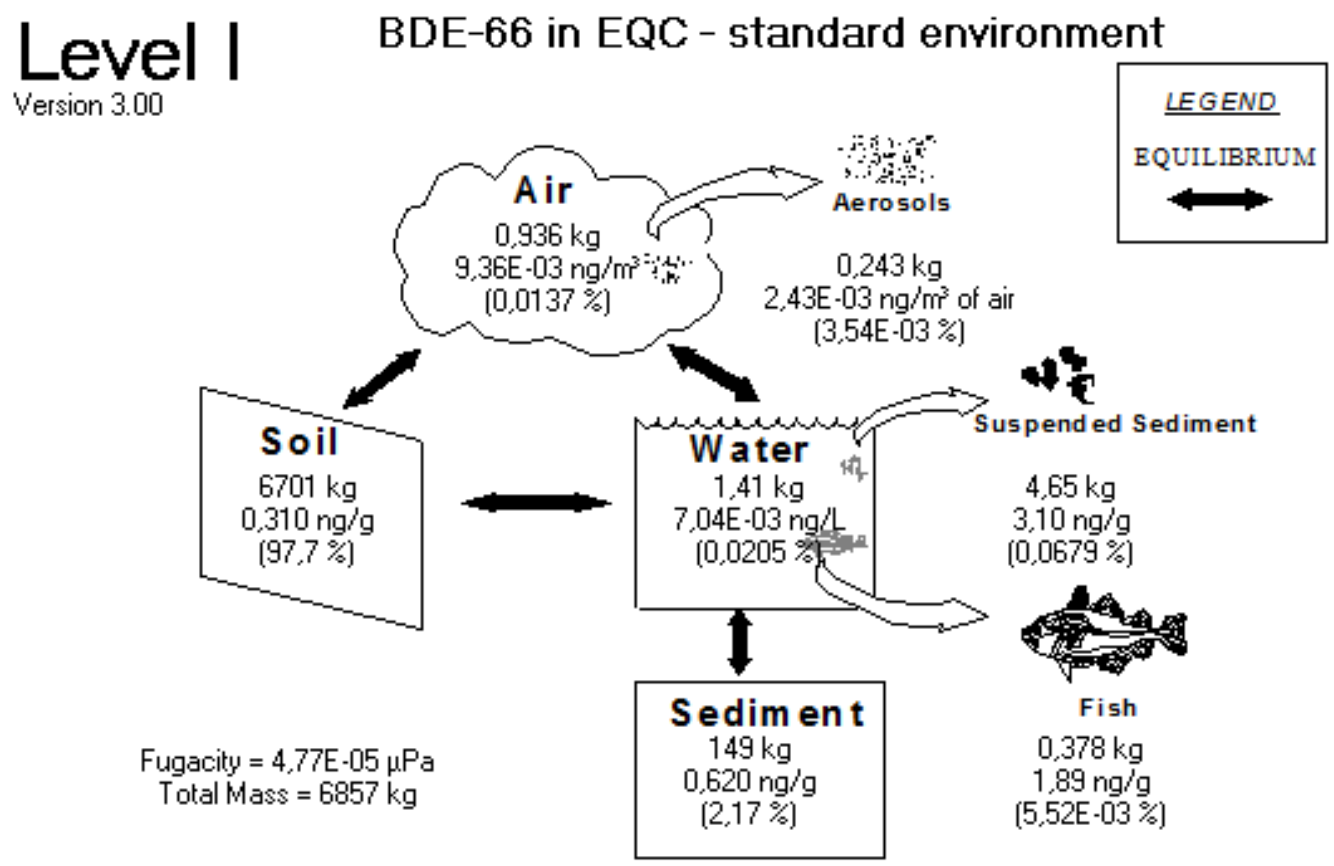

Figura 48. Diagrama de fugacidade do BDE-66 no ponto BIC

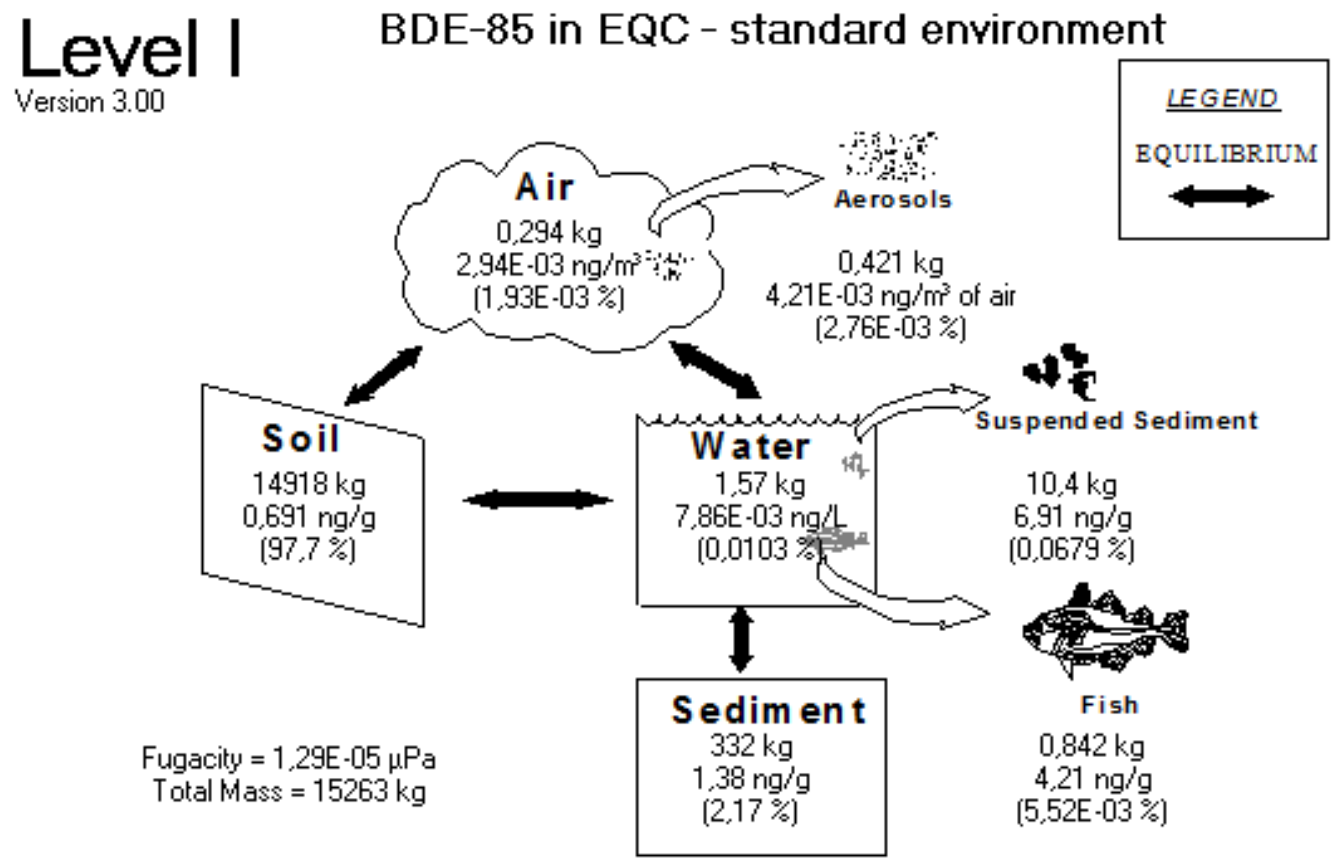

Figura 49. Diagrama de fugacidade do BDE-85 no ponto BIC 


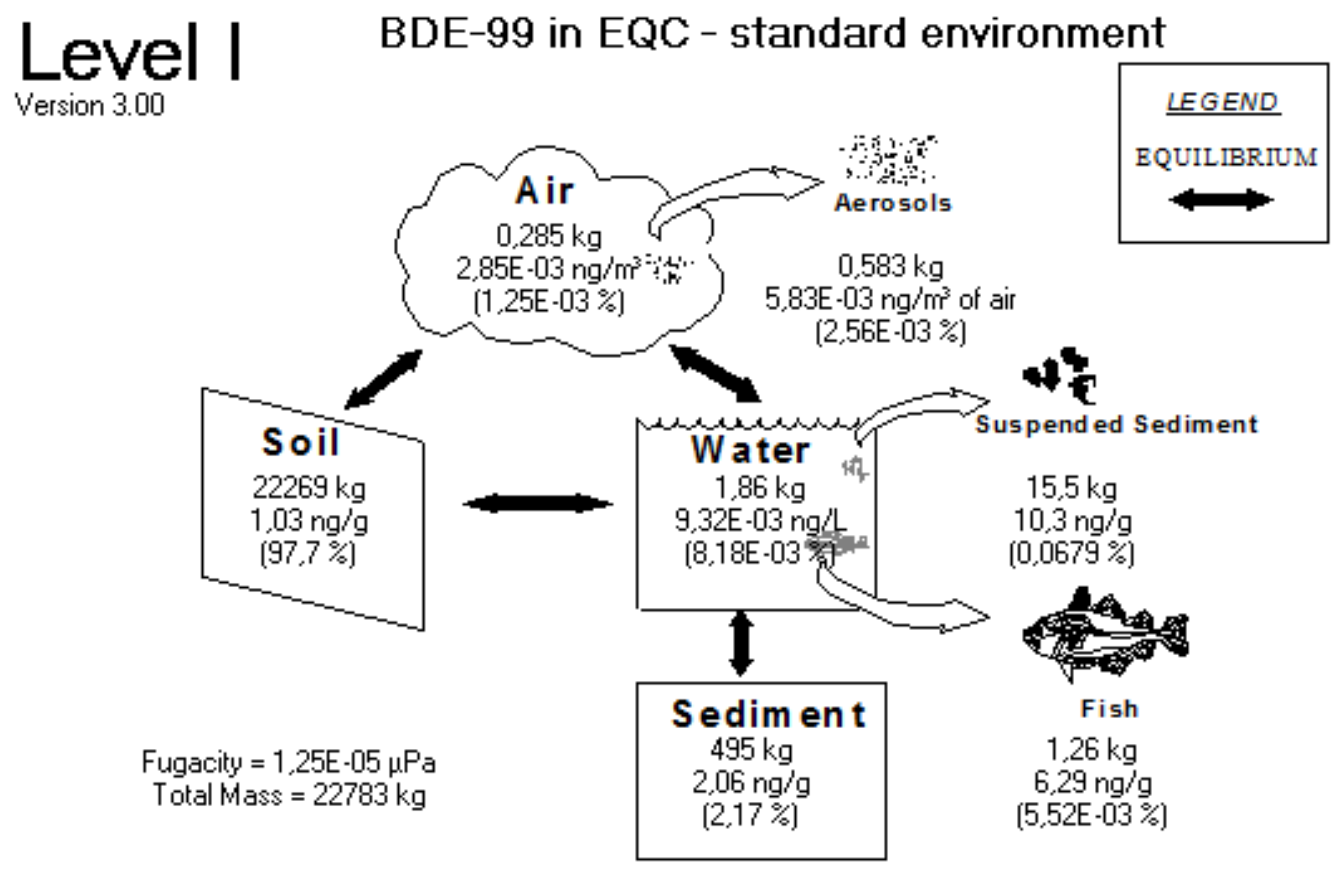

Figura 50. Diagrama de fugacidade do BDE-99 no ponto BIC

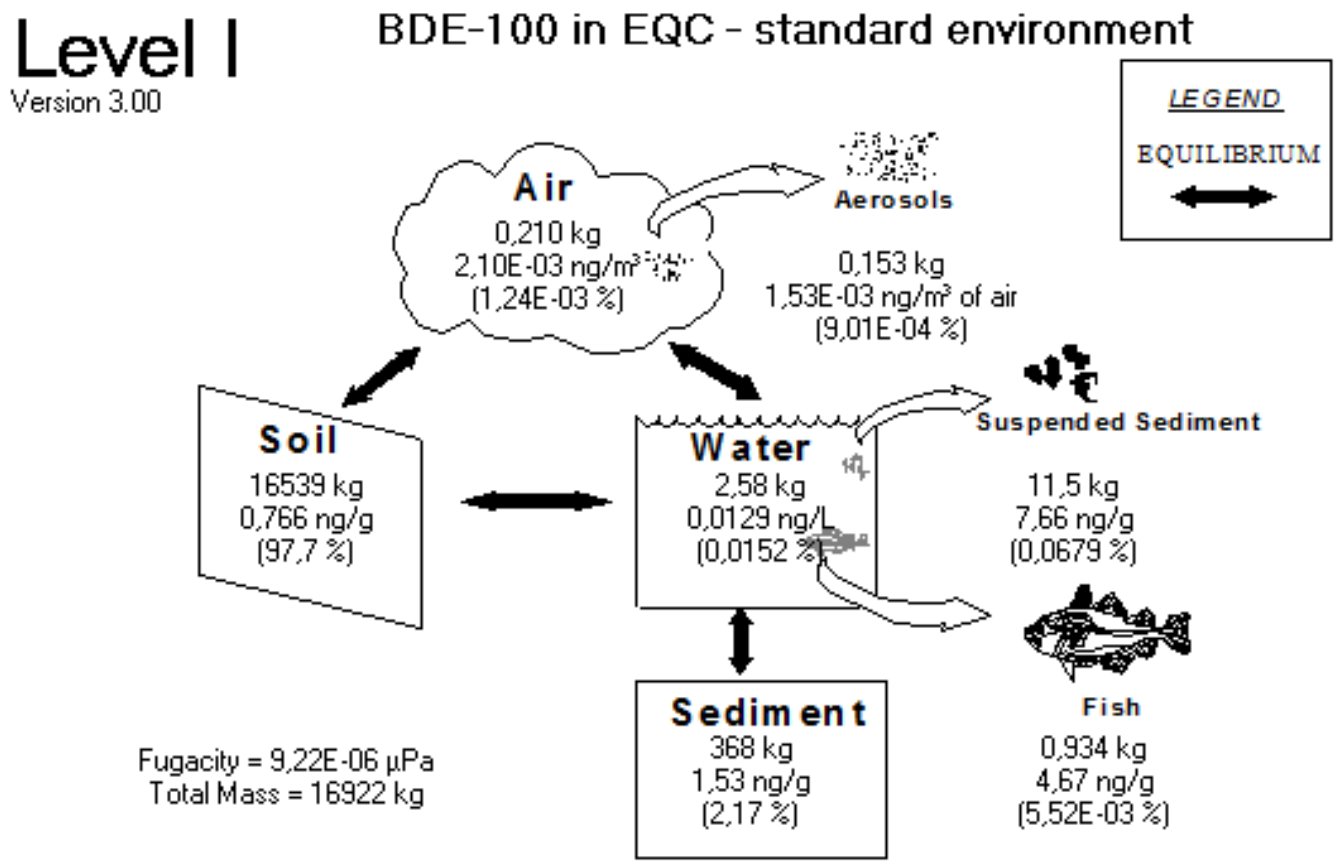

Figura 51. Diagrama de fugacidade do BDE-100 no ponto BIC 